\title{
Yield of fluorescence from various tissue layers during fluorescence angiography of the ocular fundus
}

Citation for published version (APA):

van der Biesen, P. R. (1995). Yield of fluorescence from various tissue layers during fluorescence angiography of the ocular fundus. [Doctoral Thesis, Maastricht University]. Rijksuniversiteit Limburg. https://doi.org/10.26481/dis.19951215pb

Document status and date:

Published: 01/01/1995

DOI:

10.26481/dis.19951215pb

Document Version:

Publisher's PDF, also known as Version of record

\section{Please check the document version of this publication:}

- A submitted manuscript is the version of the article upon submission and before peer-review. There can be important differences between the submitted version and the official published version of record.

People interested in the research are advised to contact the author for the final version of the publication, or visit the DOI to the publisher's website.

- The final author version and the galley proof are versions of the publication after peer review.

- The final published version features the final layout of the paper including the volume, issue and page numbers.

Link to publication

\footnotetext{
General rights rights.

- You may freely distribute the URL identifying the publication in the public portal. please follow below link for the End User Agreement:

www.umlib.nl/taverne-license

Take down policy

If you believe that this document breaches copyright please contact us at:

repository@maastrichtuniversity.nl

providing details and we will investigate your claim.
}

Copyright and moral rights for the publications made accessible in the public portal are retained by the authors and/or other copyright owners and it is a condition of accessing publications that users recognise and abide by the legal requirements associated with these

- Users may download and print one copy of any publication from the public portal for the purpose of private study or research.

- You may not further distribute the material or use it for any profit-making activity or commercial gain

If the publication is distributed under the terms of Article $25 \mathrm{fa}$ of the Dutch Copyright Act, indicated by the "Taverne" license above, 


\section{Yield of fluorescence from various tissue layers during fluorescence angiography of the ocular fundus}

De lichtopbrengst uit de verschillende weefsellagen tijdens fluorescentie angiografie van de oogfundus

\section{Proefschrift}

ter verkrijging van de graad van doctor aan de Rijksuniversiteit Limburg te Maastricht, op gezag van de Rector Magnificus, Prof.Mr M.J. Cohen, ingevolge het besluit van het College van Dekanen, in het openbaar te verdedigen op vrijdag 15 december 1995 om 14.00 uur.

\section{Petrus Roverius van den Biesen}

gebaren op 18 september 1955 te Breda 
Promotores.

Prof.Dr R.S. Reneman

Prof.Dr W.PIM.A. Lamers

Co-promatores:

Dr D.W. Slat

DrW.Th. Hermens

Beoordelingscommissie:

Prof.Dr H.A.J. Struijker Boudier (voonitter)

Prof.Dr J.M.A. van Engelshoven

Prof.Dr F ten Hoor

Prof.Dr P. Simoens (Universiteit Gent)

Prof.Dr J.S. Stilma (Universiteit Utrecht).

Het onderzoek werd verricht in het Cardiovascular Research Institute Maastricht en het Academisch Ziekenhuis Maastricht en werd mede mogelijk gemaakt met financiele steun van Medical Workshop B.V. Groningen. 


\section{CONTENTS}

CHAPTER 1. Introduction.

CHAPTER 2. Review of literature and basics of fluorescence angiography.

2.1 The normal fluorescein and indocyanine green angiogram.

2.2 Fluorescence characteristics of sodium fluorescein and indocyanine green.

2.3 Dye transport to the eye after intravenous injection.

2.4 Capillary permeability and dye extravasation.

2.5 Anatomy of retina and choroid with respect to angiography.

2.6 Imaging in fluorescence angiography.

2.7 Current interpretation of the normal fiuorescence angiogram.

CHAPTER 3. Shear and hematocrit dependence of fluorescence from retinal vessels in fluorescein angiography.

CHAPTER 4. Yield of fluorescence from indocyanine green in plasma and flowing blood.

CHAPTER 5. Estimates of absolute dye concentrations in retinal vessels in fluorescein angiography.

CHAPTER 6. Dye extravasation in the choroid during fluorescein angiography of the ocular fundus.

CHAPTER 7. Summary and general discussion.

Nederlandse samenvalting.

Nawoord.

Curriculum vitae. 
C HAPTER 1

INTRODUCTION 
Sodium fluorescein (SF) angiography has been a standard procedure for diagnosis of retinal and choroidal diseases in clinical practice for many years. Because in fluorescence angiography the retinal blood vessels are delineated particularly well, it is the technique of choice for diagnosis of disturbances in the retinal circulation. Sodium fluorescein angiograms may also provide information about the choroid. Recently, indocyanine green (ICG) angiography became available for clinical use. It provides primarily information about the choroid. Although it promises to become a valuable adjunct to $\mathrm{SF}$ angiography, the clinical usefulness of IGC angiography is not fully clear yet.

Interpretation of the appearance pattern of the normal fluorescence angiogram is complicated because information from retina and choroid are superimposed. The current understanding of fluorescence appearance patterns is based on relatively simple assumptions concerning the relationship between fluorescence intensities of the angiogram on the one hand, and localization and concentration of fluorescein molecules in retinal and choroidal tissues on the other. The aim of this thesis is to assess the fluorescence yields from the various tissue layers in the normal angiogram and convert these into dye concentration distributions. To that end we performed in vitro studies to determine the relationship between dye concentration, fluorescence yield, layer thickness, hematocrit and flow. Next, we converted intensities of retinal vessels from fluorescein angiograms into an estimate of dye concentrations. Finally, a mathematical model was designed to estimate SF extravasation in the choroid. Beside enhancing the understanding of the normal angiogram, this information may improve our insight into the pathophysiology of choroidal and retinal diseases.

The thesis starts with an introduction on various aspects of fluorescence angiography and a review of the relevant literature (chapter 2). The influence of dye concentration, hematocrit, layer thickness, and shear rate on the fluorescence yield of sodium fluorescein and indocyanine green in blood is analysed in chapter 3 and 4 , respectively. In chapter 5 , the distribution of dye concentrations in choroidal and retinal circulation is estimated from the assessed fluorescence intensities. The results of these chapters are used to construct a quantitative model to estimate the time course of the fluorescence yield in the intra and extravascular compartments of the choroid (chapter 6). Finally, the consequences of the findings for the interpretation of the normal fluorescence angiogram are discussed (chapter 7). 


\section{H A P TER 2}

\section{REVIEW OF LITERATURE AND BASICS OF FLUORESCENCE ANGIOGRAPHY.}

2.1 The normal fluorescein and indocyamine green angiogram.

2.2 Fluorescence characteristics of sodium fluorescein and indocyanine green.

2.3 Dye transport to the eve after intravenous injection.

2.4 Capillary permeability and dye extravasation.

2.5 Anatomy of retina and choroid with respect to angiography.

2.6 Imaging in fluorescence angiography.

2.7 Current interpretation of the normal fluorescence angiogram. 
Figure 1 A-D. SF angiogram of a human volunteer, 2 seconds, 7 seconds, 18 seconds and 5 minutes after dye arrival, respectively. Photographs A-C were pro. vided by Dr Dr S. Wolf, RWTH, Aachen.
Figure 2 A-D. ICG angiogram of a human volunteer, 2 seconds, 4 seconds, 13 seconds and 40 minutes after dye arrival, respectively. Photographs A-C were provided by Dr Dr S. Wolf, RWTH, Aachen. 

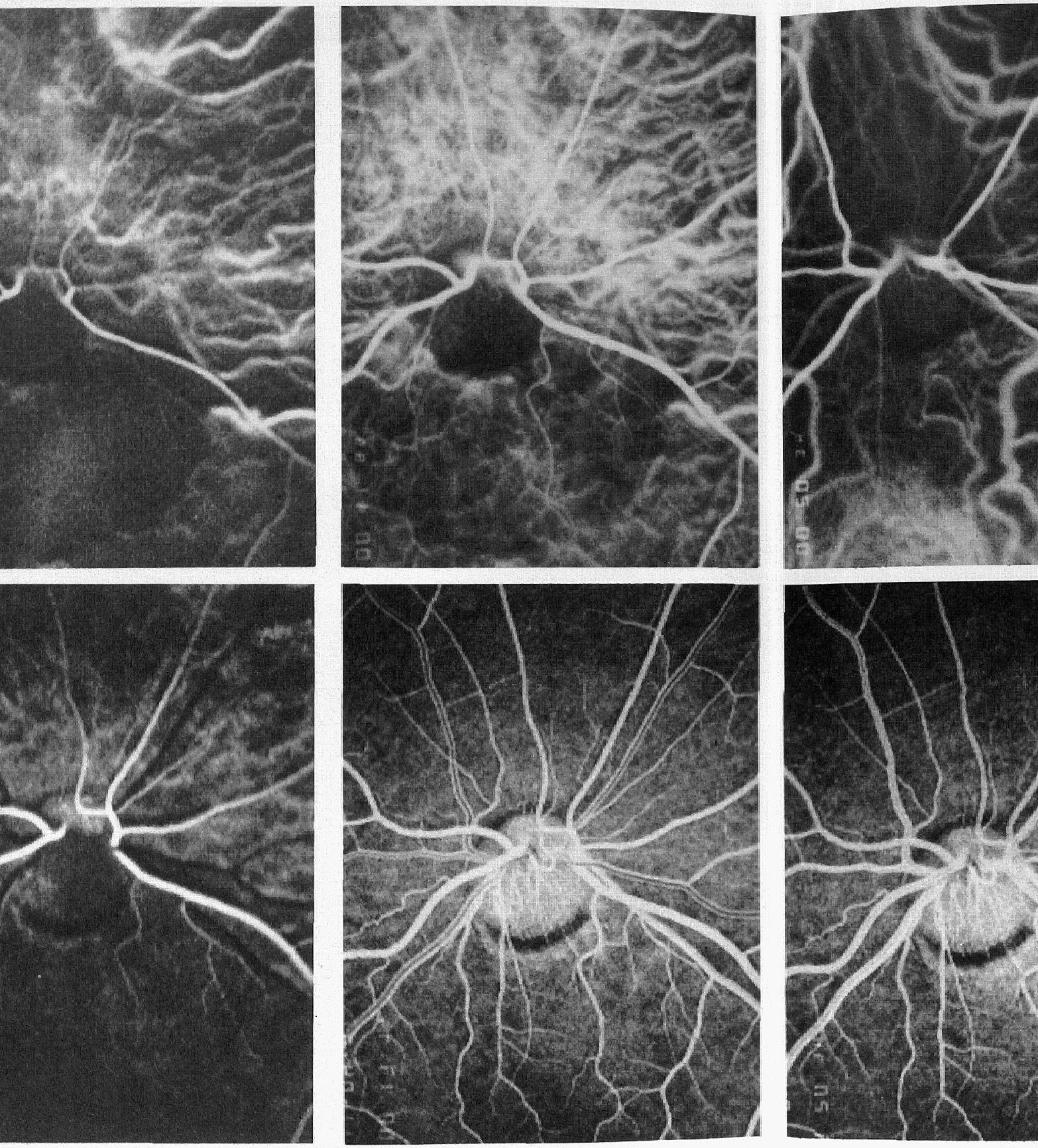


\subsection{The normal fluorescein and indocyanine $g$}

In fluorescence angiography either S] peripheral vein. The dynamics of the dye bo ded through the optical media of the eye.

\section{SF angiography.}

Several investigators pioneered the $\mathbf{u}$ lar circulation in animals.' In 1960, MacCle: application of sodium fluorescein during fur cess in the human ocular fundus. ${ }^{2}$ Novotny a documentation of the dye circulation in thr angiograms developed into an invaluable to eases. Variations in the normal pattern of $d y$ light allow classification of disorders. The $\mathrm{c}$ and the effect of therapies can be evaluated ation of the angiogram for clinical use, how

In routine fluorescein angiography 3 an antecubital vein. The passage of the dye the use of a fundus camera. Apart from ane retinal vessels, the pattern of the normal $\mathrm{fl}$ technique provides excellent images of the $\mathrm{r}$ angiogram (figure! A-D).

The dye starts to perfuse the retinal injection. The bolus proceeds into the capill lar area. Subsequently, the dye enters the I equally stained over the complete cross $s$ through the central retinal vein. About thirty pletely left the eye, dye starts to recirculate over the total blood volume, the intensities

The choroidal circulation is less we choroidal arteries about one second before of only a few choroidal arteries and arter quickly outshone by a diffuse fluorescence round fluorescence. Initially, the backgrour becomes uniform. The intensity of the bac mum and subsequently declines slowly. Th tively low throughout the time course of $t$ observed. After a few minutes, a network are hypofluorescent relative to the surrour phase, details of the choroidal circulation :

\section{ICG angiography.}

A major limitation of SF as dye $\mathrm{fc}$ Excitation and emission light are efficient: 


\subsection{The normal fluorescein and indocyanine green angiogram}

In fluorescence angiography either SF or ICG is injected into the circulation through a peripheral vein. The dynamics of the dye bolus in the ocular fundus are visualized and recorded through the optical media of the eye.

\section{SF angiography.}

Several investigators pioneered the use of intravenous SF injection to evaluate the ocular circulation in animals. In 1960, MacClean and Maumenee described for the first time the application of sodium fluorescein during fundusscopy for direct obserwation of a disease process in the human ocular fundus. ${ }^{2}$ Novotny and Alvis reported on a photographic technique for documentation of the dye circulation in the retina." Qualitative assessment of photographic angiograms developed into an invaluable tool in diagnosis and treatment of chorioretinal diseases. Variations in the nomal pattern of dye distribution and absorbance of the fluorescence inght allow classification of disorders. The course of disease processes can be followed in time and the effect of therapies can be evaluated. A method for a more refined, quantitative evaluation of the angiogram for clinical use, however, is still not available.

In routine fluorescein angiography 3 to $5 \mathrm{ml}$ of a 10 or $20 \% \mathrm{SF}$ solution is injected into an antecubital vein. The passage of the dye bolus through retina and choroid is recorded with the use of a fundus camera. Apart from anatomical variations in the branching pattern of the retinal vessels, the pattern of the normal fluorescein angiogram is remarkably constant. The technique provides excellent images of the retinal circulation throughout the time course of the angiogram (figure $1 \mathrm{~A}-\mathrm{D}$ ).

The dye starts to perfuse the retinal arteries approximately 10 to 15 seconds after dye injection. The bolus proceeds into the capillary bed, which is very well delineated in the macuLar area. Subsequently, the dye enters the veins at their margins. Later on, the veins become equally stained over the complete cross section. The dye leaves the eye at the optic disk through the central retinal vein. About thirty seconds after injection, before the bolus has completely left the eye dye starts to recirculate in the arteries. When the bolus is thoroughly mixed over the total blood volume, the intensities of retinal arteries and veins become balanced.

The choroidal circulation is less well delineated in SF angiography. The dye enters the choroidal arteries about one second before it arrives in the retinal circulation. Usually, filling of only a few choroidal arteries and arterioles is seen. "The fluorescence of these vessels is quickly outshone by a diffuse fluorescence with a ground glass appearance, called the background tluorescence. Initially, the background flluorescence is patchy, but after a few seconds it becomes uniform. The intensity of the background fluorescence quickly increases to at maximum and subsequently declines slowly. The yield of fluorescence in the macular area is relatively low throughout the time course of the angiogram. Filling of choroidal veins can not be observed. After a few minutes, a network of large choroidal vessels becomes apparent. They are hypofluorescent relative to the surroundings. Thus, except for the very early and the late phase, details of the choroidal circulation are obscured by a diffuse background fluorescence.

\section{ICG angiography.}

A major limitation of $\mathrm{SF}$ as dye for angiography of the ocular fundus is its spectrum. Excitation and emission light are efficiently absorbed by pigments like hemoglobin and mela- 
nin and, as a consequence, information from deeper layers is limited in SF angiography. This urged investigators to look for a dye with an excitation and emission spectrum that was sufficiently different from the absorption spectrum of those pigments. ICG is such a dye. It was already in use in cardiology and data on its properties as a dye for human angiography were well known. In ophthalmology, ICG has initially been used for infrared absorption angiography of the ocular fundus. Infrared fluorescence angiography was developed by Flower and co. workers. Because the necessary equipment for ICG angiography was not commercially available, the angiograms had a relatively poor resolution and interpretation was difficult. Propagation of the technique was slow. Only recently, ICG angiography has become readily applicable for clinical use with the introduction of high-resolution indocyanine green imaging with infrared video cameras mounted on a fundus camera and the scanning laser ophthalmoscope. Its value for diagnosis of chorioretinal diseases is currently the subject of intensive research."

The general aspect of the normal ICG angiogram differs profoundly from the SF angiogram because the retinal and choroidal wascular systems are seen in overlay throughout the angiogram (figure $2 \mathrm{~A}-\mathrm{D}$ ). A standard dose of $25 \mathrm{mg} \mathrm{ICG}$ is given intravenously. Fluorescence starts in the large choroidal arteries and, shortly thereafter, the retinal arteries are lilled. Subsequently, a faint flush of diffuse fluorescence veils the image of all vessels. Two to four seconds after the first dye appearance. the largest choroidal veins reach their maximal value. In the very late phase of the angiogram, after $20-40$ minutes, the choroidal vessels can be seen as hypofluorescent structures against a hyperfluorescent background. Only large blood vessels are delineated in ICG angiography and the tangle of choroidal and retinal vessels gives the angiogram a confounding appearance.

\subsection{Fluorescence characteristics of sodium fluorescein and indocyanine green}

When electrons of certain substances are excited by radiant energy, they are raised to a higher energy level. When the electron falls back to a lower, more stable, energy level a photon in a visible wavelength may be emitted. This reemission of absorbed energy in the form of light is called luminescence. Fluorescence is a form of luminescence. Light emission cannot occur unless energy is absorbed. Therefore, the wavelength of the exciting energy must conespond to some degree with the absorption band of the substance excited. The emitted spectrum has, as a rule, a longer wavelength than the excitation spectrum.

In biology and medicine, the difference between excitation and emission spectra of a fluorescent substance is widely used to image exclusively those parts of a tissue that contain the fluorescent substance. From the many fluorescent dyes that are available, sodium fluorescein (SF) and indocyanine green (ICG) have emerged for ocular angiography because of their low toxicity and high fluorescence efficiency in blood at concentrations that can be reached in ocular vessels. The most important differences between the two dyes are their absorption and emission spectra, and their binding properties to blood proteins.

The maximum absorption and emission occurs for sodium fluorescein at 490 and 530 $\mathrm{nm}$ and for indocyanine green at 790 and $825 \mathrm{~nm}$ (figure 3). This maximum in the visible light for SF and in the near intrared spectrum for ICG, results in a different aspect of the SF and ICG angiogram. The three major pigments present in the ocullar fundus, xanthophyll in the macular retina, melanin in the retinal pigment epithelium and choroid, and hemoglobin in blood, absorb the spectra to a different extent (figure 4 ). ${ }^{8.9}$ Light with wavelengths within the 


\section{Sodium Fluorescein}

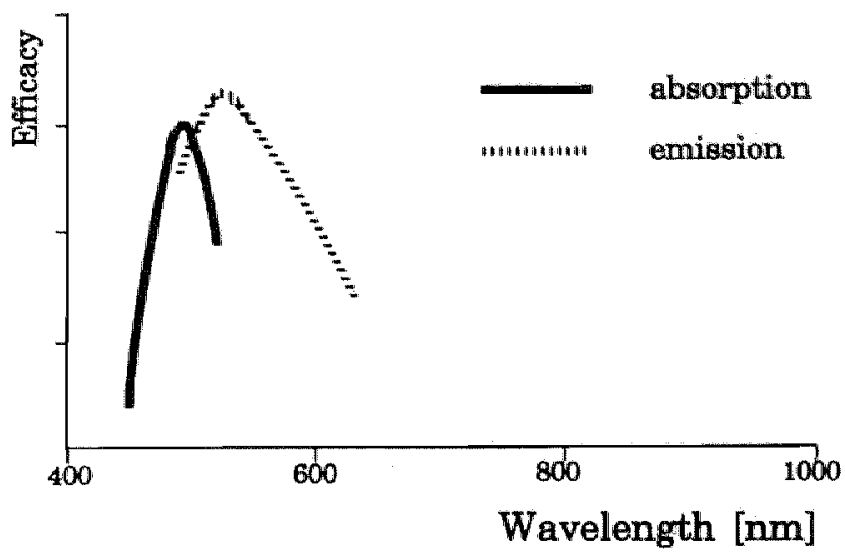

\section{Indocyanine Green}

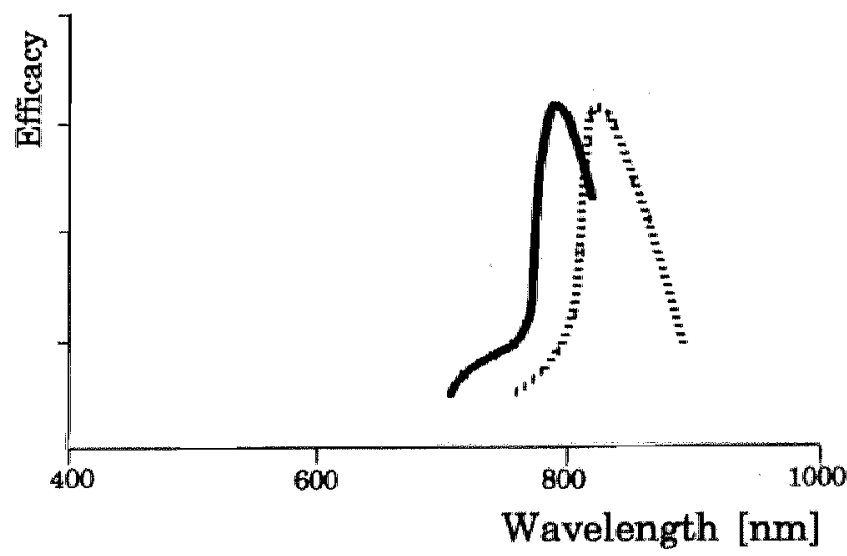

Figure 3. Absorption and emission spectra of SF and ICG in whole blood.

spectra of ICG will penetrate tissue layers that contain xanthophyll and melanin better than that of SF, because these pigments absorb longer wavelengths less. Hemoglobin has an absorption peak close to the excitation and emission spectrum of SF, while it hardly affects both spectrat of ICG (figure 4). As a consequence, blood vessels will block fluorescence from deeper layers more efficiently in SF angiography than in ICG angiography.

When dissolved in plasma, both SF and ICG molecules are bound to plasma proteins, mainly albumin. The free fraction of SF depends on the relative concentrations of SF and albumin." In plasma that contains albumin in concentrations within the physiological range, $8 \%$ of SF molecules will be bound at an SF concentration of Uess than $0.3 \mathrm{mg} / \mathrm{ml}$, while at an SF concentration of $2.5 \mathrm{mg} / \mathrm{ml}, 50 \%$ of the molecules will be bound. ICG has been reported to be bound to albumin almost completely in plasma, i.e., for $98 \%$." Apart from the binding to albu 

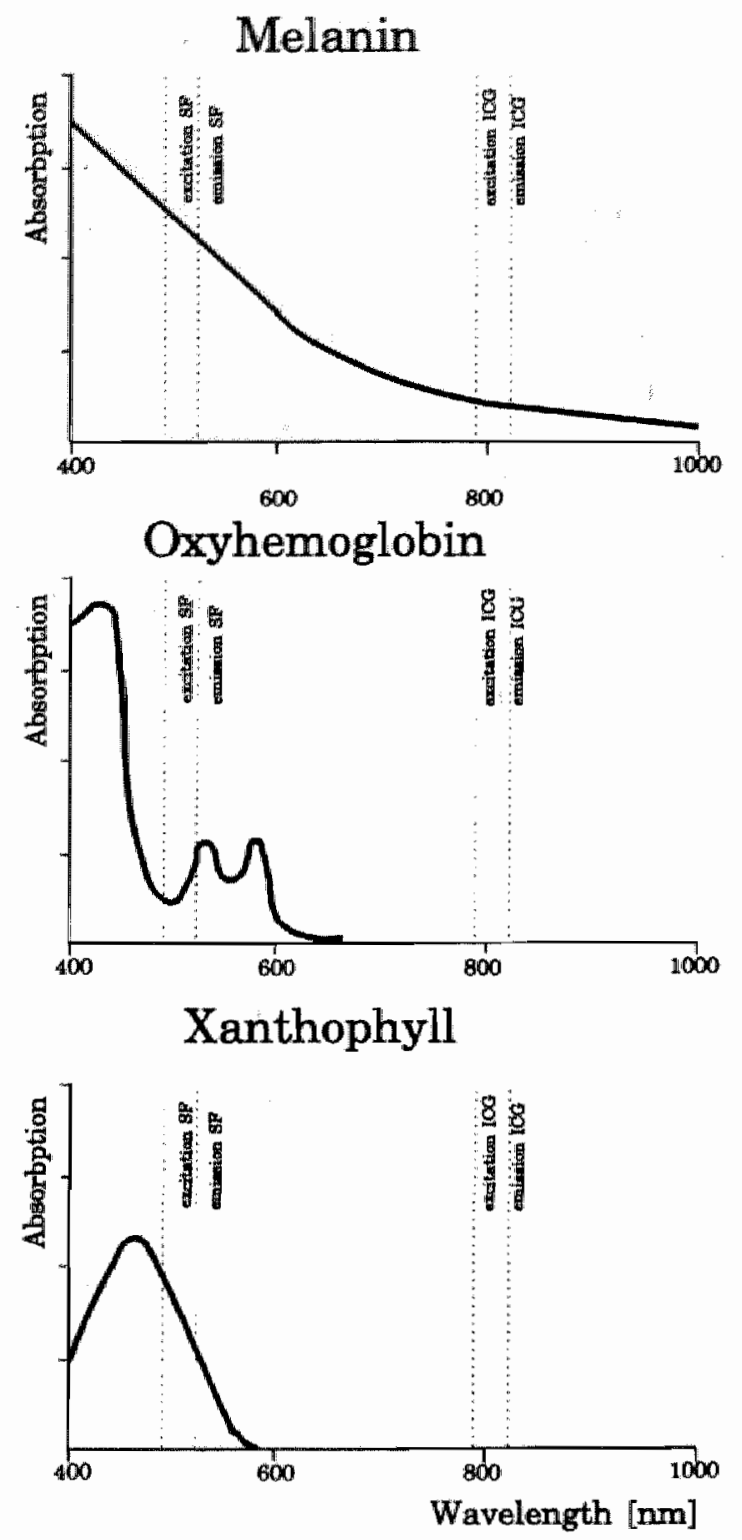

Figure 4. Relative absorption of wavelengths between 400 and $1000 \mathrm{~nm}$ by melanin, oxyhemogiobin, and xanthophyll. Absolute absorption depends on pigment concentration and layer thickness.

min, a small fraction of the SF molecules seems to be bound to red blood cells. ${ }^{12}$ Other data indicate that SF may also stain leukocytes and blood platelets." Because unbound molecules extravasate more readily, fluorescence from extravascular compartments will be more significant in SF angiography than in ICG angiography.

Layer thickness and dye concentration influence the yielld of fluorescence independently and will be discussed separately. When the yield of fluorescence is plotted against layer 
thickness while the concentration is kept constant, the yield of fluorescence will increase linearly with layer thickness for thin layers (figure $5 \mathrm{~A}$, see also chapter 3 ). In frontal illumination and detection, as is used in fluorescence angiography, an increase in layer thickness eventually results in levelling off of the curve at a certain thickness because significant amounts of excitation light are absorbed in superficial layers and the light reaches deeper layers at reduced intensities. In the end, the intensity becomes independent of layer thickness because the excitation light is completely absorbed by more superficial layers. In principle, an increase of dye concentration at fixed layer thickness results in similar curves, but at higher concentrations

A

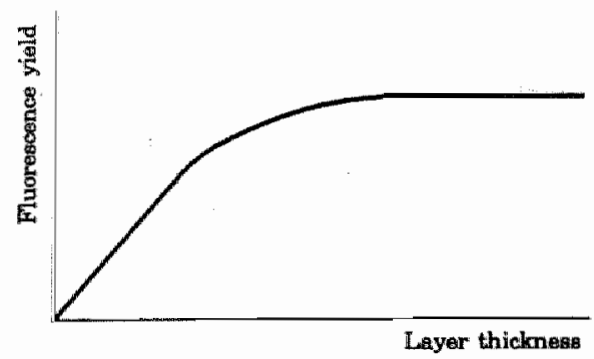

B

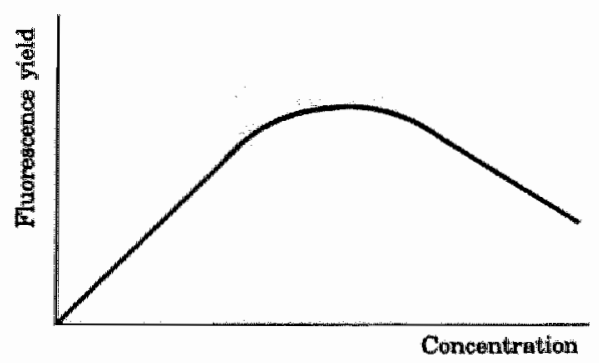

Figure 5. A: Relationship between yield of fluorescence (intensity) and layer thickness of dye containing fluid. B: Relationship between yield of fluorescence (intensity) and dye concentration.

quenching may occur. Quenching arises at high dye concentrations because fluorescein molecules form dimers and polymers which absorb light but are non-fluorescent themselves. Due to the combined effect of light absorption in superficial layers and quenching, the plot of intensity against concentration will increase with increasing concentration at low concentrations, level off at a certain concentration, and decrease with a further increase of concentration (figure $5 \mathrm{~B}$ ). In literature, anly limited data on the relationship between yield of fluorescence, dye concentration, and layer thickness of SF and ICG in plasma are available. Delori reported an intensity-concentration curve for a layer thickness of $300 \mu \mathrm{m}$ and the relation between intensity and layer thickness for an SF concentration of $0.05 \mathrm{mg} / \mathrm{ml}^{12}$

A factor that influences the yield of a fluorescent dye in blood is the actual distribution of red blood cells. It is well known that the transparency of blood depends on the extent of red cell aggregation. ${ }^{14.15}$ During flow, when the red cells are dispersed by shearing forces, the transparency of blood is low, whereas in stasis red cells are aggregated and transparency is high because gaps formed between the aggregates allow contribution from deeper layers to the fluo-

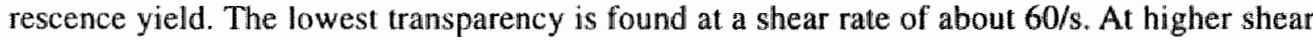
rates the transparency increases because of red cell elongation and orientation. This effect is only small. The degree of aggregation also influences light scatter in blood. Dispersed cells will cause more scatter. This results in a longer path length of the excitation light through the blood and a higher chance of excitation of a dye molecule. As a consequence of this phenomenon, the yield of fluorescence will be higher in flow than in stasis. Thus, on the one hand, aggregation will increase the yield of fluorescence because transparency of blood increases, while, on the other hand, aggregation will decrease the yield because there is less scatter. 
Whether the effect of red cell distribution on transparency or on light scatter prevails is determined by the absorption spectrum of hemoglobin: In the case of SF the excitation and emission spectra are close to the absorption peak of hemoglobin. Because light absorption is high, the fluorescence yield of SF in blood will be highther in stasis than in flow. In the case of ICG, excitation and emission spectra and the absorption spectrum of hemoglobin do not overlap. Light absorption by hemoglobin is insignificant and scatter will be more important. The fluorescence yield of ICG will thus be higher in flow than in stasis. All reported measurements of intensity-concentration curves of SF and ICG in blood were performed in stasis and are therefore not applicable to flowing blood. ${ }^{5.12}$

\subsection{Dye transport to the eye after intravenous injection}

Injection of an indicator into the circulation allows the study of the hemodynamics of a vascular system by analysis of the actual bolus distribution in blood. Measuring the dilution of the indicator is a technique that is routinely used for determining blood flow. Two variants of the method exist: the constant infusion or Stewart principle and the bolus injection or Henriques-Hamilton-Bergner principle. ${ }^{\text {I" }}$ By using constant infusion, Stewart was the first to report an indicator dilution method for measuring cardiac outpult, but now it is the bolus techninue that is preferred for measuring blood flow: ${ }^{10}$ An indicator substance is injected into the circulation upstream of a mixing place and its diluted concentration is measured continuously downstream. Registration of the concentration in time results in an indicator dilution curve. Higher cardiac output causes a higher flow in the main circulation and earlier appearance of the indicator at the measuring location as well as more rapid passage of the complete indicator profile. Thus, the shape of the indicator dilution curve in the aorta is a measure for cardiac output. In a closed circulation system a problem may arise when recirculating dye distorts the down slope. In that case, a reconstruction is needed of the time-concentration curve of the first dye passage by correction for recirculation.

The indicator dilution theory further predicts that the time-concentration profile, as measured in any artery down stream of the heart, murrors the time-concentration profile of the indicator in the aorta as long as the indicator is not additionally mixed or lost between the injection and measuring sites (Bergner principle). This fundamental principle of indicator dilution theory will be discussed in more detail in chapter 5 . This principle implies that cardiac output can be calculated from the time-concentration curve as assessed in any peripheral artery. On the other hand, the time-concentration curve in a peripheral artery contains no information about the local blood flow in that artery.

Any substance may be used as an indicator as long as it does not alter circulatory dynamics, is not lost in the extravascular space, and is not additionally diluted between the mixing place and the site of measurement. When a dye is used as an indicator the term dye dilution method can be used alternatively.

Ocular fluorescence angiography is, in fact, an indicator dilution technique. The passage of the dye can be recorded by measuring the course of the intensity of a retinal vessel in time. To obtain a dye dilution curve the time-intensity curve has to be converted into a timeconcentration curve. However, there are insufficient data available in literature about the relationship between intensity and SF concentration to make such a conversion feasible. Only Riva and co-workers discussed the relationship between fluorescence intensity of retinal arteries and the local SF concentration in blood in detail." They concluded that fluorescence intensity of a retinal artery is proportional to the SF concentration as long as the intensity at any point 
in the vessel is proportional to the local SF concentration. Their study allows no conversion of intensities into absolute dye concentrations and no information is provided on the dye dosages to which their assumption of local proportionality applies.

In intravenous fluorescence angiography, the dye bolus is thoroughly mixed with blood at several sites, i.e., the right ventricle, the lung circulation, and the left ventricle. As a consequence, no well defined bolus front is visible when the dye arrives in the ocular fundus and peak concentrations are relatively low. Maximum dye concentrations in ocular vessels have been estimated to be about 1/600 of the intravenously injected amount of dye."

\subsection{Capillary permeability and dye extravasation}

Extravasation of small solutes like SF and ICG takes place by ulltrafiltration of fluid and concurring solvent drag, and by diffusion. Ultrafiltration exchange is controlled by the balance of hydrostatic and colloid osmotic forces in the intra and extravascular fluid, and the hydraulic conductivity and surface area of the vessel wall. Diffusion exchange is determined by solute concentration differences and solute permeability of the vessel wall. Variation in ultrastructure of the wall of ocular capillaries reflects differences in dye permeability. Choroidal capillaries have fenestrations which facilitate exchange of solutes between blood and interstitial space. The permeability of the choriocapillaris to small hydrophilic substances like ICG and SF is very high." The endothelium of the choriocapillaris, on the other hand, substantially restricts the passage of proteins. ${ }^{2}$ the extravasculat albumin concentration in the choroid is, for example, only $10 \%$ of that in plasma." "Thus, probably only unbound SF and ICG molecules. will extravasate to a significant extent during the time course of the angiogram. Histological studies on freeze dried eyes after intravenous dye injection in vivo indicate that both SF and ICG actually enter the interstitial space of the choroid. ${ }^{22.23}$ Intercellular junctions of the endothelial cells of the retinal capillaries are of the zonulla occludens type. In analogy with the blood-brain barrier, the retinal capillaries constitute a blood-retina barrier together with the retinal pigment epithelium (see next paragraph). This barrier precludes dye extravasation into the interstitium of the retina. . $^{\text {.? }}$.s

Once extravasated, transport within the interstitial fluid takes also place by solvent drag or diffusion. Little is known about fluid movements in the interstitial space, but most flow probably occurs along capillaries. Simple diffusion is more likely to be the dominant transport mechanism into parts of the extravascular space that are more remote from the capillaries. Beside on the size of the diffusing substance, concentration difference, distance, and temperature, diffusion rate depends on the composition and structure of the interstitium. Diffusion is, for example, dependent on hydration. number of fibers, and binding properties of the tissue. Only limited information is available on the structure of the interstitium of the choroid and no experimental data are reported on diffusion kinetics of SF and ICG in this medium. Part of the extravasated dye molecules will be removed from the interstitial fluid by reuptake into the blood. This process is governed by the same principles as dye extravasation. Ocular tissues lack lymphatic vessels. Large proteins in the interstitial fluid of the choroid leave the eye by passing through the sclera. Part of the dye molecules will probably leave the eye by this pathway. 


\subsection{Anatomy of ratina and choroid with respect to angiography}

In thurescence angiography the appearance of images obtained from the ocular fundus is determined by the actual distribution of dye molecules over the tissues of retina and choroid. Apart from dye concentration. the yicld of fluorescence is determined by the structure of the vascular systems, distribution of pigments, and dimensions of the extravascular space accessible to the dye. The most importank aspects of anatomy with respect to dye distribution and appearance pattern of the normal ocular fluorescence angiogram will be discussed below. In the description of the anatomy, the designation inner and outer indicate a localisation relatively close to or far from the center of the eye, respectivelly.

\section{Retina.}

The retina is the innermost tunic of the eye (figure 6). Its interstitial space is transpa rent to visible light except in the macular area which contains xanthophyll, a yellow pigment. The vascular system is localized in the inner layers of the retina and is basically two-dimensional in structure. The central retinal artery enters the eye at the optic disc and bifurcates into four secondary branches that spread out over four quadrants. Arterial dimensions decrease with branching order. The capillary network is positioned between the arterial and venous systems and is arranged in two layers in most parts of the fundus. No data about the surface density of the network could be found in literature. The blood from the capillaries is collected in venules which coverge into veins. The veins take a centripetal direction to the optic disk and drain eventually into the central retinal vein, which is the only outflow channel

for the retinal circulation. The large arteries have sizes of up to $120 \mu \mathrm{m}$, the large veins up to $130 \mu \mathrm{m}$. The capillaries typically have lumina ranging in diameter from 3.5 to $6 \mu \mathrm{m}$. Intercellular junctions of the endothelial cells of the capillaries and of cells of the retinal pigment epithelium (see below) are of the zonula occludens type.

\section{Retinal pigment epithelium.}

The retinal pigment epithelium lies between the sensory retina and Bruch's membrane and consists of a single, continuous layer of cuboidal cells. The epithelial cells are connected by zonulae occludentes and contain numerous melanin granules. The amount of melanin varies with fundus location. The melanin content of the epithelial cells is relatively high in the macular area. Transmission of the retinal pignent epithelium in the macular and paramacular area is about $50 \%$ and $68 \%$, respectively, for the excitation and emission wavelengths of SF. It is in both areas much higher, about $90 \%$, for the spectra of ICG. ${ }^{\%}{ }^{2 h}$ There is no statistically significant difference in transmission of the pigment epithelium between whites and blacks.

\section{Choroid.}

The choroid is a pigmented vascular tissue situated between the retinal pigment epithelium and the sclera (see below). The choroid consists of several layers: Bruch's membrane, choriocapillaris, stroma, and lamina suprachoroidea. Bruch's membrane is a thin, multi-layered structure between the retinal pigment epithelium and the choriocapillaris. The choriocapillaris is the only capillary system of the choroid and has the structure of a dense, two-dimensional sinusoidal network. The shape of the capillaries is somewhat flattened. The mean density of the network, as assessed from histologic sections, decreases with age from about 0.8 in 
the first decade to about 0.4 in the eighth decade. The capillary diameter perpendicular to the plane of the choriocapillaris also decreases with age from 10 to $7 \mu \mathrm{m}$. The endothelial cells are fenestrated. The stroma contains the medium and large choroidal vessels in addition to cellular components (such as melanocytes) and loose connective tissue. The short posterior ciliary

\section{cross section:}

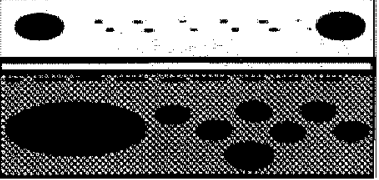

chorioretinal complex frontal view:

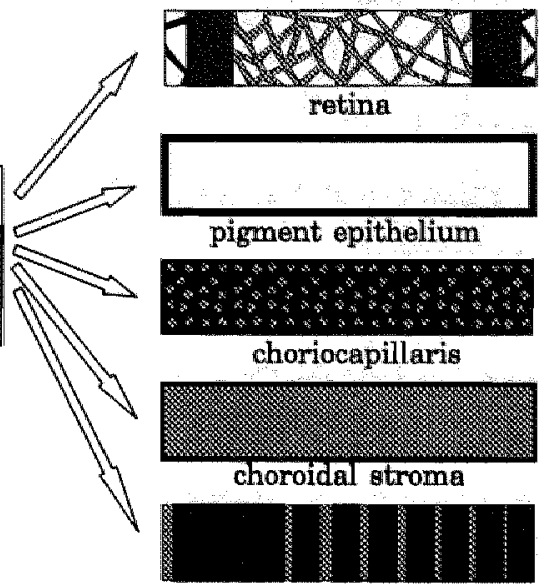

choroidal veins

Figure 6. Cross section and frontal view of various tissue layers of retina and choroid that potentially contribute to the intensities of the fluorescein angiogram. Grey indicates contribution to fluorescence yield of a tissue layer, black casing indicates that the tissue layer contains a pigment that absorbs light. Note: The layer of the choriocapillaris consists mainly of the lumen of the capillaries. The intercapillary columns of interstitial tissue are indicated as hatched circles.

arteries enter the sclera at the posterior pole of the eye and branch to form the large choroidal arteries. These large arteries are localized in the outer layers of the choroidal stroma and give off arterioles at right angles, perpendicular to the plane of the choroid. These arterioles penetrate the inner stromal layers to supply the choriocapillaris. The transition from choroidal artery to choriocapillaris is noted to be very abrupt ${ }^{27.25}$ The choriocapillaris is drained by venules that combine in large vessels in the inner stromal layers. The abundance of veins, as can best be appreciated from cast studies, is such that they form an almost continuous layer when projected on a plane (figure 7). The veins ewentually drain into the vortex systems at the equator of the eye. The melanin content of the choroidal stroma decreases from the macular area to the periphery. ${ }^{2 t}$ Blacks have a significantly higher amount of melanin in the choroidal stroma than Caucasians.

\section{The sclera}

The sclera, the outermost tunic of the eye, consists mainly of collagen and contains only few blood vessels. 


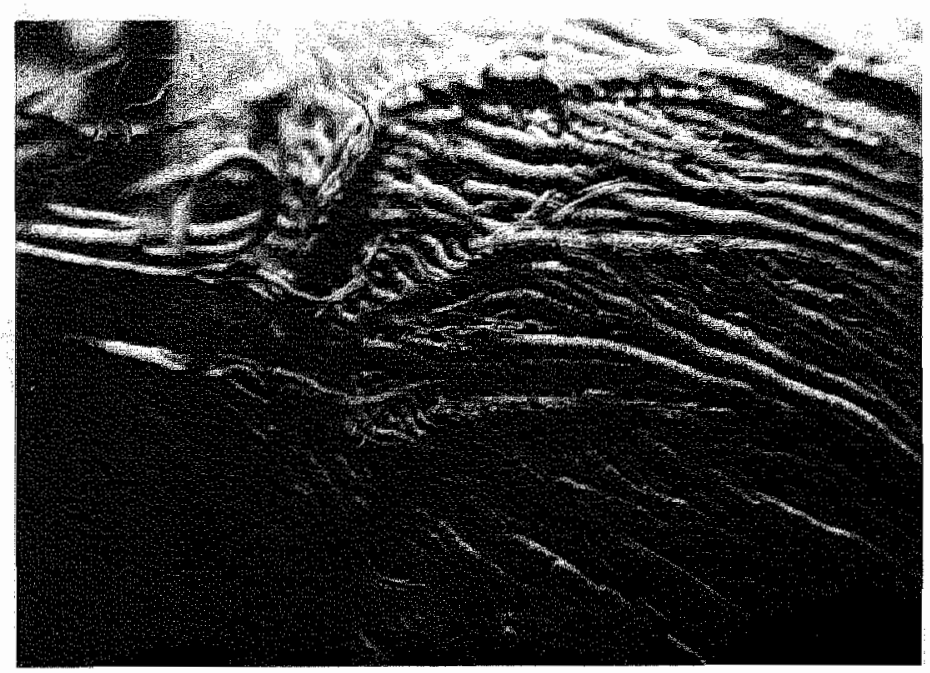

Figure 7. Photograph of a vascular corrosion cast of the porcine choroid. External aspect of the posterior pole. Cast has been prepared by Prof Dr P. Simoens, Gent, Belgium.

\subsection{Imaging in fluorescence angiography}

To resolve details of the ocular fundus, the optical system used for angiography should have an appropriate resolution. Resolution is determined by the properties of the objective lens and the illuminating system in combination with the resolving power of the human lens. The resolution of the human eye is a limiting factor. Under optimal conditions, it is about 7 and 11 $\mu \mathrm{m}$ for the excitation and emission spectrum of SF and $\mathrm{ICG}_{\text {, respectively.29 }}{ }^{24}$ ight scatter and specular reflections reduce the optical quality of the eye. Retinal capillaries have diameters that are below the optical resolution of the eye and, thus, their diameter cannot be measured from the angiogram. Capillaries can be visualized in the macular area thanks to the efficiency of fluorescence of the intravascular dye molecules and the dark background. For the same reason, the yield of fluorescence of capillaries can not be measured because the fluorescence yield seems to come from a larger area than their actual dimensions.

Good quality photographic documentation of the ocular fundus became available with the introduction of the Zeiss fundus camera in $1956 .{ }^{\circ}$ The description of fluorescence emission photography of the human choroidal and retinal circulation by Novotny and Alvis in 1961 marks the beginning of fluorescence angiography. "Haining introduced the cine fluorography, which resulted in a better time resolution of the dye passage. "The method was impractical and not suitable for clinical use. Rontine continuous recording of the angiogram became possible with the development of low light level TV systems. Van Heuven was the first to report on a TV system mounted on a fundus camera. ${ }^{32}$ With the advent of the scanning laser ophthalmoscope (SLO), a method of retinal imaging became available for angiography that differs considerably from the techniques based on a conventional fundus camera. ${ }^{37}$ The SLO uses a focused, scanning laser beam to illuminate the fundus and has a numerical aperture (N.A) of 0.06. 
The resolution of the SLO is limited by the size of the laser spot on the retima, which is about $20 \mu \mathrm{m}$ for the $40^{\prime \prime}$ field. The SLO thus provides angiograms with a relatively low optical separation. However, the contrast of the images is high, since the image is generated by collecting the reflecting light from one retinal point at a time, thus generating little background scatter. The better contrast and a lower separation of the SLO provides angiograms with a better optical resolution than a conventional fundus camera with a higher separation (NA up to 0.45) and a higher level of stray light: $4 ., 15$

Fundus camera and SLO are widely applied in SF and ICG angiography. Both systems are valuable for routine, qualitative evaluation of angiograms in clinical practice. Only the SLO angiograms can be used for quantitative angiography, because the level of background scatter is acceptably low. Illumination conditions are also important for quantitative angiography. Fundus illumination should be uniform when intensities on various locations are compared. This situation is exclusively met when the axis of the visual optics and that of the illumination system are aligned. For relative intensity measurements at a fixed location in time, however, illumination only needs to be stable.

Image storage is performed either analogically on photographic film or videotape, or digitally on optic disc or CD-ROM. For technical reasons digital storage is still confined to a few dozens of selected images. For qualitative diagnostic purposes storage of selected images on photographic film, optical disk, or CD-ROM is adequate. ${ }^{37}$ For quantitative angiography continuous recording of the dye passage may be necessary. With modern equipment short periods of continuous recording can be read into a real time video digitizer." Storage of complete dye dilution curves is presently only possible analogically on videotape.

\subsection{Current interpretation of the normal fluorescence angiogram}

The appearance pattern of the fluorescence angiogram is determined by superimposition of fluorescence from various tissue layers. Compartments that potentially contribute are the intra and extravascular space of retina and choroid, and the sclera.

The interpretation of the appearance of the retina in SF angiography is relatively straight forward and undebated. The yield from the retina originates only from the intravascular compartment because dye molecules normally have no access to the interstitium of the retina, as is pointed out in paragraph 4 . In the early phases of the SF angiogram, the large vessels of the retinal circulation are well delineated because fluorescence from deeper layers is partly absorbed by the pigment epithelium (paragraph 2.2). The choroidal fluorescence quickly becomes uniform. Since the dye bolus is thoroughly mixed on its way from injection site to the eye (paragraph 2.3), no sharp front is seen when the dye enters the retinal arteries.

Passage of the bolus into the capillaries is more difficult to observe because vessel dimensions are below the optical resolution (paragraph 2.6) and the relatively low fluorescence yield from those vessels is outshone by fluorescence from the choroid. Only in the macula individual capillaries can be delineated because the xanthophyll and the relatively large amounts of melanin in this area absorb almost all fluorescence from the choroid (paragraph 2.2). The two dimensional structure of the retinal circulation causes the dye to enter the veins at their margins (paragraph 2.5). This fluorescence at the vessel margins is maintained downstream and is a manifestation of laminar flow in the veins. It is particularly well seen near the optic disk. Here, the margins of veins drain part of the retinal vascular network that is located near the disk and has a short passage time from large artery to vein, while the center of the veins drain 
blood from more remote areas of the vascular network which have longer passage times.

In ICG angiography, the appearance of the retinal circulation is, in principle, simflar to that in SF anglography. However, since fluorescence from deeper layers is absorbed less by pigments and the fuorescence from the choroid is not uniform in ICG angiography, retinal vessels are less well defined (paragraph 2.2).

The interpretation of the choroidal appearance pattern in SF angiography is more complicated. The background fluorescence, defined as the yield of fluorescence at fundus locations not occupied by large retinal wessels, is a summation of the yield from retinal capillaries and the yield from choroidal layers. Choroidal compartments that may contribute to background fluorescence are the choriocapillaris, the large choroidal vessels, and also the extravascular space of the choroid, since SF molecules can extravasate from the choriocapillaris (paragraph 2.4). Only a few authors discuss the choroidal layers actually adding to the yield of the background fluorescence. Some authors ${ }^{34-42}$ attribute the choroidal fluorescence in the early phase of the angiogram to the yield from the choriocapillaris, while Gass assumes that early choroidal luorescence is mainly coming from extravasated SF molecules that stain Bruch's membrane and the choroidal interstitium. ${ }^{43}$ Riva concluded that the relative contribution of intra and extra wascular compartments to background fluorescence depends on ocular pigmentation, the contribution of the intravascular compartment being very low in subjects with a high degree of fundus pigmentation. ${ }^{4}$ The patchy pattern of the background fluorescence in the filling phase is a normal aspect of the SF anglogram. Although the choriocapillaris anatomically seems to be a freely anastomosing system, most authors agree that it is functionally divided into small segments, the lobules, each with one feeding arteriole and several draining venules. ${ }^{4 s, 46}$ The patchy filling pattern can be explained by a physiological difference in dye transport times from the ophthalmic artery to various groups of lobules. Invisibility of the filling phase of choroidal veins is by the various authors explained by the high fluorescence yield from choriocapillaris or extravasated SF molecules. The relative hypofluorescence of choroidal vessels in the late phase of the angiogram is attributed by most authors to a delay in the return of extravasated dye molecules into the choriocapillaris. The intravascular dye concentration diminishes rapidly because of dye distribution over body fluids and the extravascular concentration remains relatively high. As a result, hypofluorescent vessels bath in hyperfluorescent extravascular fluid. Grass, however, explains the relative hypofluorescence of choroidal vessels mainly by assuming that only the thin plasma layer at the vessel wall contributes to the fluorescence yield of blood vessels, while the fluorescence from the extravascular space originates from thicker layers. ${ }^{3}$ None of the aforementioned interpretations of the appearance of the SF angiogram is supported by experimental studies.

The nomal appearance pattern of the choroid in $\mathrm{ICG}$ angiography has drawn little attention because the interpretation seemed to be relatively straightforward. Authors agree that ICG molecules normally do not extravasate either in the retina or in the choroid and that the normal ICG angiogram thus only contains information on intravascular compartments. ${ }^{16,47}$ The choroidal circulation is better visualised in ICG angiography than in SF angiography because absorption of fluorescence originating in the choroid is hardly absorbed by the pigment epithelium. ${ }^{62}$ For the same reason, little difference exists in the visibility of choroidal vessels in the macula as compared to vessels in other fundus areas. There is, however, a striking difference between the density of the network of large choroidal vessels when one compares the ICG angiogram with choroidal cast studies. Obviously, not all vessels that are present in the cast studies can actually be observed during angiography. In addition, no explanation can be found in literature for the relative hypofluorescence of large choroidal vessels in the very late 
phase of the ICG angiogram.

In conclusion, no undebated concept of how the intensities in fluorescence angiography come about is available. None of the prevailing concepts is verified by experiments on a numerical model. The information in literature on the relationship between dye concentration and yield of fluorescence and on the dynamics of dye distribution in the tissues of retina and choroid during angiography is insufficient to develop such a concept.

\section{REFERENCES}

1. Schatz H, Burton TC, Yannuzzi LA, Rabb MF. History of fluorescein angiography. In: Interpretation of Fundus Fluorescein angiography. St.Louis: C.V. Mosby: 1978:3-9.

2. MacClean AL, Maumenee AE. Hemangioma of the choroid. Am J Ophthalmol. 1960;50:3

3. Novotny HR, Alwis DL. A method of photographing fluorescence in circulating blood in the human retina. Circulation. $1961 ; 24: 82$.

4. Kogure K. David NJ, Yamanouchi $U_{*}$ Choromokos E. Infrared absorption angiography of the fundus circulation. Arch Ophthalmol. 1970;83:209.

5. Flower RW. Hochheimer BF. A clinical technique and apparatus for simultaneous angiography of the separate retinal and choroidal circulations. Invest Ophthal. 1973;12:248-261.

6. Bischoff PM، Flower RW. Ten years experience with choroidal angiography using indocyanine green dye:a new routine examination or an epilogue? Doc Ophthalmol. 1985;60:235-291.

7. Yannuzzi LA, Sorenson JA, Guyer DR, Slakter JS, Chang B, Orlock D. Indocyanine green videoangiography: current status. Europ J Ophthalmol. 1994;4:69 81.

8. Mainster MA. Wavelength selection in macular photocoagulation. Ophthalmology. 1986;93;952-958.

9. Gabel VP, Birngruber R. Hillenkamp F. Individuelle Unterschiede der Lichtabsorption am Augenhintergrund im sichtbaren und infraroten Spektralbereich. Ber Disch Ophthalmoll Ges. 1977:74:418-422.

10. Rockey JH. Weiye L. Eccleston JF. Binding off fluorescein and carboxyfluorescein by human proteins: significance of kinetic and equilibrium parameters of association in ocular fluorometric studies. Exp Eye Res. 1983:37:455-466.

11. Cherrick GR. Stein SW, Leevy CM. Davidson CS. Indocyanine green: observations on its physical properties, plasma decay, and hepatic extraction. J Clin Inwest. 1960;39:592-600.

12.Delori, F.C. M.A. Castany, R.H. Webb. Fluorescence characteristics of sodium fluorescein in plasma and whole blood. Exp Eye Res. 1978:27:417-424.

13. Tanaka $T$. Muraoka $\mathrm{K}_{\text {}}$ Shmizu $\mathrm{K}$. Fluorescein fundus angiography with scanning laser ophthalmoscope. Ophthalmology. 1991:98:1824-1829.

14.Schmid-Schoenbein. H. E. Volger, H.J. Klose. Microrheology and light transmission of blood. II. The photometric quantilication of red cell aggregate formation and dispersion in flow. Pfluggers Arch. $333: 140-155,1972$.

15.Klose. H.J., E Volger. H. Brechtelsbauer. L. Heinich, H. Schmid-Schoenbein. Microrheology and light transmission of blood. I. The photometric aspects of red cell aggregation and red cell orientation. Pflügers Arch. 333:126-139. 1972.

16. Lassen NA, Henriksen O. Sejrsen $P$. Indicator methods for measurement of organ and tissue blood flow In: Renkin EM, Michel CC, eds. Handbook of Physiology, The Microcirculation, Volume III. Bethesda. MD: American Physiological Society; 1984:21-63.

17. Riva CE. Feke GT. Ben-Sira 1. Fluorescein dye-dilution technique and retinal circulation. Am J Physiol 1978:234:H315-H322.

18. Flower RW. Injection technique for indocyanine green and sodium fluorescein dye angiography of the eye. Invest Ophthalmol. 1973;12:881-895.

19.Tronquist P. Capillary permeability in cat choroid, studied with the single injection technique. Acta Physiol Scand. 1979:106:425-430.

20. Pino RM. Essner E. Permeability of rat choriocapilaris to hemeproteins. J Histochem Cylochem. $1981: 2: 281-290$ 
21. Toris CB, Pederson JE, Truboi S. Gregerson DS, Rice TJ. Extravascular albumin concentration of the uvea. Invest Ophthalmol Vis Sici. 1990:31:43-53.

22. Grayson MC, Laties AM. Ocular localisation of sodium fluorescein. Arch Ophinal. 1971;85:600-609.

23. Matsubara T, Uyama $M$. Takahashi $K$, Fukushima 1, Tobe $T$, Matsunaga $H$. Histological proof of localization of indocyanine green in the healthy choroid and retina, and the experimentall choroidal neovascularization. ARVO abstracts. Invest Ophthalmol Vis Sci. 1995,36:1101.

24. Mill A, Tornquist P. Alm A. Permeability of the intraocular bloodvessels. Trans Ophthalmol Soc UK. $1980 ; 100: 332-336$.

25. Murra JN, Cunha-Vaz JG, Sabo CA, Jones CW, Laski ME. Microperfusion studies on the permeability of retinal wessels. Invest Ophthalmol Vis Sci. 1990;31:471-480.

26. Weiter JJ, Delori FC, Wing GL, Fitch KA. Retinal pigment epithelial lipofuscin and melanin and choroidal melanin in human eyes. Invest Ophthalmol Vis Sci. 1986

27. Ring HC, Fujino T, Observations on the anatomy and pathology of the choroidal vasculature. Arch Ophthal. 1967:78:431*444.

28. Shimizu K, Ujiie K. Structure of ocular vessels. Igaku-Shoin, Tokyo 1978.

29. Flower RW, Hochheimer BF. Indocyanine green dye fluorescence and infrared absorption choroidal angiography performed simultaneously with fluorescein angiography. Johns Hopkins Med J. 1975; $138: 33-42$

30. Littmann H. Die Zeiss-Funduskamera. Ber Dtsch Ophthalmol Ges. 1955;59:318-321.

31. Haining WM, Wright MP. Perkins RE. Recent advances in the technical aspects of fluorescein angiography: cinefluorography. Int Ophthalmol Clin. 1974;14:15-29.

32. Van Heuven WAJ, Schaffer C. Advances in televised Pluorescein angiography. International symposium of fluorescein angiography, Tokyo. In: Fluorescein angiography. Tokyo: Igaku Shoin. 1973:10-14.

33. Webb RH. Hughes GW, Pomerantzelf O. Flying spot TV ophthalmoscope. Appl Optics. 1980;19:2991-2997.

34. Wolf $\mathrm{S}$, Wald $\mathrm{KJ}$, Elsner AE. Staurenghi G. Indocyanine green angiography: a comparison of imaging analysis with the scanning laser ophthalmoscope and the fundus camera. Letter to the editor. Retina. 1993;13:266-269.

35. Peli E. Electro-optic fundus imaging. Surv Ophthalmol. 1989;34:113-122.

36. Fonda $S$, Gatti AM, Vecchi D. Reliability of photometric measurements in the Zeiss fundus camera. Acta Ophthalmol (Copenh). 1983;61:58-66.

37. Mimoun $G$, Soubrane $G$, Coscas $G$. Clinical experience with digitized fluorescein angiography. Int Ophthalmol. 1991:15:41-46.

38. Wolf $S$, Toonen $H$, Arend $O$, Jung F, Kaupp $A_{x}$ Keisewetter $H$, Meyer-Ebrecht D, Reirn M. Zur Quantifizierung der retinalen Kapillardurchblutung mit Hilfe des Scanming-Laser-Ophthalmoskops. Biomed Technik. 1990;35:131-134.

39. Oosterhuis JA, Boen-Tan TN. Choroidal fluorescence in the normal human eye. Ophthalmologica. $1971: 162: 246-260$.

40. Hyvarinen L, Maumenee, AE, George T, Weinstein GW. Fluorescein angiography of the choriocapillaris. Am J Ophth. 1969;67:653-666.

41. Archer D, Krill AE, Newell FW. Fluorescein studies of normal choroidal circulation. Am J Ophth. 1970;69: 543-554.

42.de Schatepdrijwer L. Simoens P, Pollet L, Lauwers H, de Laey JJ. Morphologic and clinical study of the retinal circulation in the miniature pig. B: Fluorescein angiography of the retina. Exp Eye Res. 1990;54:975-985.

43.Gass JDM. Stereoscopic Atlas of Macular Diseases. 3rd ed. St.Louis: C.V.Mosby Company; 1987:12-18.

44. Riva CE, Ben-Sira 1, Feke GT. Flow and diffusion of indocyanine green and fluorescein dyes in the fovea centralis. Exp Eye Res. 1977;24;15-23.

45. De Laey JJ. Fluorescein angiography of the choroid in health and disease. Int Ophthalmol. $1983 ; 6: 125 \backsim 138$.

46. Hayreh SS. In wivo choroidal circulation and its watershed zones. Eye. 1990;4:273-289.

47. Scheider A, Voeth A, Kaboth A. Neuhauser L. Fluorescence characteristics of indocyanine green in the normal choroid and in subretinal neovascular membranes. German J Ophthalmol. 1992;1:7-11. 
CHAPTER 3

\section{SHEAR RATE AND HEMATOCRIT DEPENDENCE OF FLUORESCENCE FROM RETINAL VESSELS IN FLUORESCEIN ANGIOGRAPHY.}

P.R. van den Biesen, F.H. Jongsma, G.J. Tangelder, D.W. Slaaf. 


\section{ABSTRACT}

Purpose. To obtain more quantitative knowledge about the yield of fluorescence from retinal vessels during fluorescein angiography. The influence of shear rate, concentration of sodium fluorescein, hematocrit, and layer thickness on the yield of fluorescence from blood were investigated.

Methods. Measurements were performed in vitro on samples of human blood in a cone-plate shear chamber using frontal illumination.

Results. Application of physiologically rellewant levels of shear $(>88 / \mathrm{s})$ decreased the yield of fluorescence from the blood sample considerably as compared to stasis. The yield of fluorescence was proportionally related to the logarithm of the sodium fluorescein concentration in blood up to a sodium fluorescein concentration of $1.2 \mathrm{mg} / \mathrm{ml}$. Above that concentration quenching occurred. An increase in layer thickness at a hematocrit of $45 \%$ only resulted in an increase of the yield of fuorescence up to a layer thickness of $25 \mu \mathrm{m}$.

Conclusions. The sodium fluorescein concentration in blood is the only important factor that determines the yield of fluorescence from the larger retinal vessels in the successive phases of the fluorescein angiogram in a subject with a given hematocrit and hemoglobin concentration. The yield of fluorescence from retinal vessels $(>25 \mu \mathrm{m})$ is proportionally related to the logam rithm of the sodium fluorescein concentration over a broad range of concentrations.

\section{INTRODUCTION}

The scanning laser ophthalmoscope (SLO) provides fluorescein angiograms in the form of high-quality, digitized images. The contribution of scatter to the angiogram is strongly reduced as compared to routine photographic angiograms, With the SLO it is possible to obtain angiograms at rates of 25 pictures per second. From these images time-intensity curves of the fluorescence from retinal vessels can be extracted. A more precise knowledge of the processes that lead to differences of the yield of fluorescence from retinal vessels would certainly increase our understanding of the angiogram. Romanchuk' reviewed the knowledge about the physicochemical factors that affect fluorescence and concluded that the information needed for understanding the lluorescence intensity from retinal vessels is still incomplete. Delori and 10 -workers ${ }^{2}$ investigated the fluorescence characteristics of fluorescein in plasma and in blood in stasis. However, these studies did not provide information on the yield of fluorescence from nowing blood.

The yield of fluorescence from blood vessels does not only depend on concentration of the fluorochrome, layer thickness in which it is present, and the illumination intensity, but also on the transparency of the lowing blood for excitation and emission light. Since hemoglobin absorbs the blue excitation light of the SLO (wave length $480-520$ nm) quite well, ${ }^{\text {it reduces }}$ the excitation efficacy in deeper layers: the yield of fluorescence strongly depends on vessel hematocrit. Absorption and scatter of light are nonlinear processes which make the actuall distribution of blood cells within the vessels important: the degree of aggregation of the red blood cells will affect the transparency of blood for excitation and emission light. The dependency of light transmission on the distribution (aggregation) of red blood cells is well known and is actually used to measure red blood cell aggregation. ${ }^{4}$ In the case of fluorescence, the yield for a given hematocrit will be optimal during stasis when red cells have formed aggregates. In this 
situation transparent gaps are present between the aggregates and effective absorption is minimal. When blood is flowing the yield of fluorescence will be lower than in stasis, because the shear forces break down the aggregates, the cells are dispersed and become more homogeneously distributed and, hence, effective absorption and scatter is increased.

The purpose of this study was to elucidate the influence of rheologic parameters on the yield of fluorescence from blood vessels with diameters as can be found in retina. The largest retinal arteries and veins have a diameter of $100 \mu \mathrm{m}$ and $130 \mu \mathrm{m}$ respectively. We performed in vitro experiments on blood flowing in a rotating test chamber to evaluate the influence of variations in shear rate, hematocrit, and red cell aggregation on the yield of fluorescence from blood layers with thicknesses up to $150 \mu \mathrm{m}$ and sodium fluorescein (SF) concentrations ranging from 0.02 to $20 \mathrm{mg} / \mathrm{ml}$. Part of the $S F$ concentrations tested, exceeded $0.4 \mathrm{mg} / \mathrm{ml}$, a concentration which has been assumed to be the maximal one in the retinal vessels after an intravenous injection." A maximal concentration of $0.4 \mathrm{mg} / \mathrm{ml}$, however, is not in line with hemodilution as it occurs in the circulation. In routine fluorescein angiography up to $1000 \mathrm{mg} \mathrm{SF}$ are injected. The major part of the bolus typically passes the retinal arteries in about $10-15$ seconds." With a cardiac output of a normal subject of about $5 \mathrm{l} / \mathrm{min}$, the quantity of $1000 \mathrm{mg}$ SF is mixed with a volume of maximally 1 liter. Therefore. SF concentrations in the retinal circulation will be at least $1 \mathrm{mg} / \mathrm{ml}$. The results of our experiments contribute to the insight into the changes of the yield of fluorescence from retinal vessels in the fluorescein angiogram as obtained with the SLO.

\section{MATERIALS AND METHODS}

The yield of thorescence from flowing blood was measured using a modification of the aggregometer as described by Klose and co-workers. ${ }^{*}$ The modified aggregometer consisted of a rotating cone (black acrylate) and fixed glass plate (figure 1). The wedge between cone and glass plate had an angle of $3^{\circ}$ and a diameter of $20 \mathrm{~mm}$, which resulted in a layer thickness

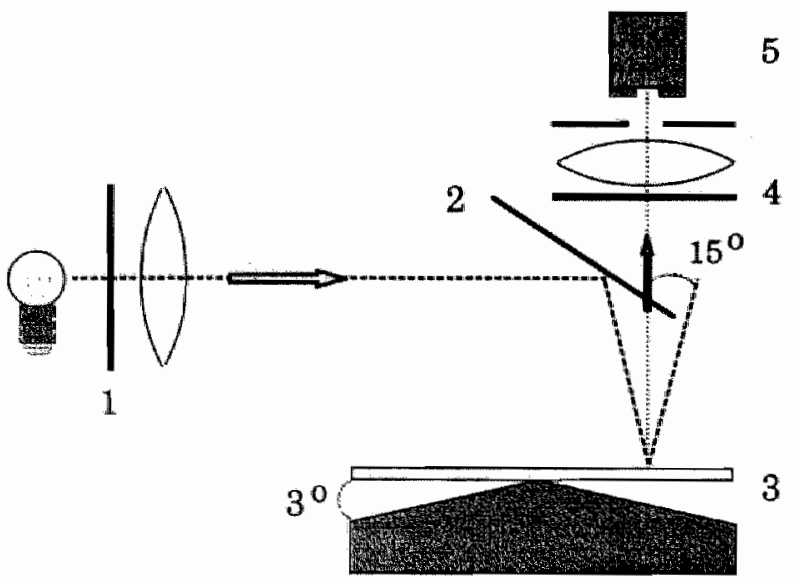

Figure 1. Experimental setup: the excitation light from a tungstem halogen lamp passed through an excitation filter (1) and was reflected by a dichroic blue reflective filter (2) on the blood in the shear chamber (3). The emitted fhorescence passed through the dichroic filter (2) and a barvier filter (4) and was focused on the radiometer (5). 
that increased from 0 in the center to about $500 \mathrm{\mu m}$ at the edge of the cone. The glass plate was an object glass of $1 \mathrm{~mm}$ thickness. In this configuration both the thickness of the blood layer as well as its velocity are proportional to the radial distance. Hence, a homogeneous shear rate field is applied to the blood, since the shear rate (i.e., the velocity gradient) of the blood between the cone and the plate is independent of the radial distance.

The experimental setup was designed to observe fluorescence under conditions similar to those in clinical practice when an SLO is used (figure 1). The light of a 50 Watt tungstenhalogen lamp was focused on the surface of the blood sample in the shear chamber by a lens with an effective numerical aperture (NA) of 0.1 . The excitation light passed a Topcon TRC50 VT blue excitation filter and was reflected by a Corion CR-500 dichroic blue reflective filter at an oblique angle. The illuminance of the sample was $5.26 \mathrm{~mW} / \mathrm{cm}^{2}$. The emitted fluorescence light passed through the dichroic filter and a Schott OG 515 barrier filter and was cotlected by a lens onto an E.G.\&G. radiometer. The lens was a Melles-Griot microscope objective (E.G.\&G., model 585-38-11, serial no 109) with a NA of 0.1 and a $2.5 x$ magnification. The radiometer consisted of a model 585-35-13 fiber optics probe, a model 585-63 high sensitivity head, and a model 580-13 indicator unit. Linearity of the radiometer output was checked with calibrated filter values. The output proved to be directly proportional to the light intensity. The illumination beam hit the blood sample at an angle of about 15 degrees with the optical axis of the radiometer; it had a diameter of about $1 \mathrm{~mm}$ within the sample. Due to this dark field illumination (see figure 1) direct reflections from the glass plate of the shear chamm ber were not received by the sensor. The fluorescence emitted from the blood was projected through the microscope objective on a field aperture with an effective diameter of $0.25 \mathrm{~mm}$, which was positioned in the intermediate image plane. The microscope objective was focused on the surface of the blood sample. Consequently, the detector only measured the intensity of fluorescence from an approximately cylindrical volume with a diameter of about $250 \mu \mathrm{m}$ from

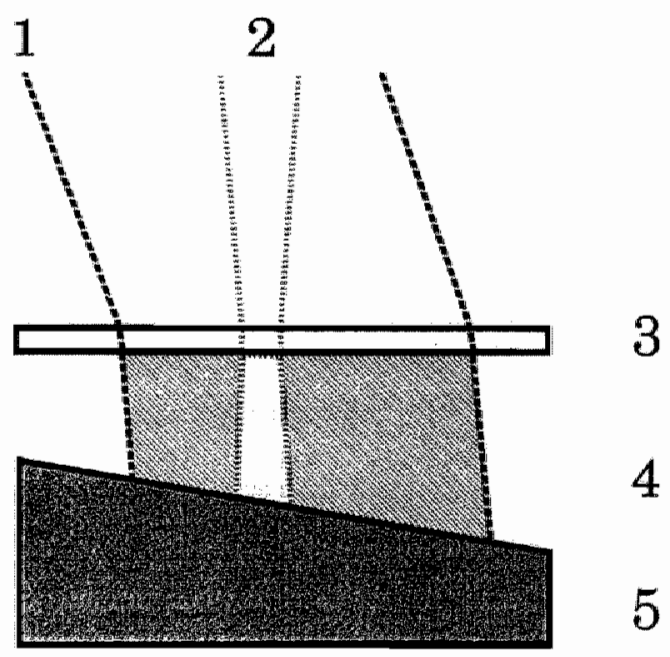

Figure 2. Schematic representation of the relationship between illumination volume and sample volume; illumination beam (11), sample volume (2), cover plate (3), shear chamber (4) and rotating cone (5). 
the illuminated area (figure 2 ). The width of the illumination beam ( $1 \mathrm{~mm}$ diameter) exceeded by far that of the sampling volume of the sensor. This resulted in an almost homogeneously illuminated sample volume. The depth of field of the system exceeded the $150 \mu \mathrm{m}$

Measurements were performed at warious sites across the cone by shifting the rotating cone over the desired distances. Measurements started in the center of the cone (position zero) and were repeated at lateral intervals of $100 \mu \mathrm{m}$ for the first $\mathrm{mm}$, intervals of $200 \mu \mathrm{m}$ for the second mm and finally at $3 \mathrm{~mm}$ from the center. An increment of $100 \mu \mathrm{m}$ across the cone resulted in an increase in depth of $5.2 \mu \mathrm{m}$. Positioning was performed using a Heidenhain digital length gauge (model MT 30 ) with an accuracy of about $5 \mu \mathrm{m}$ as reference. The setup will be referred to as "shear chamber" in this paper.

Blood samples were taken from an antecubital vein of three healthy male subjects. The blood was anticoagulated with EDTA $(1.5 \mathrm{mg} / \mathrm{ml})$. The hematocrit and hemoglobin values were $44 \%, 45 \%$, and $46 \%$, and $9.6,9.6$, and $8.0 \mathrm{mmol} / 1$, respectively. The blood was centrifuged and a hematrocrit of $45 \%$ was constituted by adding autologous plasma. We then added various amounts of a solution of $200 \mathrm{mg} / \mathrm{ml}$ sodium fluorescein (SF) by exchanging the soltstion against an equal volume of plasma to obtain the desired concentrations in this blood sample with a hematocrit of $45 \%$. After a second centrifugation step, various hematocrits were reconstututed by adding the required amount of plasma taken from the supernatant containing the SF. This procedure ensured that the SF concentration in plasma was independent of the constituted hematocrit. The whole blood SF concentration, however, varied inversely with the hematocrit. It simulates an intravenous injection best: after an intravenous injection the SF is diluted in the plasma; consecuently, the SF concentration in plasma is independent of hematocrit changes such as occur in the microcirculation. The blood samples were kept in closed plastic tubes at room temperature (about $22^{\prime \prime} \mathrm{C}$ ) and well shaken just before application to the shear chamber. All experiments were performed at room temperature and within 4 hours after vena puncture.

After application to the shear chamber, the bllood was sheared at the desired rate. Measurements started 60 seconds later and were completed within two minutes. We used a new sample of the blood for each step in shear rate. Preliminary measurements demonstrated a stable fluorescence intensity for all measurements performed between 30 seconds and four minutes after the start of shear application. Secondary flow and turbulence as described by Sdougos and co-workers? are not present in our range of layer thicknesses and within this measuring period. For experiments in stasis the blood sample was mixed at a shear rate of $528 / \mathrm{s}$ during 60 seconds and measurements were started 10 minutes after stopping the shear. To check the effect of bleaching of the SF by the excitation light, the change of the yield of fluorescence from $\mathrm{SF}$ in plasma was measured during 2 minutes of excitation. The decrease of intensity was less than $1 \%$ for all layer thicknesses. Three different sets of experiments were performed. First, we compared the yield of fluorescence from various concentrations of SF in plasma and in blood with a hematocrit of $45 \%$ and at a shear rate of $528 / \mathrm{s}$. We measured the yield of fluorescence from blood starting with a concentration of SF of $0.02 \mathrm{mg} / \mathrm{ml}$, and increasing it by factors of 2 up to a concentration of $20 \mathrm{mg} / \mathrm{ml}$. The resulting concentrations of SF in plasma ranged from $0.01 \mathrm{mg} / \mathrm{ml}$ up to $9.1 \mathrm{mg} / \mathrm{ml}$.

In the second set of experiments, we evaluated the influence of shear rate on the yield of fluorescence. SF was added to obtain a concentration of $0.3 \mathrm{mg} / \mathrm{ml}$ in whole blood with a hematocrit of $45 \%$. Blood samples were prepared with hematocrits of $15 \%, 30 \%$, and $45 \%$, yielding SF concentrations in whole blood of $0.46,0.38$, and $0.30 \mathrm{mg} / \mathrm{ml}$ respectively. Measurements were done at shear rates of $0,88,176,352$, and $528 / \mathrm{s}$. In this range of shear rates, differences in light transmission of blood of a given hematocrit must be attributed to 
shear dependent differences in dispersion of aggregates, red cell deformation "alignment, and orientation."

The third set of experiments was conducted to study the effect of the addition of an erythrocyte aggregation stimulating agent ${ }^{k, 9}$ We prepared blood with a hematocrit of $45 \%$ containing $0.3 \mathrm{mg} / \mathrm{ml} \mathrm{SF}$ and we dissolved a high molecular weight dextran (average mol wt 485.000 , Sigma Chemical co., St Louis) in isotonic saline (10 nmol/ $)$. Next, we centrifuged the blood and exchanged $0.05 \mathrm{ml}$ of plasma from $5 \mathrm{ml}$ blood for either $0.05 \mathrm{ml}$ of the dextran solution (giving a dextran concentration of $0.1 \mathrm{nmol} / \mathrm{l}$ blood) or $0.05 \mathrm{ml}$ isotonic salt solution. We performed measurements of the yield of fluorescence from the blood at shear rates of 88 , 176, 352 and 528/s. After the addition of dextran, differences in light transmission of the blood in this range of shear rates must be altributed to shear dependent differences in red cell aggregation. ${ }^{8}$ The effect of the addition of the dextran on aggregation was verified with the Myrenne Erythrocyte Aggregometer (Myrenne GmbH, Roetgen, Germany).

At each measuring position in the shear chamber, the fluorescence intensity value of each of the three subjects was taken. These values were marked in a graph and subsequently connected with straight lines to obtain curves. Because all intensity values from the blood of the subject with the lower hemoglobin concentration were about a factor 1.3 higher than those of the two other subjects, all values of experiments with his blood were divided by 1.3 . In this way a good comparison was made possible. Subsequently, the means of data at each of the positions were taken to represent the mean curve. The results are given in arbitrary, but calibrated units. At most measuring positions the coefficient of variation was less than $15 \%$. Only in layers of less than $20 \mu \mathrm{m}$ thickness and in blood samples with SF concentrations which exhibited the lowest yield of fluorescence, we found coefficients of variation in the range of $0-30 \%$, with some stray values up to $60 \%$.

To have some insight in the cause of the higher yield of fluorescence from blood with a lower hemoglobin concentration, we repeated some of the experiments three months later with the blood of the subject with the lower hemoglobin concentration. The hemoglobin concentration of this subject was $9.5 \mathrm{mmol} / \mathrm{l}$ at that moment. The yield of fluorescence from blood with a hematocrit of $45 \%$, a SF concentration of $0.3 \mathrm{mg} / \mathrm{ml}$, at a shear rate of $528 / \mathrm{s}$, and with and without the addition of dextran was compared with blood of one of the other two subjects, which had a hemoglobin concentration of $10.3 \mathrm{mmol} / \mathrm{l}$ at that time.

Because the NA of the illumination beam might have a large effect on the detected yield of fluorescence "we adapted our experimental setup in such a way that the NA of the scanning laser ophthalmoscope of Rodenstock $(\mathrm{NA}=0.06)$ was simulated. Experiments with blood with a hemalocrit of 45 , a shear rate of $528 / \mathrm{s}$ and a SF concentration of $0.3 \mathrm{mg} / \mathrm{ml}$ with and without the addition of the dextrans were repeated and compared with the same experiments in the setup with an NA of 0 . I.

All experiments followed the tenets of the Declaration of Helsinki and informed consent was obtained from each subject after the nature and possible consequences of the study had been explained.

\section{RESULTS}

The graphs of fluorescence intensity as a function of layer thickness are shown in figure 3 for increasing concentrations of sodium fluorescein (SF) in plasma. At the lowest concentrations of SF fluorescence intensity increases almost linearly with thickness of the layer. 
At higher concentrations the yield of fluorescence saturates at a certain thickness of the layer. The results of the same experiment are presented in another way in figure 4 . In this figure the yield of fluorescence is plotted against the concentration for layer thicknesses of 25,50,100 and $150 \mu \mathrm{m}$. The yield of fluorescence increases with the SF concentration up to a certain concentration. A further increase in SF concentration results in a decrease in intensity. For smaller Jayer thicknesses the turning point occurs at higher SF concentrations.

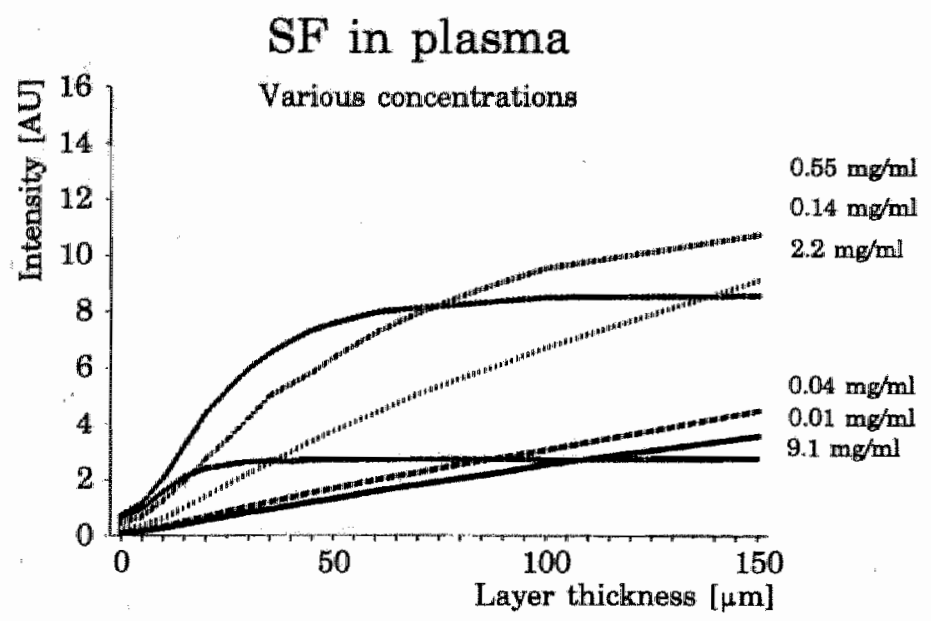

Figure 3. Revationship between the vield of fluorescence (intensity) and thickness of the layer for various concentrations of sodium fluorescein (SF) in plasma. Only every other SF concentration studied is shown. Mean intensities in arbitrary units (AU) from plasma samples of three subjects.

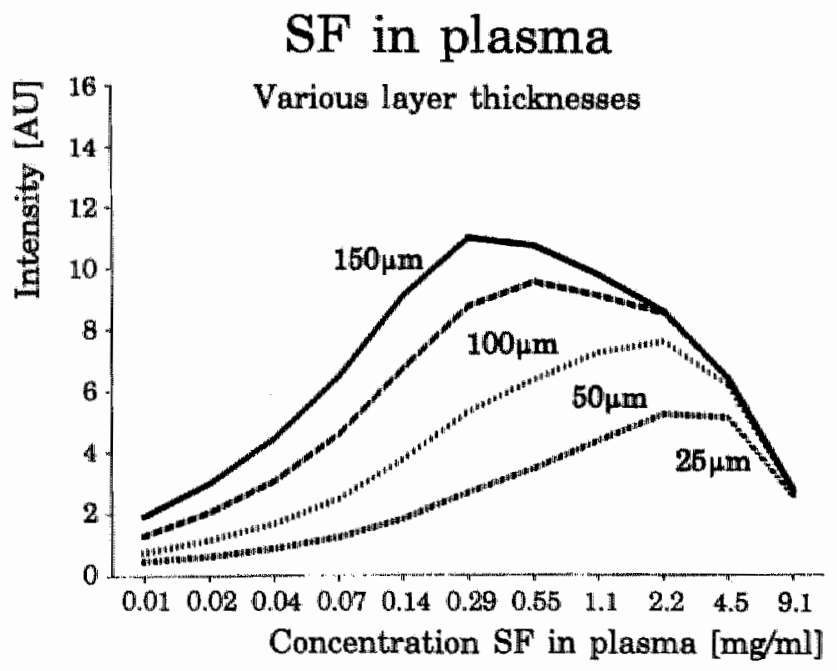

Figure 4. Fielationship between the yield of fluorescence (intensity) and sodium fluorescein (SF) concentration in plasma for four layer thicknesses. Mean intensities in arbitrary units (AU) from plasma samples of three subjects. 


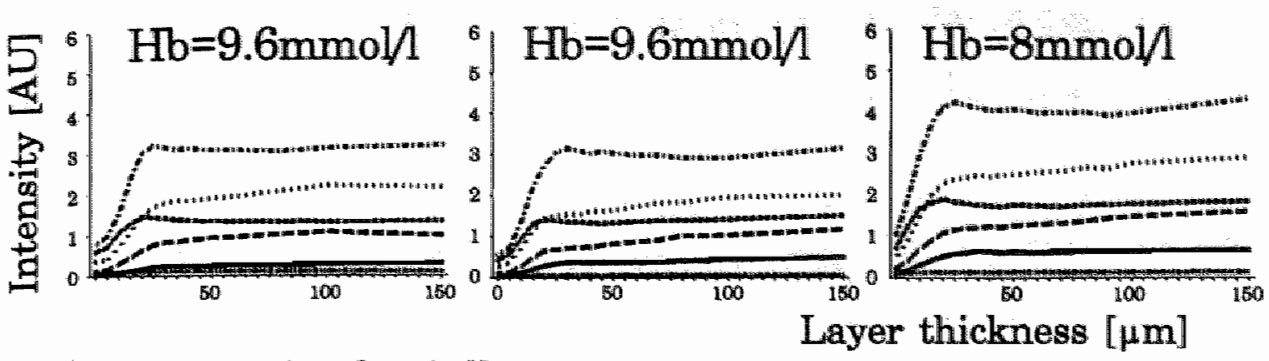

SF concentration $[\mathrm{mg} / \mathrm{ml}]$

0.02

0.08

0.3

1.2

Figure 5. Relationship between the yield of ffuorescence (intensity) and thickness of the layer for various con. centrations of sodium fluorescein (SF) in blood with a hematocrit (Hct) of $45 \%$ at a shear rate of $528 / \mathrm{s}$. Intensities in arbitrary units (AU) from blood samples of the three subjects. Note the cross over between the curves at $0.3 \mathrm{mg} / \mathrm{ml}$ and $5 \mathrm{mg} / \mathrm{ml}$.

Figure 5 presents the graphs of the yield of fluorescence as a function of layer thickness for various concentrations of SF in blood with a hematocrit of $45 \%$ and subjected to a shear rate of $528 / \mathrm{s}$. The figure shows the original data of the three subjects. In figure 6 , the means of values of the three subjects are presented after correction of the value of one subject by a factor 0.7 . A relatively steep increase of the yield of fluorescence occurs in the thinnest layers and a levelling off results at about $25 \mu \mathrm{m}$. The highest yield of fluorescence is obtained at a concentration of $1.2 \mathrm{mg} / \mathrm{ml} \mathrm{SF}$. Any further increase in concentration generates a lower yield of fluorescence. In figure 7 , the yield of fluorescence is plotted against concentration for layer thicknesses of $25,50,100$, and $150 \mu \mathrm{m}$. It is apparent that the differences between intensities from the layers of 50,100, and 150 $\mu \mathrm{m}$ thickness are small; much smaller than for plasma (see figure 4). Since the relationship between the logarithm of SF concentration and the intensity is

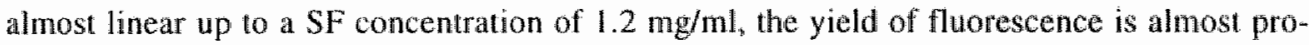
portionally related with the logarithm of the SF concentration.

The fluorescence intensity of blood as a function of layer thickness is shown in figure 8 for various shear rates and for different hematocrits. In stasis, the yield of fluorescence is maximal for each of the hematocrits. At hematocrits of 30 and $45 \%$ and for layers thicker than $25 \mu \mathrm{m}$ all intensities of each of the three subjects were lower with shear than without shear. At a hematocrit of $15 \%$ the yield of fluorescence is less influenced by the presence of shear. Increasing the hematocrit results in overall lower yield of fluorescences. For a correct interpretation of the differences between the yield of fluorescences of the various hematocrits, one has to realize that due to the sequence of addition of SF prior to the preparation of the various hematocrits, the concentration of SF in plasma is the same for all hematocrits. However, solutions with a lower hematocrit have in total a higher SF content (see above). In stasis, the reduction of the yield of fluorescence with increasing hematocrit almost completely reflects the reduced total quantity of SF.

The effect of stimulation of red blood cell aggregation by a high molecular weight dextran on the yield of fluorescence from flowing blood is shown in figure 9 for blood with a 
hematocrit of $45 \%$ and containing $0.3 \mathrm{mg} / \mathrm{ml} \mathrm{SF}$. At a shear rate of $88 / \mathrm{s}$ there is no important effect of the dextran on the yield of fuorescence. Similar results are obtained at shear rates of 176,352 and $528 / \mathrm{s}$, respectively. The Myrenne aggregometer readings, however, were nearly doubled after addition of the dextran: a factor of $1.85,1.92$, and 2.11 was found for the three subjects, respectively.

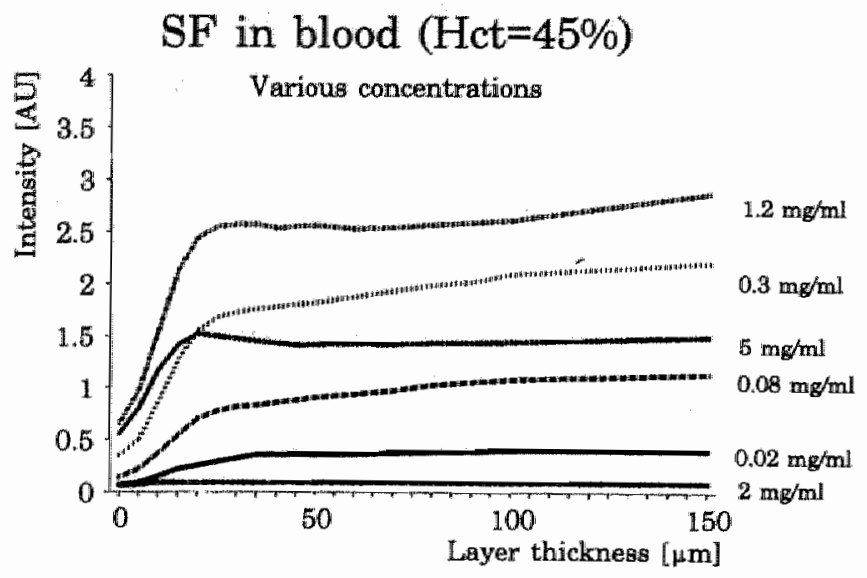

Figure 6. Relationship between the yield of fluorescence (intensity) and thickness of the layer for various concentrations of sodium fluorescein (SF) in blood with a hematocrit ( $\mathrm{Hct}$ ) of $45 \%$ at a shear rate of $528 / \mathrm{s}$. Mean of intensities in arbitrary units (AU) from blood samples of three subjects. Values from one subject were corrected for a low hemoglobin concentration.

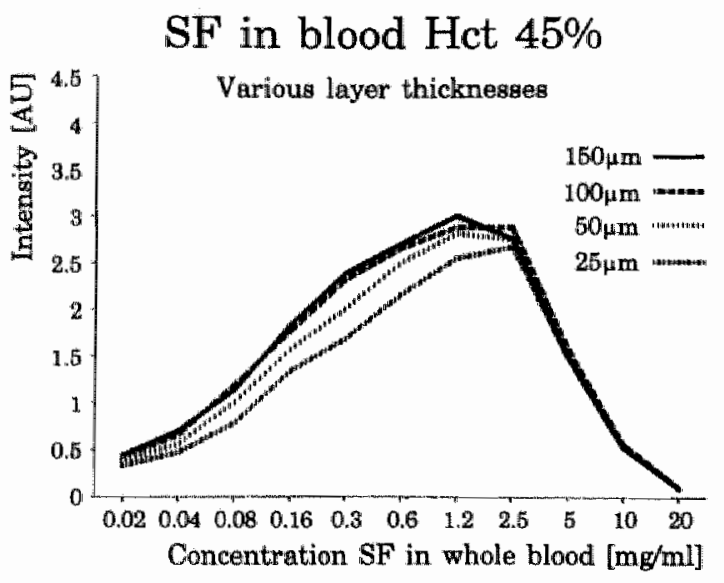

Figure 7. Relationship between the yield of fluorescence (intensity) and sodium fluorescein (SF) concentration for four layer thicknesses in blood with a hematocrit (Hct) of $45 \%$ at a shear rate of $528 / \mathrm{s}$. Mean of intensities in arbitrary units (AU) from blood samples of three subjects. Values from one subject were corrected for a low hemoglobin concentration. 
The experiments that were repeated to examen the higher yield of fluorescence from blood of the subject with the lower hemoglobin concentration at a moment that the concentration had increased to $9.5 \mathrm{mmol} / \mathrm{l}$ resulted in a yield that was only a factor 1.03 higher than the yield of blood from a subject with a hemoglobin concentration of $10.3 \mathrm{mmol} / \mathrm{l}$.

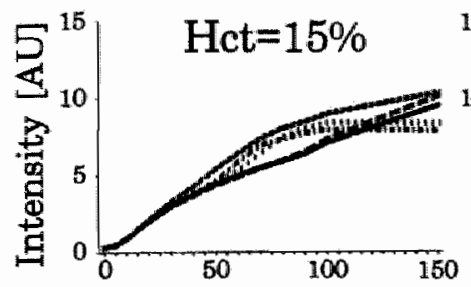

Shear rate $\left[\mathrm{s}^{-1}\right]$
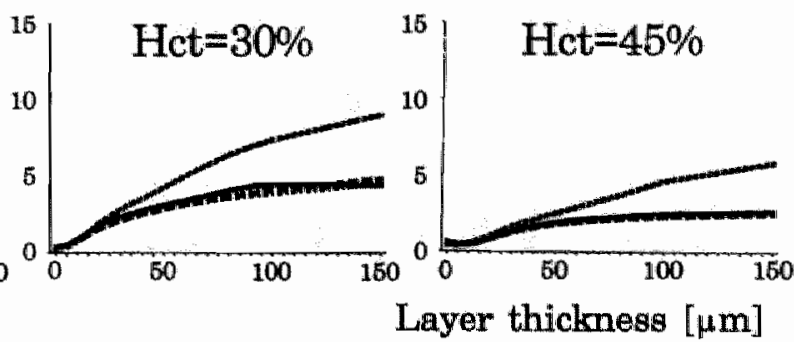

88 176 352

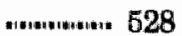

Figure 8. Relationship between the vield of fluorescence (intensityl and thickness of the layer for blood of three hematocrits (Hct) and at various shear rates and a plasma sodium fluorescein (SF) concentration of $0.5 \mathrm{mg} / \mathrm{ml}$. Mean of intensities in arbitrary units (AU) from blood samples of three subjects. Values from one subject were corrected for a low hemoglobin concentration.

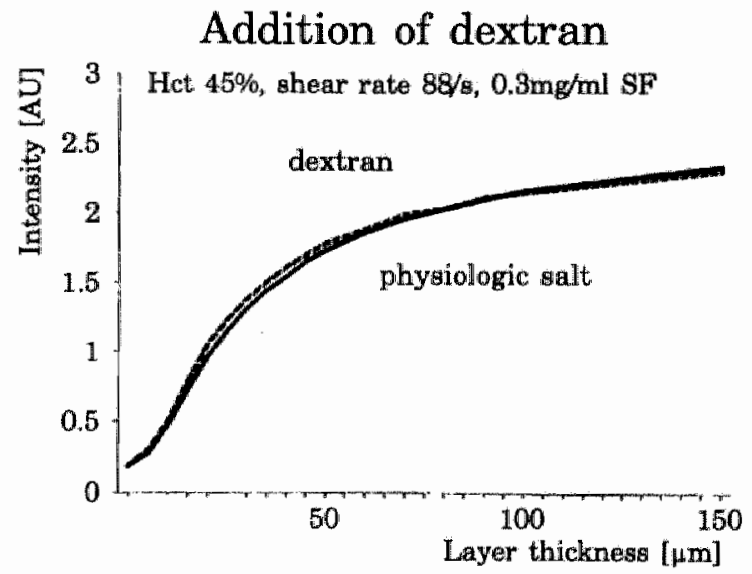

Figure 9. Relationship between the vield of fluorescence (intensity) and layer thickness for blood after the addition of a high molecular weight dextran (485.000 MW) as compared to the addition of the same volume of a physiological salt solution. Mean of intensities in arbitrary units $(A U)$ from blood samples of three subjects. Values from one subject were corrected for a low hemaglobin concentration. SF: sodium fiuorescein, Hct= hematocrit. 
The yicld of the fluorescence from SF in blood decreased to $33 \%$ after changing the NA of the illumination bean from 0.1 to 0.06 . There was, on the other hand, no difference in the shape of the curves from SF in blood either with or without the addition of dextran.

\section{DISCUSSION}

The presence or absence of flow had a considerable influence on the yield of fluorescence from layers of blood up to a layer thickness of $150 \mu \mathrm{m}$. Application of physiologically relevant levels of shear (see below) decreased the yield of fluorescence considerably as compared to stasis. The yield of fluorescence was proportionally related to the logarithm of the sodium fluorescein concentration in the blood up to a concentration of $1.2 \mathrm{mg} / \mathrm{ml}$. Above that concentration the yield of fluorescence decreased. In blood with a hematocrit of $45 \%$ an increase in layer thickness only resulted in an increase in the yield of fluorescence up to a layer thickness of $25 \mu \mathrm{m}$. Further increases in layer thickness did not result in an increase of the yield of fluorescence.

For the interpretation of the figures two phenomena are of importance: saturation as result of increasing layer thickness and quenching as result of increasing SF concentration. In figure 3 , where the graphs of fluorescence intensity are shown as a function of layer thickness for increasing concentrations of sodium fluorescein (SF) in plasma, the yield of fluorescence saturates at a layer thickness of about $70 \mu \mathrm{m}$ for a SF concentration of $2.2 \mathrm{mg} / \mathrm{ml}$. This saturation can be explained by the fact that the excitation light is reaching the deeper layers at reduced intensities due to the absorption and scatter in the more superficial layers. This results in a levelling off of the curves. Finally, all excitation light will be absorbed and, hence, the deeper layers will no longer contribute to the yield of fluorescence. The second phenomenon, quenching, can also be seen in figure 3. Compare the curves of 2.2 and $9.1 \mathrm{mg} / \mathrm{ml}$. At higher SF concentrations, dimers and polymers of fluorescein are formed, which have a lower emitting energy. 'This leads to an actual reduction in the yield of fluorescence at higher SF concentrations. The combined influence of saturation and quenching leads to the effect that while in the thinner layers the yield of fluorescence increases with increasing concentrations, it decreases in the thicker layers: compare for example the curves at $0.55 \mathrm{mg} / \mathrm{ml}$ and $2.2 \mathrm{mg} / \mathrm{ml}$ in figure 3, for which crossover occurs at a layer thickness of $70 \mu \mathrm{m}$. This effect is more clearly depicted in figure 4 . In this figure the yield of fluorescence is plotted against the concentration for layer thicknesses of $25,50,100$, and $150 \mu \mathrm{m}$. The influence of quenching is seen for a layer of $150 \mu \mathrm{m}$ thickness at SF concentrations of more than $0.29 \mathrm{mg} / \mathrm{ml}$ and for a layer of $25 \mu \mathrm{m}$ thickness at concentrations over $2.2 \mathrm{mg} / \mathrm{ml}$. The same phenomena can be observed in the experiments with flowing blood. The influence of the SF concentration on the saturation is not important, because hemoglobin absorbs the excitation light quite well. This results in saturation at the same layer thickness for all SF concentrations (figure 6) and, as a consequence, quenching at the same SF concentration for all layer thicknesses (figure 7).

A lower hemoglobin concentration of the blood from one of the subjects $(8.0 \mathrm{mmol} / \mathrm{l}$ as compared to $9.6 \mathrm{mmol} / \mathrm{l}$ for the other two subjects) resulted in a consistently higher yield of fluorescence in the experiments with blood. The shape of the curves, however, was not altered. Repetition of some of the experiments after normalization of the hemoglobin concentration at a later date demonstrated an adjustment of the yield of fluorescence. This indicates that the low hemoglobin concentration probably was the cause of the higher yield of fluorescence from the blood samples with the low hemoglobin concentration. Although this also implies 
that the hemoglobin concentration is another factor that significantly influences the yield of fluorescence from retinal vessels, we did not investigate this factor any further because we were only interested in the shape of the time-intensity curves in the angiogram. It seems unlikely that it ever will be possible to measure absolute intensities from retinal vessels.

Our results are obtained from blood that was exposed to a homogenous shear field over the whole layer thickness. In vivo, shear rate varies over the cross-section of a blood vessel, being maximal at the vessel wall and negligibly small in the center of the vessel. Low shear rates of less than $88 / \mathrm{s}$ will only occur in the central part of the vessel, which constitutes less than $5 \%$ of the cross-sectional area." Because a shear rate of $88 / \mathrm{s}$ was already sufficient to exert the maximal effect on the yield of fluorescence in blood with a hematocrit of $45 \%$, our results can be extrapolated to explain the yield of fluorescence from the larger retinal vessels. The data obtained from the measurements at a hematocrit of $45 \%$ are the most important ones, because the larger retinal vessels have a hematocrit that is close to the systemic value..$^{12}$

We found a significant difference in the yield of fluorescence from SF between flowing blood and blood in stasis. Comparable differences in light transmission have also been described in the rheological literature. ${ }^{4 . x}$ Our results from flowing blood with a hematocrit of $45 \%$ indicate that the yield of fluorescence is maximal at a layer thickness of $25 \mu \mathrm{m}$, whereas in stasis the yield increases with layer thickness at least up to a layer thickness of $150 \mu \mathrm{m}$ (see figure 8). Delori and co-workers ${ }^{2}$ reported only on the efficacy of SF in blood in stasis. They stated that $90 \%$ of the total fluorescence coming from a $100 \mu \mathrm{m}$ layer of blood in stasis originates from the first $50 \mu \mathrm{m}$. These values of Delori and co-workers for blood in stasis are surprisingly similar to our results for flowing blood. In our setup it took at least 20 seconds after stop of shear for a $10 \%$ change in fluorescence intensity to occur. Therefore it is well possible that Delori's experiments have been performed in an initial state of the aggregation process in which the red blood cell distribution in the plasma was comparable to that of flowing blood.

Our measurements did not show any substantial influence of variations in shear rate above $88 / \mathrm{s}$ on the yield of fluorescence from $\mathrm{SF}$ in flowing blood. The same was observed for an increase in red blood cell aggregation tendency as caused by the addition of high molecular weight dextrans. Klose and Schmid-Schoenbein ${ }^{4,8}$ on the other hand, could demonstrate an effect of shear rate and addition of dextran on the light transmission of flowing blood using a similar cone-plate device for their experiments. However, the differences found by Klose and Schmid-Schoenbein were only about $10 \%$ over the range of shear rates that we used. Therefore, variation in shear rate and aggregation tendency in flowing blood will not significantly affect the intensities of the blood vessels in the fluorescein angiogram.

Changing the NA of the illumination beam from 0.1 to 0.06 decreased the yield of fluorescence to $33 \%$ but did not affect the shape of the intensity-concentration curves of SF in blood and plasma. The decrease in yield is in accordance with what can be expected theoretically, i.e., a decrease to $36 \%$, because the yield of fluorescence varies with the square of the NA." Because shape of the concentration-intensity curves did not change, they can be used for the conversion of time-intensity curves from the scanning laser ophthalmoscope into time-concentration curves after calibration. It was not possible to adapt our setup to a system with a NA that is comparable with the NA of about 0.45 of a standard fundus camera. Therefore, we are not completely sure whether our results are applicable to the routine sequential photographic fluorescein angiogram. However, based on the work of Seki and Lipowsky, we may state that the differences in shape will probably be of minor significance.

The appearance pattern of the retinal vessels in a routine photographic fluorescein angiogram is in accordance with our finding that almost all fluorescence is coming from the top $25 \mu \mathrm{m}$ of a vessel: all but the smallest retinal vessels have about the same maximal fluo- 
rescence intensity and at arterio-venous crossings there is no increase of the yield of fluorescence due to superposition of the fwo vessels (unpublished observation).

In conclusion, in a subject with a given hematocrit and hemoglobin concentration, the local SF concentration in the blood will be the only important factor that determines the yield of fluorescence from the larger retinal vessels in the successive phases of the fluorescein angiogram. This yield of fuorescence proved to be proportionally related to the logarithm of the $\mathrm{SF}$ concentration over a broad range of concentrations.

\section{REFERENCES}

1. Romanchuk KG. Fluorescein. Physiochemical factors affecting its fluorescence. Surv. Ophthalmol. 1982;26:269-283.

2. Delori FC, Castany MA, Webb RH. Fluorescence characteristics of sodium fluorescein in plasma and whole blood. Exp. Eye. Res. 1978;27:417-424.

3. Tangelder GJ, Slaaf DW, Reneman RS. Fluorescent labelling of blood platelets in vivo. Thrombosis Research 1982;28:803-820.

4. Klose HJ, Volger E, Brechtelsbauer H, Heinich L, Schmid-Schoenbein H. Microrheology and lighi transmission of blood. I. The photometric aspects of red cell aggregation and red cell orientation. Pflugers Arch. 1972;333:126-139.

5. Flower RW. Injection technique for indocyanine green and sodium fluorescein dye angiography of the eye. Invest, Ophthalmol. 1973;12:881-895.

6. Blair PN, Feke GT, Morales-Stoppello J, Riva CE, Goger DG, Collas G, McMeel JW. Prolongation of the retinal mean circulation time in diabetes. Arch. Ophthalmol. 1982;100:764-768.

7. Sdougos HP, Bussolari SR, Dewey CF. Secondary flow and turbulence in a cone-and-plate device. J. Fluid Mech. 1984:138:379-404.

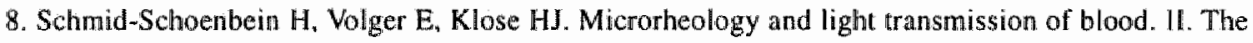
photometric quantification of red cell aggregate formation and dispersion in flow. Pfluggers Arch. 1972:333:140-155.

9. Rampling MW. Red cell aggregation and yield stress. In: Clinical Blood Rheology, Volume $I_{\text {" edited by }}$ G.D. Lowe. Boca Raton: CRC Press Inc, 1988, pp. 48-50.

10.Seki J, Lipowsky HH. In vivo and in vitro measurements of red cell velocity under epifluorescence microscopy. Microvascular Research 1989;38:110-124.

UI.Slaal DW, Tangelder GJ, Reneman RS. Physics of the microcirculation. In: The physics of heart and circulation, edited by J. Strakee, and N. Westerhof. Bristol: Institute of Physics Publishing Ltd, 1993, pp. $383-416$.

12.Lipowsky HH, Usami S, Chien S. In vivo measurement of apparent wiscosity and microvessel hematocrit in the mesentery of the cat. Microvasculat Research 1980;19:297-319.

13. SIat DW, Jongsma FH. Tangelder GJ, Reneman RS. Characterisyics of optical systems for intravital microscopy. In: Microcirculatory Technology, edited by C.H. Baker, and W.L. Nastuk. Orlando: Academic Press Inc, 1986, pp. 211-228. 


\section{H A P TE R 4}

\section{YIELD OF FLUORESCENCE FROM \\ INDOCYANINE GREEN IN PLASMA \\ AND FLOWING BLOOD.}

P.R. van den Biesen, F.H. Jongsma, G.J. Tangelder, D.W. Slaaf.

The study described in this chapter has been published in Ann. Biomed. Engin. 23:475-482, 1995. 



\section{ABSTRACT}

Purpose. To obtain more quantitative knowledge about the yield of fuorescence from retinal vessels during indocyanine green angiography (ICG). The yield of fluorescence from blood was investigated for various shear rates, concentrations of $\mathbb{I C G}_{4}$ and layer thicknesses.

Methods. Measurements were performed in vitro on samples of human blood in a cone-plate shear chamber using frontal illumination as in scanning laser angiography. In blood and in plasma, the yield of fluorescence of ICG increased with concentration up to $0.05 \mathrm{mg} / \mathrm{ml}$ and $0.1 \mathrm{mg} / \mathrm{ml}$, respectively. At higher concentrations, the yield decreased for all layer thicknesses. Results. For increasing layer thicknesses, both in plasma and in blood, the yield of ICG fluorescence increased non-linearly for concentrations higher than $0.012 \mathrm{mg} / \mathrm{ml}$. Saturation occurred for layers thicker than $200 \mu \mathrm{m}$ in combination with ICG concentrations of $0.4 \mathrm{mg} / \mathrm{ml}$ and higher. Application of shear rates within the physiological range of the microcirculation (88/s and 528/s) increased the yield of fluorescence from the blood sample as compared to stasis. Conclusion. The high transparency of blood for the excitation and emission light of ICG that was demonstrated, will lead to superposition of fluorescence from superficial and deeper layers. This superposition precludes quantitative indocyanine angiography of ocular vessels.

\section{INTRODUCTION}

With the introduction of high-resolution indocyanine green (ICG) imaging with ICG fundus cameras ${ }^{1.2}$ and the scanning laser ophthalmoscope ${ }^{3}$ ICG angiography has become more readily available for clinical use. ICG has two basic differences compared to sodium fluorescein (SF), until recently the only dye that was used in routine angiography in clinical practice: Firstly, ICG is strongly bound to blood proteins, which precludes massive extravasation into the choroidal interstitium. 4,5 Secondly, the excitation and emission spectra are located in the near-infrared region. Light from both spectra are absorbed to a lesser extent by the retinal pigment epithelium and blood, and penetrate into the deeper layers of the choroid." As a result the choroidal circulation is far better visualised with $\amalg \mathrm{CG}$ angiography than with SF angiography

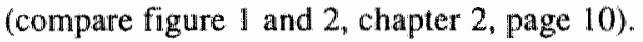

As with any newly introduced imaging technique, many questions still need to be answered about the interpretation of the $\mathrm{ICG}$ angiograms. For SF angiography, we reported that the intensities of retinal vessels with diameters of more than $25 \mu \mathrm{m}$ and with a local hematocrit of $45 \%$ are determined by intravascular SF concentrations but not, for example, by vessel diameter or shear rate." This makes quantitative studies on the yield of fluorescence from the larger retinal vessels in SF angiography feasible. The goal of the present study was to investigate for ICG angiography if quantitative measurements on individual vessels are basically possible. We performed in vitro experiments to elucidate the factors that determine the yield of fluorescence from larger vessels in retina and choroid during ICG angiography. The experiments were performed in the same rotating test chamber that we used in our study on the thorescence yield from retinal vessels in sodium fluorescein angiography but with adapted optics. We measured the yield of indocyanine green fluorescence in blood for various concentrations of ICG, layer thicknesses, and shear rates. The light conditions in our setup were similar to those that can be found in ICG angiography with a scanning laser ophthalmoscope (SLO). 


\section{MATERHALS AND METHODS}

The conical shear chamber that we developed for determination of the yield of sodium fluorescen in flowing blood was adapted to the use of near infrared light.

The modified setup, further referred to as "shear chamber", consisted of a rotating cone (black acrylate) and fixed glass plate (figure 1). The wedge between cone and glass plate had an angle of $3^{\circ}$ and a diameter of $20 \mathrm{~mm}$, which resulted in a layer thickness that increased from 0 in the center to about $500 \mu \mathrm{m}$ at the edge of the cone, respectively. The glass plate was an object glass of $1 \mathrm{~mm}$ thickness. In this configuration both the thickness of the blood layer as well as its velocity are proportional to the radial distance. Hence, a homogeneous shear rate field is applied to the blood, since the shear rate (i.e., the velocity gradient) of the blood between the cone and the plate is independent of the radial distance.

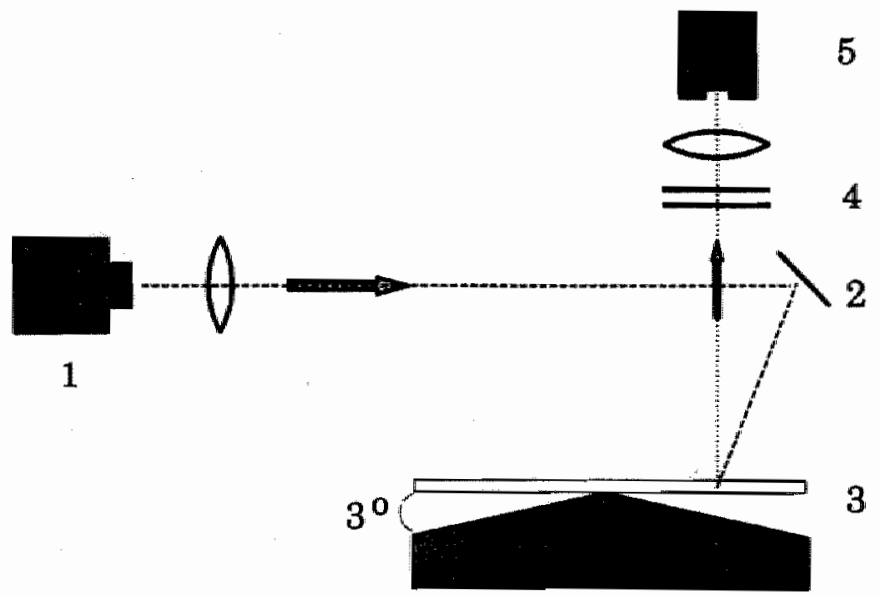

Figure 1. Experimental setup: the excitation light from a infrared laser (1) was reflected by a mirror (2) and focused on the surface of the blood sampte in the shear chamber (3). The emitted fluorescence passed two barrier filters (4) and was focused on a diode (5).

The experimental setup was designed to observe fluorescence under conditions similar to those in clinical practice when an SLO is used (figure 1). The light of an infrared laser (Micro-Lase Diode Laser, Mod. MLS, Vector Technology Lid, Stansted, U.K., wave length $810 \mathrm{~nm}$, power output $3 \mathrm{~mW}$ ) was focused on the surface of the blood sample in the shear chamber by a combination of lenses with an effective numerical aperture (NA) of 0.06 . The excitation light was reflected by a mirror and projected on the blood at an oblique angle. The intensity of the illumination of the blood sample was about $0.1 \mathrm{~mW} / \mathrm{mm}^{2}$. The emitted fluorescence light passed two bandpass filters with a center wave length of $850 \mathrm{~nm}$ and a bandwith of $70 \mathrm{~nm}$ (NIR bandpass filter, mod LS 850-S957B, Corrion, Holliston, MA, USA). These two filters blocked the scattered excitation light. The light was collected by a microscope objective lens of $3.5 \times(N A=0.1$, Spindler and Hoyer, Göttingen, Germany) and projected on an infrared sensor. The sensor consisted of a diode (EG\&G, type UV-040 BQ, spectral range 250-1150 nm, Salem, MAS, USA) connected with a multimeter (Philips, type PM 2434, Eindhoven, the Netherlands). Linearity of the sensor output (in $\mu \mathrm{V}$ ) was checked with calibrated filter values. The output proved to be linearly proportional to the light intensity. The oblique illumination of 
the sample secured that the light which was reflected by the glass plate could not enter the collecting lens (dark field illumination, see figure 1). The illumination beam had a diameter of about $5 \mathrm{~mm}$ within the sample (figure 2). The microscope objective was focused on the surface of the blood sample. The light sensitive area of the diode had an area of $0.81 \mathrm{~mm}^{2}$.

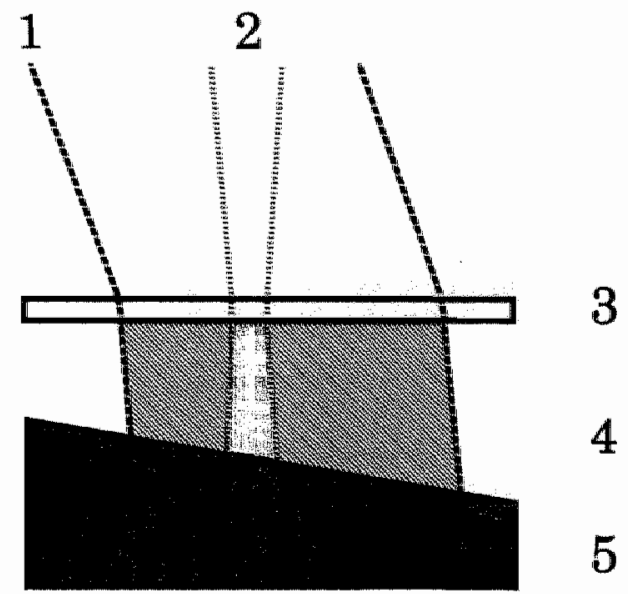

Figure 2. Schematic representation of the relationship between illumination volume and sample volume; illumination beam (1), sample volume (2), cover plate (3), shear chamber (4), and rotating cone (5).

Consequently, the detector only measured the intensity of fluorescence from an approximately cylindrical volume with a diameter of about $0.3 \mathrm{~mm}$ in the center of the illuminated volume (figure 2). Since the width of the illumination beam exceeded by far that of the sampling volume of the sensor, an almost homogeneously illuminated sample volume was obtained, taking into account the light distribution within the illumination cone. Because of the $45 \mathrm{~mm}$ focal length of the collecting lens with respect to the depth in the shear chamber, i.e., $0.3 \mathrm{~mm}$ or less, no inner filter effect ${ }^{7}$ was present.

Measurements were performed at various sites across the rotating cone by shifting the shear chamber over the desired distances. Measurements started in the center of the cone (position zero) and were repeated at lateral intervals of $100 \mu \mathrm{m}$ for the first $\mathrm{mm}$, intervals of 200 $\mu \mathrm{m}$ for the second $\mathrm{mm}$, and at 3,4,5, and $6 \mathrm{~mm}$ from the center. An increment of $100 \mu \mathrm{m}$ across the cone resulted in an increase in depth of $5.2 \mu \mathrm{m}$. Positioning was performed using as reference a Heidenhain digital length gauge (Heidenhain, model MT 30, Traunreut, Germany), adjusted with an accuracy of about $5 \mu \mathrm{m}$.

Blood samples were taken from an antecubital vein of three healthy male subjects. The blood was anticoagulated with EDTA $(1.5 \mathrm{mg} / \mathrm{ml})$. The hematocrit and hemoglobin walues were $42 \%, 46 \%$, and $45 \%$, and $9.1,9.6$, and $9.6 \mathrm{mmol} / 1$, respectively. We did not correct for the small differences in hematocrit. Part of the blood was centrifuged for $15 \mathrm{~min}$ at 3000 rotations per second to obtain plasma. We then added various amounts of a solution of $20 \mathrm{mg} / \mathrm{ml}$ indocyanine green (ICG) to the whole blood or to the plasma by exchanging the solution against an equal volume of plasma. This resulted in a set ICG concentrations per total volume. Thus, as the result of the volume exclusion by the red blood cells, the plasma in the blood samples contained an almost double ICG concentration as compared to a plasma sample with the same concentration per volume. The blood samples were kept in closed plastic tubes at room temperature (about $22^{\prime \prime} \mathrm{C}$ ) and were well shaken just before application to the shear 
chamber. All experiments were performed at room temperature and within 4 hours after vena puncture.

After application to the shear chamber, the blood was sheared at the desired rate. Fluorescence intensity measurements started 60 seconds after application and were completed within two minutes. We used a new sample of blood for each shear rate. Preliminary measurements demonstrated a stable fluorescence intensity for all measurements performed between 30 seconds and four minutes after the start of shear application. Secondary flow and turbulence as deseribed by $S$ dougos and co-workers are not present in our range of layer thicknesses and shear rates within this measuring period. For experiments in stasis, the blood sample was mixed at a shear rate of $528 / \mathrm{s}$ during 60 seconds and measurements were started 10 minutes after stopping the rotation. To check the effect of bleaching caused by the excitation light, the change of the yield of fluorescence from ICG in plasma was measured in stasis during 2 minutes of excitation. The decrease of intensity was less than $1 \%$ for all layer thicknesses.

Two sets of experiments were performed. First, we compared the yield of fluorescence from various concentrations of ICG in plasma and in whole blood at a shear rate of $528 / \mathrm{s}$. We measured the yield of fluorescence from plasma and blood starting with an ICG concentration of $0.8 \mu \mathrm{g} / \mathrm{ml}$, and increasing it by factors of $2 \mathrm{up}$ to a concentration of $0.8 \mathrm{mg} / \mathrm{ml}$.

In the second set of experiments, we evaluated the influence of shear rate on the yield of fluorescence. ICG was added to obtain a concentration of $0.05 \mathrm{mg} / \mathrm{ml}$ in whole blood. Measurements were done at shear rates of 0,88 , and 528/s, respectively. Measurement in stasis was performed because light transmission of whole blood is maximal in stasis due to the formation of red cell rouleaux; rate into deeper layers. At a shear rate of about $88 / \mathrm{s}$ the dispersion of red blood cells is already maximal and the right penetration into the depth will be minimal. As a consequence, the yield of fluorescence will be at its lowest. At shear rates higher than $88 / \mathrm{s}$ red blood cells will elongate and the transparency will rise with increasing shear. To determine the effect of elongation on the fluorescence yield we measured at a shear rate of $528 / \mathrm{s} .{ }^{.}$

At each measuring position in the shear chamber, the fluorescence intensity value of each of the three subjects was taken and the mean was calculated. These means were marked in a graph and subsequently connected with straight lines to obtain mean curves.

All experiments followed the tenets of the Declaration of Helsinki and informed consent was obtained from each subject after the nature and possible consequences of the study had been explained.

\section{RESULTS}

The yield of fluorescence of ICG in plasma increased with layer thickness for all ICG concentrations (figure 3). Up to a concentration of $0.05 \mathrm{mg} / \mathrm{ml} \mathrm{ICG}$, fluorescence intensity increased linearly with thickness of the layer. At higher concentrations the increase of the yield of fluorescence was not linear with layer thickness, and from a concentration of $0.2 \mathrm{mg} / \mathrm{ml}$ onwards the yield saturated at a certain thickness of the layer.

Figure 3 also indicates that a higher ICG concentration does not necessarily result in an increased yield. This is more readily seen in figure 4 , where the yield of fluorescence is plotted against the logarithm of the concentration for layer thicknesses of $50,100,200$, and $300 \mu \mathrm{m}$, respectively. The yield of fluorescence increased linearly with the ICG concentration 


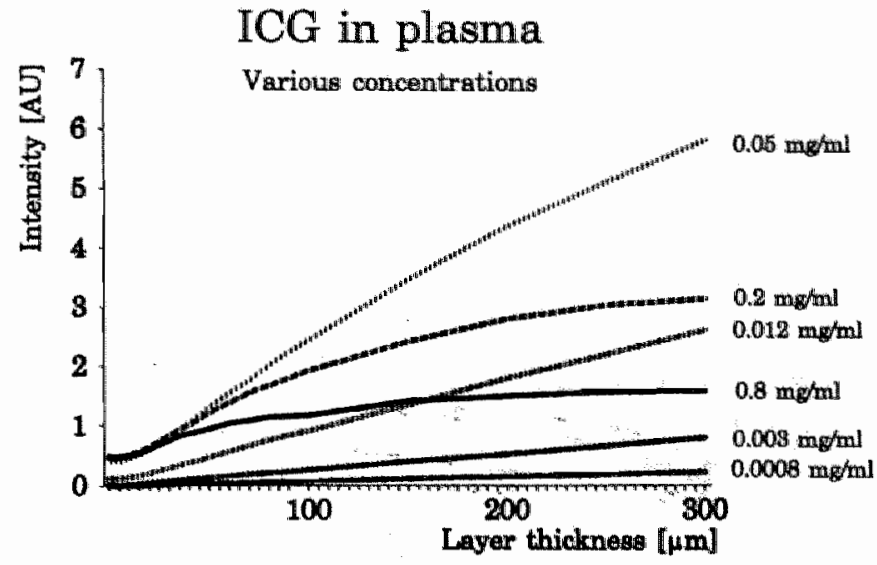

Figure 3. Relationship between the vield of fluorescence (intensity) and thickness of the layer for various concentrations of indocyanine green (ICG) in plasma. Only every other ICG concentration studied is shown. Mean intensities in arbitrary units (AU) from plasma samples of three subjects.

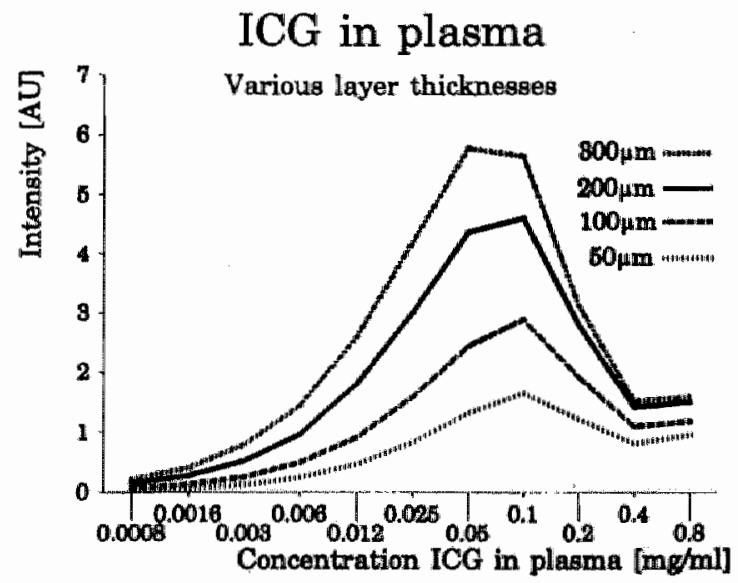

Figure 4. Relationship between the yield of fluorescence (intensity) and indocyanine green (ICG/ concentration in plasma for four layer thicknesses. Mean intensities in arbitrary units $(A U)$ from plasma samples of three subjects.

up to and including a concentration of $0.006 \mathrm{mg} / \mathrm{ml}$. A further increase in ICG concentration resulted in a non-linear increase and, from a concentration of $0.1 \mathrm{mg} / \mathrm{ml}$ onwards, actually in a decrease in intensity.

Figure 5 presents the yield of fluorescence from ICG in blood as a function of layer thickness for various concentrations, while figure 6 shows this yield as a function of concentration for four different layer thicknesses. The blood, having a hematocrit of $45 \%$, was subjected to a shear rate of $528 / \mathrm{s}$. The general picture resembles the curves we found in plasma. 


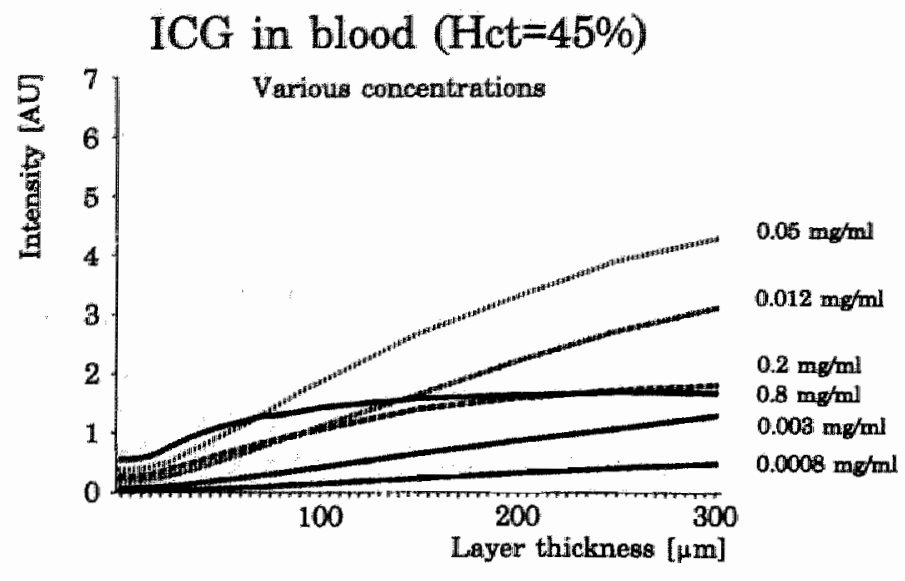

Figure 5. Relationship between the yield of fluorescence (intensity) and thickness of the layer for various concentrations of indocyanine green (ICG) in blood with a hematocrit (Hct) of $45 \%$ at a shear rate of $528 / \mathrm{s}$. Mean of intensities in arbitrary units (AU) from blood samples of three subjects.

\section{ICG in blood Het $45 \%$}

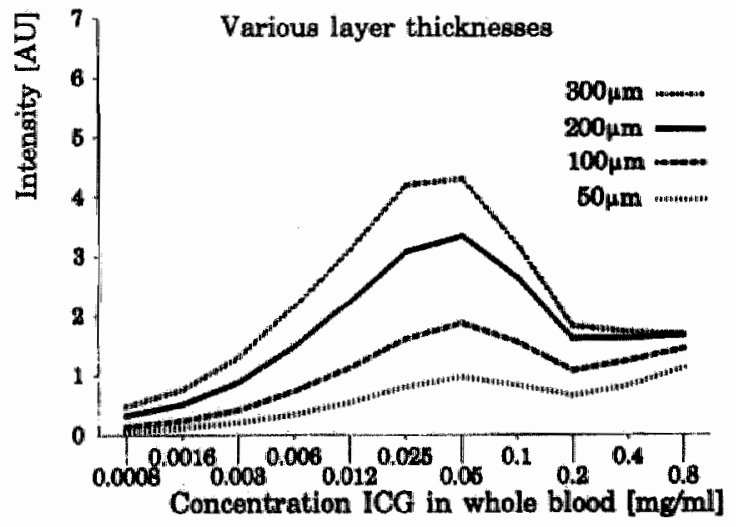

Figure 6. Relationship between the yield of fluorescence (intensity) and indocyanine green (ICG) concentration for four layer thicknesses in blood with a hematocrit (Hct) of $45 \%$ at a shear rate of $52.2 / \mathrm{s}$. Mean of intensities in arbitra$r y$ units (AU) from blood samples of three subjects.

However, for the same concentration per unit of volume, the intensities were higher for ICG in blood than for ICG in plasma up to a concentration of $0.025 \mathrm{mg} / \mathrm{ml}$. At higher concentrations, the yield of fluorescence of ICG in plasma was higher. This is best appreciated from figure 6. This figure also shows that the yield started to decrease from a concentration of about $0.05 \mathrm{mg} / \mathrm{ml}$ onwards for all layer thicknesses. In plasma this decrease occurred from $0.1 \mathrm{mg} / \mathrm{ml}$ onwards.

The fluorescence intensity of whole blood with an ICG concentration of $0.05 \mathrm{mg} / \mathrm{ml}$ as a function of layer thickness is shown in figure 7 for shear rates of $88 / \mathrm{s}$ and $528 / \mathrm{s}$, as well as 


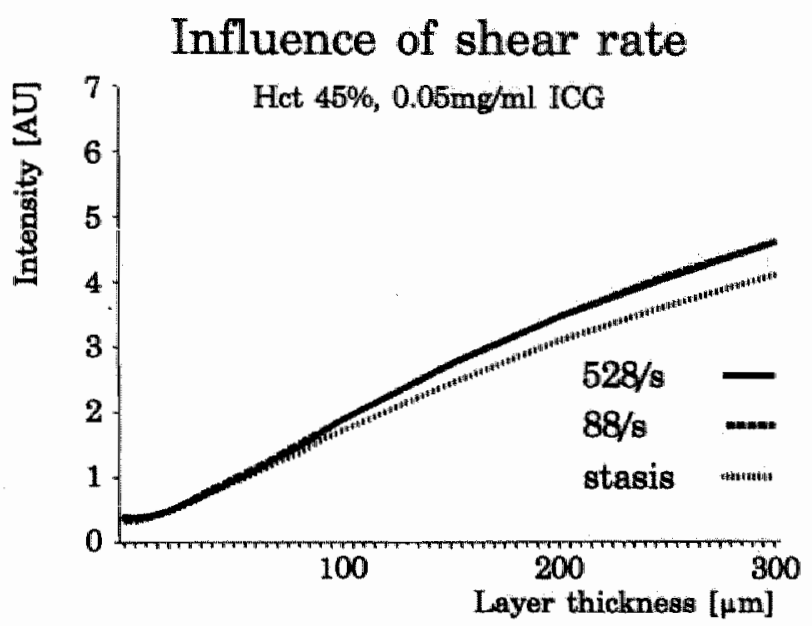

Figure 7. Relationship between the yield of fluorescence (intensity) and thickness of the layer for blood at various shear rates with a hematocrit (Hct) of $45 \%$ and a plasma indocyanine green (ICG) concentration of $0.05 \mathrm{mg} / \mathrm{ml}$. Mean of intensities in arbitrary units (AU) from blood samples of three subjects.

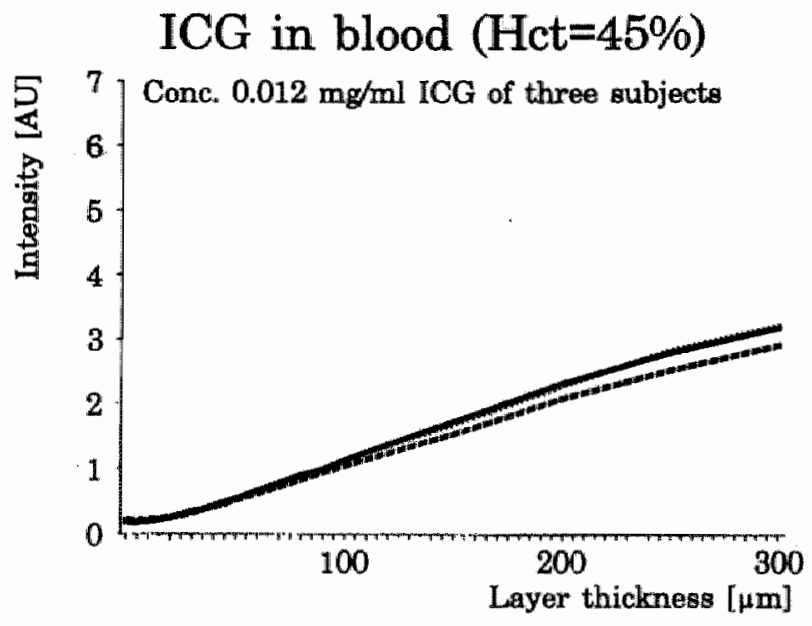

Figure 8. Relationship between the yield of fluorescence and thickness of the layer for a concentration of $0.012 \mathrm{mg} / \mathrm{ml}$ indocyanine green (ICG) in blood. Intensities from blood samples of three subject, illustrating the variation of the measurements.

after 10 minutes of stasis, respectively. The yield of fluorescence was about $10 \%$ lower in stasis than in shear. There was no measurable difference in intensity between the two shear rates.

The sets of curves had a regular and uniform aspect, both for blood and plasma. Only the intensity level of the curves as a whole showed some variation between the subjects. This variation was less than $10 \%$ for plasma and less than $20 \%$ for blood. As typical example of the variation, the curves of $0.012 \mathrm{mg} / \mathrm{ml} \mathrm{ICG}$ in blood for the three subjects are presented in figure 8 . 


\section{DISCUSSION}

Both in blood and in plasma, the yield of fluorescence of indocyanine green (ICG) increased with concentration up to a certain concentration. The yield decreased for all layer thicknesses above that concentration. For increasing layer thicknesses we found, both in plasma and in blood, an increase of the yield of ICG fluorescence. For the thicker layers, saturation of the yield of ICG fluorescence occurred at the highest concentrations. Flowing blood gave a higher yield of ICG fluorescence than blood in stasis. Differences in shear rate within the physiological range of the microcirculation did not influence the yield from flowing blood. This demonstrates the high transparency of blood for the excitation and emission light of ICG, which will lead to superposition of fluorescence from superficial and deeper layers.

The fluorescence yield of ICG is governed by two phenomena: the first is quenching, which is associated with dye concentration, the second is the effect of dispersion and absorption of the excitation and emission light. Quenching is explained by the fact that at higher ICG concentrations, dimers and polymers of indocyanine green are formed, which have a lower emitting energy. ${ }^{7}$ Quenching was observed at plasma concentrations of $I C G$ of $0.1 \mathrm{mg} / \mathrm{ml}$ and more: a further increase in ICG concentration leads to an actual reduction in the yield of fluorescence (figure 4). Due to volume exclusion by the blood cells and the resulting doubling of the ICG concentration in the plasma compartment, quenching started to reduce the yield of ICG in whole blood at a concentration of $0.05 \mathrm{mg} / \mathrm{ml}$ (figure 6). For sodium fluorescein (SF) in whole blood, quenching occurs at a concentration of $2.5 \mathrm{mg} / \mathrm{ml} \mathrm{SF}$ and higher. In plasma, the concentration at which SF quenches depends on the layer thickness. ${ }^{6}$

The effect of light absorption and/or dispersion may explain saturation of the ICG curves as a result of increasing layer thickness (figures 3 and 5 ). With increasing layer thickness. an increasing part of the excitation and emission light will be absorbed and dispersed by the superficial layers and, as a consequence, the contribution from the deeper layers to the total yield will diminish. This results in a levelling off of the curves with increasing layer thickness. Finally, all light to and from the deeper layers will be absorbed and dispersed and, hence, the deeper layers will no longer contribute: The curves saturate.

Dispersion and absorption will have different effects on the fluorescence of ICG and sodium tluorescein (SF) in blood. The excitation and emission light of ICG are hardly absorbed by hemoglobin, whereas hemoglobin absorbs the excitation and emission spectrum of SF very well. Dispersion of the near infrared light by red blood cells results in a increased yield of fluorescence of ICG. The longer path of the excitation light through the dye solution makes excitation of a dye molecule more probable. This explains why the same amount of ICG per unit volume resulted in a higher yield of fluorescence in blood than in plasma, at least for concentrations up to $0.012 \mathrm{mg} / \mathrm{ml}$ (compare figure 4 with figure 6). At higher concentrations, quenching masks this effect. As mentioned above, due to volume exclusion by the blood cells. the plasma in blood samples contains an almost double dye concentration as compared to a plasma sample with same concentration per volume. As a result, the quenching occurs in blood at lower concentrations per unit volume. Dispersion also accounts for the higher yield of thuorescence from $1 \mathrm{CG}$ in flowing blood than in stasis. In flowing blood the red blood cells are disaggregated, while in stasis aggregates are formed. The extent of dispersion of the near infra red light by disaggregated blood cells will be higher than by aggregated blood cells. The result is a higher yicld of luorescence of ICG in flowing blood than in stasis.

In the case of SF, with high absorption of the excitation and emission spectra by hemoglobin, light absorption dominates light dispersion. ${ }^{\circ}$ As a consequence, the yield of SF 
fluorescence is higher in plasma than in whole blood. The yield of SF in blood is higher in stasis than in flow for the same reason: because of the high light absorption, the disaggregated flowing blood cells preclude light penetration into the deeper layers. By contrast, in stasis transparent gaps are formed between the aggregates, which makes excitation of dye molecules in deeper layers possible. A higher yield of SF fluorescence in stasis will thus result. The high absorption by disaggregated red blood cells even leads to an restriction of the effective layer thickness to no more than about $25 \mu \mathrm{m}$ (figure 9). For thicker layers of flowing blood the yield of SF does not depend on layer thickness but, in contrast to the yield of ICG, only on SF concentration.

We found a maximum yield of fluorescence in flowing blood at an ICG concentration of $0.05 \mathrm{mg} / \mathrm{ml}$. Flower" performed experiments in blood in stasis and found a maximum at $0.03 \mathrm{mg} / \mathrm{ml}$. This small difference is in line with our observation that disaggregation of red blood cells due to shearing has a limited effect on the yileld of fluorescence (figure 7 ).

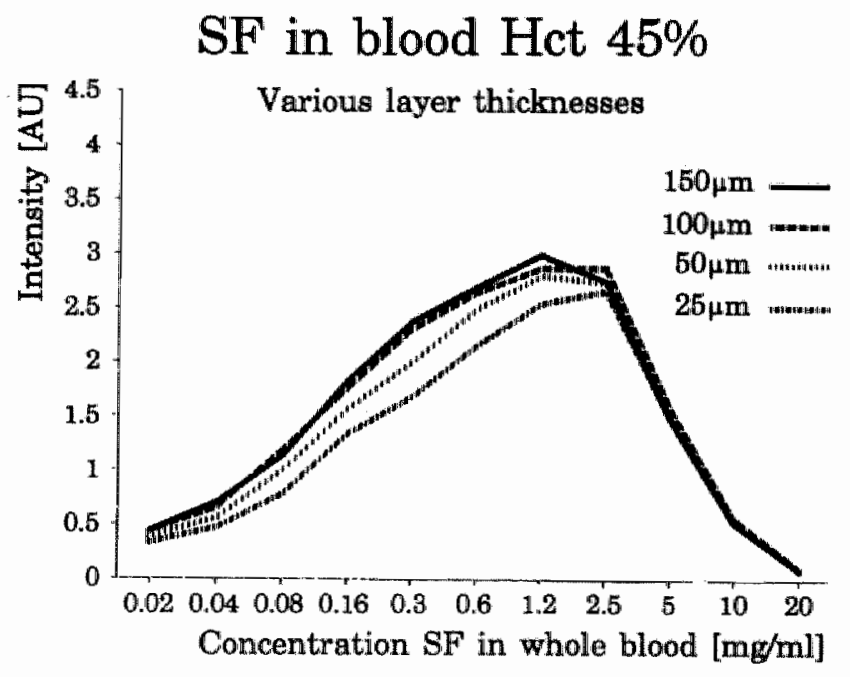

Figure 9. Relationship between the yield of fluorescence (intensity) and sodium fluorescein (SF) concentration for four layer thicknesses in blood with a hematocrit (Hict) of $45 \%$ at a shear rate of $528 / \mathrm{s}$. Mean of intensities in arbitrary units (AU) from blood samples of three subjects. Values from one subject were corrected for a low hemoglobin concentration.

As argued in our previous report on sodium fluorescein the results of our experiments in a shear chamber with a constant shear rate in the whole blood sample are relevant lo blood vessels in vivo. The results of the present study revealed no measurable influence of shear rate on the yield of fluorescence from $1 \mathrm{CG}$ for shear rates higher than $88 / \mathrm{s}$, and only a small effect of the absence of shear. Shear rates lower than $88 / \mathrm{s}$ occur only in the central part of a vessel, which constitutes no more than about $5 \%$ of the cross-sectional area. ${ }^{12.13}$ Another factor that might limit the relevance of our study for the in wivo situation is the preferred orientation of the red cells at the side wall of a blood vessel as described in frog mesentery by Wiederhielm and Billig for vessels with diameters above $150 \mu \mathrm{m} .{ }^{14}$ In transillumination, red cell orientation affected light scattering and, thus, the absorption of blood at the side wall of a vessel. Michoud and co-workers ${ }^{15}$ on the other hand, could not demonstrate an altered light absorption in ham. 
ster skinfold at the side walls of vessels below $70 \mu \mathrm{m}$ in diameter. In addition, in incident illumination, as in our setup, a change in shear rate from 88 to 528 that is known to affect red cell orientation" did not affect the yield of fuorescence from ICG (figure 7). Moreover, we did not observe any effects of light scatter at the border of vessels in fluorescence angiography of the ocular fundus. Therefore, our in vitro data can be extended to the in vivo microcirculation for vessels with a local hematocrit that is near the systemic value, i.e., vessels with diameters of more than 25 to $50 \mu \mathrm{m}^{.15}$

Our experiments were performed under similar light conditions as present in ICG angiography with a scanning laser ophthalmoscope $(\mathrm{NA}=0.06)$. The scanning laser ophthalmoscope provides angiograms with a limited optical resolution but with good contrast, i.e., a low level of the background scatter. The better resolution in the case of an ICG fundus camera (NA up to 0.45), does not result in better quality angiograms due to the high level of stray light. The unknown level of this background scatter precludes quantitative measurements from ICG fundus camera angiograms from the very start. We therefore did not investigate whether our results are also applicable to ICG angiography with a CCD-camera attached to a fundus camera.

Examining the appearance pattern of ICG angiograms, it is evident that the yield of fluorescence at the crossing of two blood vessels is superimposed (unpublished observation). It means that the fluorescence which is coming from the deeper vessel is not blocked by the superficial vessel. This is in accordance with our finding that the ICG concentration-intensity curves do not saturate for vessels up to in diameter of $200 \mu \mathrm{m}$, even not at the highest concentrations (figure 6). A diameter of $200 \mu \mathrm{m}$ is approximately the maximum for vessels in the retina and choroid. Due to the high density of larger vessels in the retina and choroid, superposition poses a problem for intensity measurements of individual vessels. Avoiding of superposition could be accomplished by true confocal angiography, but this imaging technique is precluded by the low aperture of the eye. In principle, superposition could be corrected by subtraction of the background fluorescence, but this is hardly possible in ICG angiography because the background is ill defined. Only when vessels could be measured without superposition, intensities would be dependent on absolute vessel diameter. This would require accurate assessment of vessel diameter, which is difficult, since the diffraction properties of the individual eye are unknown. The conditions for intensity measurements are better for sodium fluorescein angiography. Here, because the hemoglobin blocks the fluorescence from deeper layers, inten sity measurements are feasible for retinal vessels with a diameter of more than $25 \mu \mathrm{m}$ with a local hematocrit that is near the systemic value (i.e., vessels of 25 to $50 \mu \mathrm{m}$ diameter or more, depending on the local hematocrit ${ }^{8}$ ). The local concentration of SF is the only factor that determines the intensity of these vessels (figure 9)."

For quantitative fluorescein angiography it is essential that the retinall vessels are isolated from their environment by blocking the fluorescence from deeper layers and suppression of the stray light. Sodium fluorescein angiography performed with a scanning laser ophthalmoscope meets the criteria for quantitaiive angiography. ICG angiography, however, cannot be used for quantitative angiography, due to the high transparency of blood for the excitation and emission light of $\mathbb{I C G}$.

\section{REFERENCES}

1. Guyer DR, Puliafito CA, Mones JM, Friedman E, Chang W, Verdooner SR. Digital indocyanine-green angiography in chorioretinal disorders. Ophthalmology 1992;99:287-291. 
2. Yannuzzi LA, Slakter IS, Sorenson JA, Guyer DR, Orlock DA. Digital indocyanine green videoangio graphy and choroidal neovascularization. Retina 1992;12:191-223.

3. Scheider $A$, Schroedel $C$. High resolution indocyanine green angiography with a scanning laser ophthal moscope. Am. J. Ophthalmol. 1989;108:458-459.

4. Moneta G, Brulisauer $M_{*}$ Jager $\mathrm{K}$, Bollinger A. Infrared fluorescence videomicroscopy of skin capillaries with indocyanine green. Int. J. Microcirc. Clin. Exp. 1987;6:25-34.

5. Bischoff PM, Flower RW. Ten years experience with choroidal angiography using indocyanine green dye: a new routine examination or an epilogue? Doc. Ophthalmol. 1985;60:235-291.

6. Van den Biesen PR, Jongsma FH, Tangelder GJ, Slaaf DW. Shear rate and hematocrit dependence of fluorescence from retinal vessels in fluorescein angiography. Ann. Biomed. Engin. 1994:22:456-463.

7. Romanchuk KG. Fluorescein. Physiochemical factors affecting its fluorescence. Surv. Ophthalmol. $1982 ; 26: 269-283$.

8. Sdoagos HP, Bussolari SR, Dewey CF. Secondary flow and turbulence in a cone-and-plate device. J. FluidMech. 1984;138:379-404.

9. Klose HJ, Volger E, Brechtelsbauer H, Heinich L, Schmid-Schönbein H. Microrheology and light transmission of blood. I. The photometric aspects of red cell aggregation and red cell orientation. Pflugers Arch. 1972;333:126-139.

10.Schmid-Schönbein H, Volger E. Klose HJ. Microrheology and light transmission of blood. II. The photometric quantification of red cell aggregate formation and dispersion in flow. Pflugers Arch. 1972;333:140-155.

11. Flower RW, Hochheimer BF. Quantification of indicator dye concentration in ocular blood wessels. Exp. Eye. Res. 1977;25:103-111.

12.Slaaf DW. Tangelder GJ, Reneman RS. Physics of the microcirculation. In: The physics of heart and circulation, edited by J. Strakee, and N. Westerhof. Bristol: Institute of Physics Publishing Ltd, 1993, pp. $383-416$.

13. Tangelder GJ, Slaaf DW, Reneman RS. Fluorescent labelling of blood platelets in vivo. Thrombosis Research 1982;28:803-820.

14. Wiederhielm CA, Billig L. Effects of erythrocyte orientation and concentration on light transmission through blood flowing through microscopic blood vessels. In: Hemorhology. Proceedings of the First International Conference, Reykjavic, 1966, Oxford \& New York: Pergamon Press, 1967, pp 681-694.

15. Michoud E, Carpentier P, Franco A, Intaglietta M. Two light attenuation models for automatic diameter measurement of blood vessels. Int. J. Microcirc.: Clin. Exp. 1993;12:157-171.

16. Lipowsky HH, Usami S, Chien S. In vivo measurements of "apparent viscosity" and microvessel hema tocrit in the mesentery of the cat. Microvasc. Res. 1980;19:297-319. 
C H A P T E R 5 .

\begin{abstract}
ESTIMATES OF ABSOLUTE DYE CONCENTRATIONS IN RETINAL VESSELS IN FLUORESCEIN ANGIOGRAPHY.
\end{abstract}

P.R. van den Biesen, W.Th. Hermens, F.H. Jongsma, D.W. Slaaf. 



\section{ABSTRACT}

Purpose. To convert intensities of retinal vessels from fluorescein angiograms into estimates of dye concentrations.

Methods. Fluorescein angiograms made with various dye dosages were obtained from human subjects. Dye dilution theory predicts that an $n$-fold amount of injected dye leads to an n-fold increase in dye concentrations. Due to fluorescence quenching, however, such $\mathrm{n}$-fold increase in concentration may result in less than $n$-fold increase in fluorescence intensity. Absolute dye concentrations in retinal arteries were estimated by comparing two angiograms made with different amounts of dye and using the nonlinear relationship between concentration and intensity, as assessed in vitro in previous experiments.

Results. Calculated maximal concentrations in retinal arteries after intravenous injection of equal quantities of sodium fluorescein varied widely between subjects and depended on body weight. The estimated concentrations after a bolus of $400 \mathrm{mg}$ sodium fluorescein varied between 0.35 and $1.4 \mathrm{mg} / \mathrm{ml}$.

Conclusions. After intravenous injection of dye quantities used in routine angiography, fluorescein concentrations in retinal wessels exceeded by far the linear domain of the intensityconcentration curve of sodium fluorescein.

\section{INTRODUCTION}

Sodium fluorescein (SF) angiography of ocular vessels is widely applied for the diagnosis of choroidal and retinal diseases. In clinical practice, ophthalmologists routinelly evaluate the angiograms on patterns of fluorescence intensities with little knowledge of the underlying processes that determine the appearance of the angiogram. A better understanding of the fluorescence intensities reached locally might improve our insight into the physiology of the SF angiogram and the pathophysiology of chorioretinal diseases. The appearance of fluorescein angiograms is in part dependent on dye extravasation in the choroid. A better understanding of the process of dye extravasation into the interstitial space of the choroid requires detailed knowledge of the SF concentrations in ocular vessels. Intensity measurements of fluorescence from retinal vessels without conversion into concentration data have been used to assess various parameters of retinal circulation, for instance, the retinal mean circulation time ${ }^{i, 2}$ ascending curve slope time-to-peak intensity, and time-to-50\% of peak intensity. Fluorescence intensity value, , however, directly reflect SF concentrations only under very specific conditions, i.e., a linear relationship must exist between fluorescence intensity and SF concentration. These conditions are usually not met in routine angiography.

Recently, we reported data on the nonlinear relationship between intensity of fluorescence and SF concentration in flowing blood in vitro." In the present study, we used these data to convert intensities of retinal vessels into an estimate of actual intravascular SF concentrations. SF angiograms were obtained from human subjects with a scanning laser ophthalmoscope. The intensities from the angiogram had to be calibrated with the intensities of the intensity-concentration curve assessed in vitro. Indicator dilution theory predicts that an $\mathrm{n}$-fold amount of injected dye leads to an $n$-fold increase of dye concentrations in retinal vessels. This principle was used for calibration and, therefore, angiography with various dosages were performed on the same subject. 


\section{MATERIALS AND METHODS}

\section{Angiography}

Fluorescein angiograms were obtained from the right eye of five healthy subjects (three males and two females) with a scanning laser ophthalmoscope (SLO, Rodenstock, München, Germany). Volunteers were selected for their ability to keep a stable fixation during the angiogram. The pupil was dilated with tropicamide $0.5 \%$ and phenylephrine $5 \%$. Blinking was minimised by application of oxybuprocaine $0.4 \%$ in both eyes shortly before angiography. For each subject, two angiograms were made on different days with total dye dosages of 100 and $400 \mathrm{mg} \mathrm{SF}$, respectively. The dye was dissolved in $4 \mathrm{ml}$ glucose $5 \%$ and injected in an antecubital vein through an 18 or 20 gauge cannula (Braunule, Braun AG, Meslungen, Germany, dead space 0.05 and $0.04 \mathrm{ml}$, respectively) for males and females, respectively. Duration of injection was one to two seconds. The dye injection was not followed by a flush. The gain control of the SLO was set on step 2 and the observation angle of the camera on $40^{\circ}$. The angiogram was recorded on videotape together with the signal of a video time code generator using an U-matic videorecorder. Video timing started at the beginning of the dye injection. Recording continued for at least one minute. All angiograms were performed between 3 and 6 pm. Directly after angiography, an image of the pupil was recorded on tape.

All experiments followed the tenets of the Declaration of Helsinki and informed consent was obtained from each subject after the nature and possible consequences of the study had been explained. The research was approved by the institutional human experimentation committee.

Angiograms were evaluated from still frames using a frame grabber (PC Vision plus, Imaging Technology Inc., Woburn, MA, USA) and video analysis software (Java, version 1.40 , Jandel Scientific, Corte Madera, CA, USA), installed on a 486 DX personal computer. The frame grabber was set on maximal gain and offset. Intensity measurements were performed with a linear array of 15 to 20 pixels length centered along the midline of a segment of a large retinal artery, close to the optic disk. Mean intensities were expressed in hardware gray units. To verify the instrument alignment during the angiogram, the time-course of the intensities of the complementary retinal vein and an adjacent area of background fluorescence of 19x19 pixels were obtained from each angiogram. Images were analysed at 0.5 second intervals. Linearity of the combined SLO and video analysis system was checked with calibrated filter values.

\section{Principle of estimating absolute concentrations.}

Indicator dilution techniques are used for measuring cardiac output. An indicator substance is injected as a bolus into the circulation upstream of a mixing place, usually the heart. The concentration measured on any location downstream of the heart as function of time is called the indicator dilution curve.

When the indicator is injected over a short period of time in a peripheral vein, the bolus profile along the vein will be determined by factors as the injection volume and speed, the volume and blood flow of the vein, and the characteristics of the vessel wall. In the venous circulation, the bolus is diluted. The actual duration of the bolus passing through the venous circulation may be longer than the duration of the bolus injection due to the jet effect of the injec- 
tion. In the right ventricle the indicator is mixed. During passage of the lung, where transition times along various pathways differ, dilution and elongation of the bolus takes place. Finally, the indicator is thoroughly mixed over the left ventricular volume and, consequently, the bolus enters the main circulation well mixed over the cross-sectional area of the aorta. The markedly elongated indicator profile that enters the aorta is the result of the summed dilution and ellongation between site of injection and aorta. Evidently, the degree of bolus elongation and the delay until the aorta is reached will depend on body (vasculature) dimensions.

If the concentration in the blood that leaves the heart and enters the main circulation is homogeneous over the cross-sectional area, and no additional mixing or extravasation of the indicator occurs, the shape of the indicator dilution curve is maintained when passing through a vessel segment or a bifurcation: A sharply defined indicator bolus of length li flowing through a vessel of certain diameter at velocity $v_{0}$ will have a passage time of $t_{0}=1 / v_{0}$. If the vessel becomes narrower and the cross-sectional area is reduced to, for instance, $50 \%$, the bolus length $l_{1}$ is doubled, as is the velocity $v_{1}$. Therefore, the passage time remains at $t_{0}$. When applying this principle to passage of a bolus at a bifurcation, at any moment in time the same concentration enters each of the daughter branches. At the entrance of the two daughter branches the same time-concentration curves are present. Thus, for a given flow rate, at any location downstream in the arterial tree the passage time of the indicator profile will be the same as in the aorta."

The higher the cardiac output is, the higher the flow in the main circulation will be, and the earlier the indicator will appear at the measuring location and the more rapidly the complete indicator profile will pass. For a bolus which enters the aorta, the blood volume in which the indicator is mixed (V) equals the product of the cardiac output (CO) and the duration of the bolus $(\Delta \mathrm{t})$;

$$
\mathrm{V}=\mathrm{CO} \cdot \Delta \mathrm{t}
$$

For any given period of time of length $t$, the concentration at time $t$, defined as $C(t)$, equals the amount that passes $(\mathrm{A}(\mathrm{t}) . \Delta \mathrm{t})$ divided by the volume that passes $(\mathrm{CO} . \Delta \mathrm{t})$ :

$$
C(t)=A(t) \cdot \Delta t / C O \cdot \Delta t
$$

The total amount injected is found by integration:

$$
A=\int_{0}^{t \infty} A(t) d t=C O \int_{0}^{\infty} C(t) d t
$$

where te is the time at which the indicator concentrations have returned to zero. As explained above, $\mathrm{C}(\mathrm{t})$ at measuring sites downstream will be the same as in the aorta. Recirculation of the indicator, occurring before the first passage is completed, may be a problem in the indicator dilution technique. In this case the last part of the dillution curve will be distorted and a correction will be needed to find the return to zero for the furst circulation.

The concentration $C(t)$ was calculated from the intensity of fluorescence $\mathbb{I}_{a}(t)$ by using the relationship $\mathrm{C}(\mathrm{t})=\mathrm{f}\left[\mathrm{I}_{v}(\mathrm{t})\right]$ as determined in vitro in flowing blood with a layer thickness of $50 \mu \mathrm{m}$ (figure 1). The intensities from the angiograms could not directly be transformed into concentrations, because the units of intensities $I_{a}$ of the angiogram differed by an unknown calibration factor $k$ from the intensity units of the in vitro experiments $I_{v}$ : 


$$
\mathrm{C}(\mathrm{t})=\mathrm{f}\left[\mathrm{k} \cdot \mathrm{I}_{\mathrm{a}}(\mathrm{t})\right]
$$

The factor $k$ calibrates the concentration-intensity curve. Indicator dilution theory predicts that an $\mathrm{n}$-fold dose of $\mathrm{SF}$ injected under similar conditions results in an $\mathrm{n}$-fold concentration curve. To obtain the factor $k$, we used dosages of 100 and $400 \mathrm{mg}$, respectively. Because the condi-

\section{Sodium fluorescein in flowing blood}

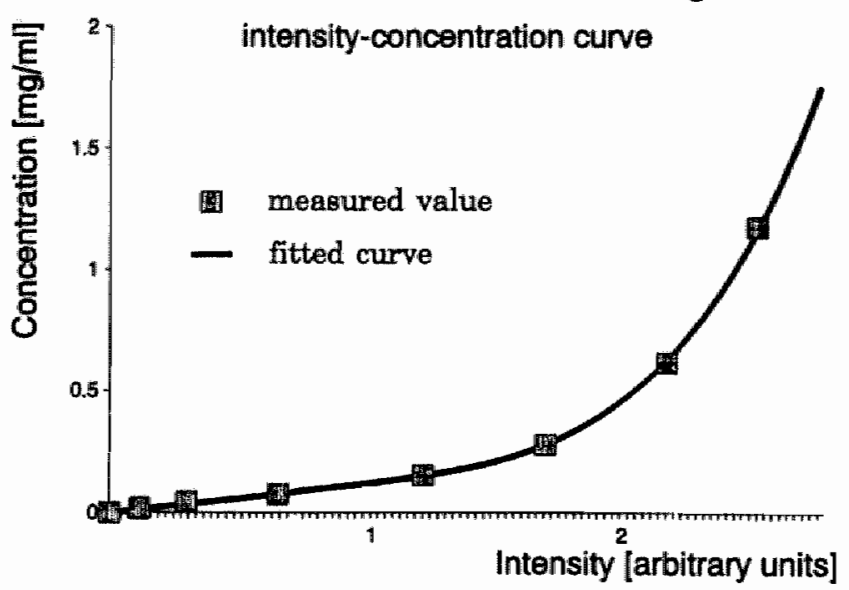

Figure 1. Relationship between the yield of fluorescence (intensityl and sodium fluorescein concentration in blood for a layer thicknesses of $50 \mathrm{\mu m}$, as assessed in vitro. The relationship was approximated by curve fitting. Data taken from van den Biesen et als.

tions during two angiograms are not exactly reproducible as far as the dye dilution between the injection site and the aorta is concerned, and because those conditions have a major influence on the dye concentration profile entering the aorta, direct comparison of the shape of the dye dilution curves of the two angiograms is not possible. Equation 3, however, holds true independent of the actual shape of the bolus. If the quantity of dye in bolus 2 is 4 -fold that of bolus I. than applying equation 3 yields:

$$
4 \mathrm{CO}_{1} \int_{0}^{\mathrm{tol}} \mathrm{C}_{1}(\mathrm{t}) \mathrm{dt}=\mathrm{CO}_{2} \int_{0}^{\mathrm{tto} 2} \mathrm{C}_{2}(\mathrm{t}) \mathrm{dt}
$$

Combination of equation 4 and 5 results in:

$$
4 \mathrm{CO}_{1} \int_{0}^{\mathrm{tel} 1} f\left[k_{1} I_{1}(t)\right] d t=\mathrm{CO}_{2} \cdot \int_{0}^{\infty e 2} f\left[k_{2} I_{a 2}(t)\right] d t
$$


Cardiac output was assumed to be equal during both angiograms and thus may be elminated from equation 6 , resulting in an equation with two unknown factors, $k_{\mathbb{I}}$ and $k_{2}$ :

$$
4 \int_{0}^{t c 1} f\left[k_{1} L_{k}(t)\right] d t=\int_{0}^{t e z 2} f\left[k_{2} I_{2} 2(t)\right] d t
$$

The $k$ values of the two angiograms will be dissimilar because of differences in pupil dilatation and instrument alignment.

A second rellationship between $k_{1}$ and $k_{2}$, required to obtain a single value for $k_{1}$ and $k_{2}$, respectively, may be derived from the final equilibrium intensities $I_{a 1}(t e 1)$ and $I_{a 2}\left(t_{e 2}\right) c a l$ culated as the averaged intensities over the last 10 data points ( 5 seconds). Assuming that at 60 seconds an equal degree of mixing has occurred during both angiograms and that the concentrations remain within the linear range of the intensity-concentration curve, one obtains the following relationship:

$$
4 k_{1} I_{a 1}\left(t_{e 1}\right)=k_{2} I_{a 2}\left(t_{e 2}\right)
$$

or:

$$
k_{1} / k_{2}=I_{a 2}\left(t_{e 2}\right) / 4 I_{a}\left(t_{e 1}\right)
$$

The in vitro determined relationship $\mathrm{C}(\mathrm{t})=\mathrm{f}\left[\mathrm{I}_{\mathrm{v}}(\mathrm{t})\right]$ was approximated by a linear part $C(t)=0.113 I_{v}(t)$ up to $S F$ concentrations of $0.08 \mathrm{mg} / \mathrm{ml}$ and the polynomiall $C(t)=$ $0.0689\left[I_{v}(t)\right] 4-0.175\left[I_{w}(t)\right] 3+0.149\left[I_{v}(t)\right] 2+0.0732\left[I_{v}(t)\right]+0.0014$ for higher intensities (figure 1).

For any given pair $\left(k_{1}, k_{2}\right)$, there is an unique solution that fits equation 7 . For each subject, $k_{1}$ and $k_{2}$ were determined by simple iteration procedure.

Then, the intensity curves could be converted into concentration curves and, using equation 3 , cardiac output could be calculated.

The disturbance due to recircullation was circumvented in the classical manner by exponential extrapolation of the final part of the down slope of $\mathrm{I}_{\mathrm{a}}(\mathrm{t})$ of each angiogram to zero and each $I_{a}(t)$ was expressed in a polynomial.

\section{RESULTS}

Measured time-intensity curves $I_{a 1}(t)$ and $I_{a 2}(t)$ corrected for offset and $k$, and the calculated time-concentration curves $C_{1}(t)$ and $C_{2}(t)$ of subject $C$ are presented in figure 2 . Corrections for the recirculation are included. The non-linear relationship between SF concentrations and fluorescence intensities is apparent from the more peaked aspect and increased range of the concentration curves, compared to the intensity curves.

Individual differences in the calculated time-concentration curves of the $400 \mathrm{mg}$ angiograms are shown in figure 3 . In spite of the standardized injection procedure, with the bolus injection completed within 1 to 2 seconds, a large variability in the time of first dye appearance and the shape of concentration profiles is demonstrated. With the exception of subject D, figure 3 suggests that short arrival times of the dye correspond to a steep initial rise of con- 
centrations.

Mean time-intensity and time-concentration curves for the five subjects are shown in figure 4. Before averaging, the time-intensity curves were corrected for offset. For ease of comparison, the time of dye arrival of each separate angiogram was set at 10 seconds, the mean arrival time of all 10 angiograms. The ratio of the peak intensities of the 100 and $400 \mathrm{mg}$ angiogram of about $1: 2$ differs clearly from the ratio of $1: 4$ of the peak concentrations of the 100 and $400 \mathrm{mg}$ angiogram.

Figure 5 presents mean concentration curves after normalization with respect to the injected dye quantities: $C_{1}(t)$ is multiplied by a factor of 4 . The time-course of the two curves is remarkably similar.
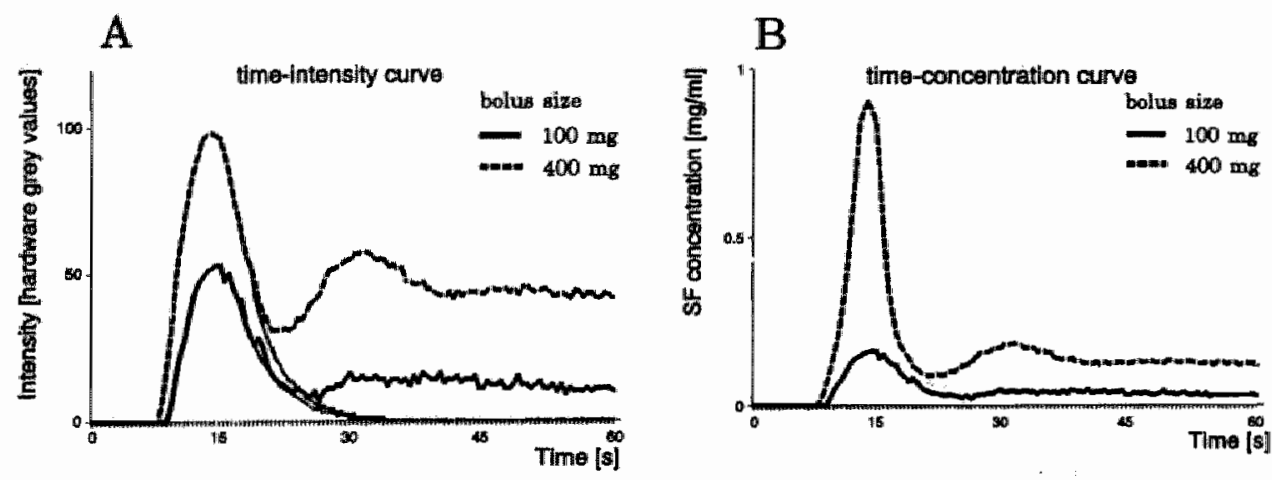

Figure 2. (A) Time-intensity curves of subject $C$ of the yield of fluorescence from a retinal artery after an intravenous injection of 100 and $400 \mathrm{mg}$ sadium fivorescein, respectively. (B) Time-concentration curves of the two dosages after conversion of the time-intensity curves from figure $2 \mathrm{~A}$.

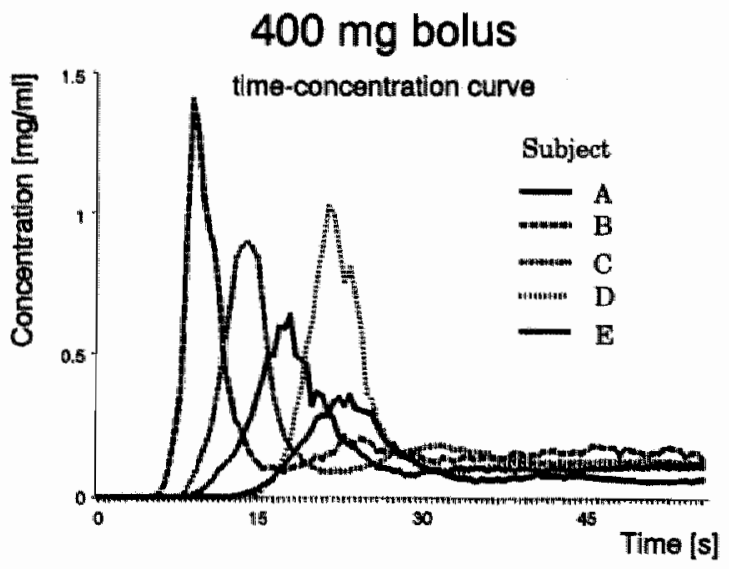

Figure 3. Time-concentration curves of the five subjects of the yield of fivorescence from a retinal artery after an injection of $400 \mathrm{mg}$ sodium fluorescein. 
Table 1 gives individual characteristics and obtained parameter values for the fiwe subjects. The mean cardiac output is within the normal range. Values of $\mathrm{k}_{\mathrm{I}}$ and $\mathrm{k}_{2}$ show a wide variation, both between the subjects as well as for each individual subject. Obviously, no relationship exists between $k$ and pupil diameter. There was also a wide variation in maximal concentrations and end-concentrations, and bolus arrival times. Body weigth was related to mean arrival time of each subject $(y=0.2 x-3.7, R=0.9673, p<0.01)$ and to mean end concentrations $(y=0.04 x+1.07, R=0.9238)$.

In two angiograms we found an indication of a change in instrument alignment during the angiogram: the $100 \mathrm{mg}$ angiograms of subject $\mathrm{D}$ and $\mathrm{E}$. Whereas in all other angiograms
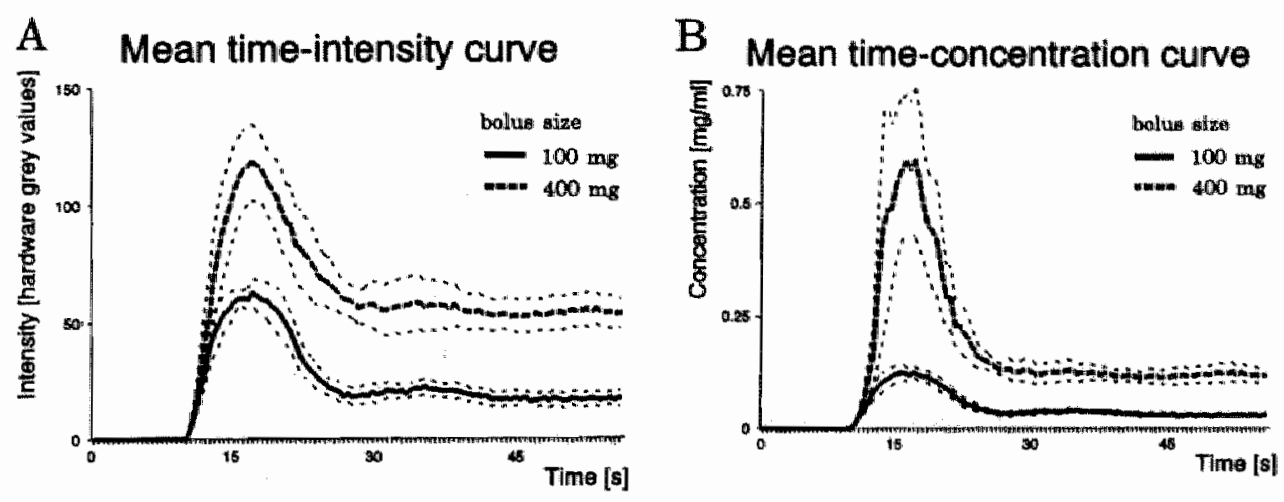

Figure 4. (A) Mean time-intensity curves of five subjects of the vield of fluorescence from a retinal artery after an intravenous injection of 100 and 400 $\mathrm{mg}$ sodium fluorescein. (B) Time-concentration curves of the two dosages after conversion of the time-intensity curves from figure $4 \mathrm{~A}$. Curves are flanked by thinner curves, indicating the standard error of the mean values.

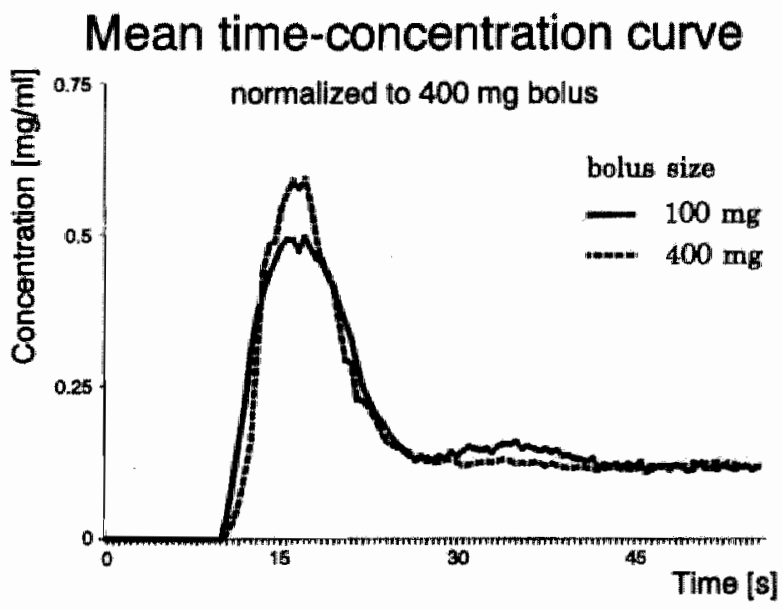

Figure 5. Mean time-concentration curves of the two dosages, normalized with respect to the injected dye quantities: the curve of the $100 \mathrm{mg}$ dose was multiplied by a factor of 4 . 
the intensities of the complementary vein and adjacent background had stabilised in the second half of the angiogram, both aforementioned angiograms showed a decrease of the intensities of the artery, vein, and background in the same phase of the angiogram (figure 6); (see Discussion).

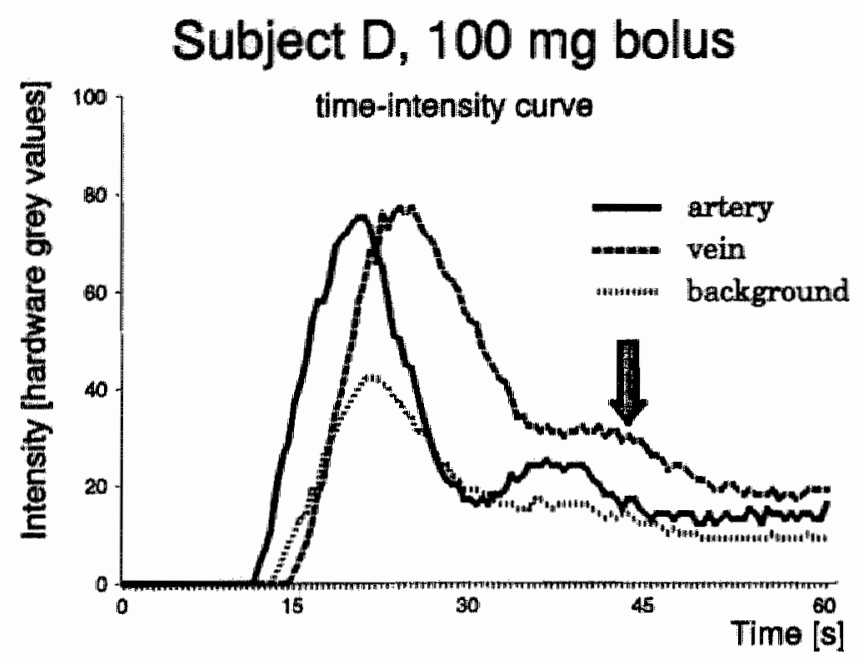

Figure 6. Time-intensity curves of subject $D$ of the yield of fluorescence from a retinal artery and vein, and an area of background after a injection of $300 \mathrm{mg}$ sodium fluorescein. Arrow indicates a coinciding drop in intensity of the three curves, revealing a change in instrument alignment.

\section{DISCUSSION}

Absolute dye concentrations in retinal vessels during fluorescein angiography were estimated by comparing two angiograms made with different amounts of sodium fluorescein (SF) and using the nonlinear relationship between SF concentration and intensity as obtained from flowing blood in vitro. The concentrations of SF that were measured in retinal arteries after injection of dye quantities used in routine angiography exceeded by far the linear domain of the intensity-concentration curve of SF in flowing blood. Maximal concentrations after injection of equal quantities of dye varied widelly between the subjects.

Methodological aspects of the present study.

The factor $k$ is the calibration factor of the concentration-intensity curve assessed in vitro. The differences in the value of $k$ (table 1) represent variations in the transfer of the excitation and emission light through the ocular media from and to the scanning laser ophthalmoscope. Variation of $\mathrm{k}$ between the angiograms of each subject is due to variation in pupil diameter and instrument alignment. Because there was no relationship between pupil diameter 


\section{TABLE 1}

\section{Measured and Calculated VARIABLES}

subject

$\operatorname{sex}$

age [years]

body surface area $\left[\mathrm{m}^{2}\right]$

pupillary surface (relative) SF dosage $\begin{array}{r}100 \mathrm{mg} \\ 400 \mathrm{mg}\end{array}$

calibration factor $\mathrm{k}[\mathrm{mg} / \mathrm{U} .1]^{*}$

SF dosage $\begin{array}{r}100 \mathrm{mg} \\ 400 \mathrm{mg}\end{array}$

cardiac output [l/min]

cardiac index $\left[1 / \mathrm{min} / \mathrm{m}^{2}\right]$

peak concentration $[\mathrm{mg} / \mathrm{ml}]$

SF dosage $\begin{array}{r}100 \mathrm{mg} \\ 400 \mathrm{mg}\end{array}$

end concentration $[\mathrm{mg} / \mathrm{ml}]$

$$
\text { SF dosage } \begin{array}{r}
100 \mathrm{mg} \\
400 \mathrm{mg}
\end{array}
$$

A $\quad$ B $\quad$ C $\quad$ D $\quad$ E

$m \quad f \quad f \quad m$

$\begin{array}{lllll}39 & 32 & 40 & 38 & 36\end{array}$

$\begin{array}{lllll}2.1 & 1.6 & 1.6 & 2 & 1.8\end{array}$

1.82

$\begin{array}{lllll}1 & 1 & 1 & 1 & 1 \\ 0.79 & 1.37 & 1.03 & 0.92 & 0.82\end{array}$

0.99

MEAN SD

37

3.16

0.23

0.017

0.006

0.018

0.004 $\begin{array}{lllll}7.1 & 5.7 & 4.5 & 3.6 & 4.4\end{array}$

$\begin{array}{lllll}3.36 & 3.58 & 2.81 & 1.79 & 2.45\end{array}$

2.80

0.72

$\begin{array}{lllll}0.090 & 0.123 & 0.160 & 0.150 & 0.139\end{array}$

$\begin{array}{llllll}0.353 & 1.400 & 0.900 & 1.027 & 0.637\end{array}$

0.132

0.027

0.863

0.396 $\begin{array}{lllll}0.022 & 0.034 & 0.029 & 0.026 & 0.027\end{array}$

0.088

0.146

0.108

0.111

0.028

0.115

0.004

0.021

time of first dye arrival [s]

$$
\text { SF dosage } \begin{array}{r}
100 \mathrm{mg} \\
400 \mathrm{mg}
\end{array}
$$

* U=hardware grey walue units.

\section{3.} 12

\subsection{7.}

5.5

9.0

1.1.5 9.0

$14.5 \quad 8.5$
10.10

2.38

9.80 
and the value of $k$, the intraindividual variation of $k$ is mainlly due to differences in instrument alignment. As suggested in figure 6, changes in instrument alignment could indeed cause a substantial change in $k$. The interindividual variation of the mean value of $k$ of each of the subjects is due to differences in absorption and scatter in the ocular media. The interindividual variation is relatively small. Only subject $A$ has relatiwely low values, possibly indicating clear ocular media. Since scatter and absorption present linear processes, $k$ value does not change during an angiogram as long as pupil diameter and instrument alignment are fixed. Thus, $k$ will not disturb the linearity of the setup for the in vitro determined relationship between intensity and SF concentrations and the linearity of the equipment used for registration and evaluation of the angiograms.

Our assumption, that cardiac output was equal during the 100 and $400 \mathrm{mg}$ angiogram for each subject may introduce an error in the calculation of $k$ and, thus, in the determination of SF concentrations and calculated cardiac output. Variation of the cardiac output during the day is about 10-15\% and especially related to intake of food. Day-to-day variation of cardiac output in sitting position, as measured with transthoracic electrical bioimpedance, has a standard deviation of only $10 \%$ in healthy volunteers. ${ }^{*}$ We evaluated the consequences for the cardiac output of a $\mathrm{CO}_{1} / \mathrm{CO}_{2}$ ratio of 0.9 and 1.1 . A ratio of 0.9 resulted in a mean decrease of $3 \%$ and $12 \%$ of the mean calculated $\mathrm{CO}_{1}$ and $\mathrm{CO}_{2}$ of the five subjects, respectively and a ratio of 1.1 resulted in a mean increase of $10 \%$ and $22 \%$ of the mean $\mathrm{CO}_{1}$ and $\mathrm{CO}_{2}$, respectively. A difference between $\mathrm{CO}_{1}$ and $\mathrm{CO}_{2}$ also has consequenses for peak and final concentrations: at $\mathrm{CO}_{1} / \mathrm{CO}_{2}$ ratio of 0.9 resulted in a mean decrease of $21 \%$ and $11 \%$ of peak and final SF concentrations of the ten angiograms, respectively; a ratio of 1.1 resulted in a mean increase of, respectively, $16 \%$ and $4 \%$.

To determine the ratio of $k_{1}$ and $k_{2}$ from the intensities at 60 seconds after injection of 100 and $400 \mathrm{mg}$ SF (equation 9 in Material and Methods), the assumption was made that at 60 seconds equal mixing has occurred during both angiograms. The blood volume in which the SF bolus was mixed all 60 seconds can be determined by dividing the quantity of dye injected on the SF concentration $C\left(t_{e}\right)$. Mean mixing blood volumes of the five subjects for the 100 and the $400 \mathrm{mg}$ angiogram are 3.6 and 3.51 , respectively, indicating that the extent of mixing at 60 seconds was almost the same after both dosages. The relatively low mixing volumes imply that mixing was still incomplete. There was a correlation between body weight and the mean mixing volumes at te of the five subjects, and, since there is a strong correlation between blood volume and body weight in general, this further validates our data.

A second assumption for the applicability of equation 9 was that the final concentrations at 60 seconds after dye injection $C\left(t_{e}\right)$ remain within the linear range of the intensity-concentration curve. The values for $\mathrm{C}_{2}\left(\mathrm{t}_{\mathrm{e}}\right)$ (table $\mathbb{l}$ ) exceed the value of $0.08 \mathrm{mg} / \mathrm{ml}$ used as limiting value for the linear range (see Material and Methods). It follows from figure 1, that for the concentrations up to $0.15 \mathrm{mg} / \mathrm{ml}$ deviations from linearity are small. The assumption of linearity introduces an error of about $3 \%$ in the ratio of $\mathrm{C}_{1}\left(\mathrm{t}_{\mathrm{e}}\right)$ and $\mathrm{C}_{2}\left(\mathrm{t}_{\mathrm{e}}\right)$ (see table 1 ).

The values obtained for cardiac index are within the standard deviation of the mean for normal subjects in the same age decade (fourth decade $3.54 \pm 0.3 \mathrm{l} / \mathrm{min} / \mathrm{m}^{2}$, fifth decade 2.96 $\left.\pm 0.17 \mathrm{l} / \mathrm{min} / \mathrm{m}^{2}\right)^{4}$ except for subject D and E. A possible explanation for the low cardiac index value of subject $\mathrm{D}$ and $\mathrm{E}$ may be the changing alignment during the $100 \mathrm{mg}$ angiogram, as concluded from the decrease of co-registered intensities of the vein and background. Instrument alignement is noted to be a serious problem in quantitative angiography. "Exact correction for the changing alignment is not possible because it occurred during the early recirculation phase of the angiogram, but correction would have resulted in a higher $I_{a 1}$, and, thus, in a higher ratio of $k_{1}$ and $k_{2}$ (equation 9). A higher ratio of $k_{1}$ and $k_{2}$ causes a larger difference between $I_{a 1}(t)$ and $I_{a 2}(t)$ (equation 7 ), which, in turn, leads to a shift to the left on the $x$-axis of figure $I$ and 
a lower range of $\mathrm{C}_{1}(\mathrm{t})$ and $\mathrm{C}_{2}(\mathrm{t})$. The lower $\mathrm{C}_{1}(\mathrm{t})$ and $\mathrm{C}_{2}(\mathrm{t})$ result in higher cardiac output and cardiac index (equation 3). Uncertainties related to different values for cardiac output and $k$ between the two angiograms probably can be reduced by combining wo injections into one angiogram, for example: a low dose of $50 \mathrm{mg}$ SF in $0.25 \mathrm{ml}$, after 15 seconds followed by a larger dose of $400 \mathrm{mg}$ in $2 \mathrm{ml}$. A small error in the shape of the second bolus by the recirculation of the first bolus is introduced in this way, but an advantage is, that instrument variabili$\mathrm{ty}$, differences in the value of $\mathrm{k}$ and the cardiac output between the two angiograms are eliminated. Because the value of $k$ and the cardiac output will be the same for both dosages. equation 6 reduces to:

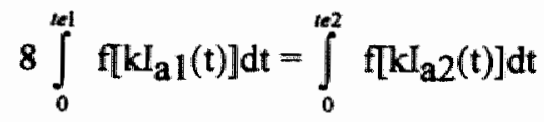

In addition, the period of recording can be shortened because it is not necessary any more to extract the ratio of the different $k$ values from final equilibrium intensities at 60 seconds after injection. A further reduction of the recording time can be accomplished by bolus compression with a fluid flush after dye injection. This procedure for measuring absolute dye concentrations in retinal vessels may be applicable in clinical practice.

\section{Clinical implications.}

A bolus injection of 100 and $400 \mathrm{mg}$ dye into a cubital vein yielded mean peak concentrations in a large retinal artery of 0.13 and $0.86 \mathrm{mg} / \mathrm{ml}$, respectivety. The only other experiments in literature that addressed absolute dye concentrations in fluorescence angiography of the ocular fundus were reported by Flower. ${ }^{11,12}$ He measured peak concentrations of ICG in the aortic arch after an intravenous dye injection into two human subjects and concluded that the effective dilution of an intravenous bolus was about 600 times before the dye reaches the ocular vessels. Application of this dilution factor to the 100 and $400 \mathrm{mg}$ bolus results in maximum concentrations that are close to the values we found: 0.17 and $0.67 \mathrm{mg} / \mathrm{ml}$, respectively. Using the same dilution factor for the calculation of peak concentrations in indocyanin green (ICG) angiography, where a dosage of $25 \mathrm{mg}$ dye is routinely employed, peak blood concentrations of $0.04 \mathrm{mg} / \mathrm{ml}$ ICG can be achieved in retinal arteries. This concentration is also within the nonlinear domain of the intensity-concentration curve for $1 \mathrm{CG}{ }^{1.3}$

The shape of the mean time-concentration curves that are normalized for dosage is remarkable similar for the two dosages (figure 5). This indicattes that the extent of extravasation of fluorescein molecules in the microvascular bed of the lung is about the same in the two angiograms and does not depend on bolus concentration. Because the extravasated dye molecules reenter the vascular bed and reach the ocular circulation with a delay, an increased dye extravasation would have resulted in a lower and elongated normalized time-concentration curve in the retinal arteries. The observation of a similar shape of the two angiograms is in contradiction with the binding data of Rockey and co-workers ${ }^{14}$ who reported that the percentage of free fluorescein molecules in plasma increases with the SF concentration. According to the ir data, at the peak SF concentrations obtained from retinal vessels $(0.25$ and $1.61 \mathrm{mg} / \mathrm{ml}$, respectively, in plasma), 92 and $70 \%$ of the fluorescein molecules would be albumin-bound for the 100 and $400 \mathrm{mg}$ bolus, respectively. The albumin-bound fraction must have been even lower in the lung circulation. Because free fluorescein molecules extravasate more readily in the microcirculation, a significant difference in extravasation of SF should have occurred after the injection of the two dosages, and, as a consequence, the mean time-concentration curves 
should have had different shapes.

The shape of the time-concentration curve seems to be related to the arrival time in the retinal vessels of the dye bolus (figure 3 ). The mean arrival time of the subjects was, in turn, significantly correlated with body weight. This suggests that body dimensions have an important influence on the shape of the time-concentration curve and is in agreement with the theory of bolus dilution as presented in Material and Methods.

Our finding, that in routine angiograms SF concentrations may readily exceed the linear domain, gives insight into some aspects of diagnostic and quantitative angiography. Due to the nonlinear relationship between SF concentrations and intensity, the intensities in routine angiography stay within the dynamic range of the SLO and provide good quality imaging in spite of the wide variation in SF concentrations. As can be seen in figure $4 \mathrm{~A}$, a higher dye quantity allows the photographer more time for scanning the ocular fundus while fluorescence intensities are still high. Thus, a higher dosage will improve the quality of the late phase images.

Parameters to describe the retinal circulation in quantitative angiography are based on intensity measurements of retinal arteries. Some of these parameters will be influenced by the nonlinear relationship between intensity and SF concentration. The influence on the time-to$50 \%$ of peak intensity ${ }^{4}$ and the measurement of vessel diameters from angiograms, when the diameter measurement is performed at $50 \%$ of the peak intensity of the vessel, ${ }^{\text {s }}$ will only be minimal. The retinal mean circulation time, which is defined as the difference between the arterial and venous mean transit times ${ }^{6.2}$ the arm-retina time ${ }^{1 / 2}$ and the time-to-peak intensity are not affected. To avoid problems due to nonlinearity, the total dosage can be kept at or below $100 \mathrm{mg}$ SF. The resulting dye concentrations would hardly exceed the limits of the linear part of the intensity-concentration curve but still provide good quality images.

Our method for estimating absolute dye concentrations in retinal vessels opens new avenues in the understanding of the appearance patterns in fluorescein angiography. Future research can now be directed to modelling techniques that will increase our insight into the time course of extravascular dye concentrations in the choroid and the aspect of pathological conditions like retinal pigment epithelial detachments and subretinal neovascular membranes.

\section{AEFERENCES}

1.wan Heuven WAJ, Malik AB, Schaffer CA, Cohen D, Mehu M. Retinal blood flow derived from dye dilution curves. Arch Opthalmol. 1977;95:297-301.

2. Blair NP, Feke GT, Morales-Stoppello J, Riva CE, Goger DG, Collas G, McMeel JW. Prolongation of the retinal mean circulation time in diabetes. Arch Ophthalmol. 1982;100:764-768.

3. Schwartz B, Kerns J. Age, increased ocular blood pressures, and retinal and disc fluorescein angiogram. Arch Ophthalmol. 1980;98:1980-1986.

4. Koyama T, Matsuo N, Shimizu K. Mihara M. Tsuchida Y, Wolf S, Reim M. Retinal circulation times in quantitative fluorescein angiography. Graefe's Arch Clim Exp Ophthalmol. 1990;228:442-446.

5. van den Biesen PR, Jongsma FH. Tangelder GJ, Slaaf DW. Shear rate and hematocrit dependence of fluorescence from retinal vessels in fluorescein angiography. Ann Biomed Eng. 1994;22:456-463.

6. Bassingthwaighte $\mathrm{JB}$, Goresky $\mathrm{CA}$. Modeling in the analysis of solute and water exchange in the microvasculature. In: Renkin EM, Michel CC, eds. Handbook of Physiology, The Cardiovascular System, Volume IV. Bethesda, MD: American Physiological Society; 1984:549-626.

7. Kool MJ, Wijnen JA, Derkx FH, Struijker Boudier HA, van Bortel LM. Diurnal variation in prorenin in relation to other humoral factors and hemodynamics. Am.J Hypertens. 1994;7:723-730.

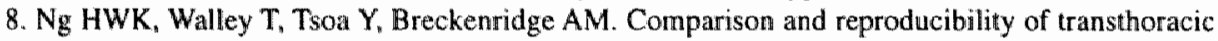


bioimpedance and dual beam Doppler ultrasound measurement of cardiac function in thealthy volunteers. BrJ Clin Pharmac. 1991;32:275-282.

9. Brandfonbrener $M$, Landowne $M$, Shock, NW. Changes in cardiac output with age. Circulation. 1955; 12:557-566.

10.Peli E. Electro-optic fundus imaging. Surv Ophthalmol. 1989;34:113-122.

11.Flower RW. Injection technique for indocyanine green and sodium fluorescein dye angiography of the eye. Invest Ophthalmol. 1973;12:881-895.

12. Flower RW, Hochheimer BF, Quantification of indicator dye concentration in acular blood vessels. Exp Eye Res. 1977;25:103-111.

13.van den Biesen PR, Jongsma FH, Tangelder GJ, Slaaf DW. Yieid of fluorescence from indocyanine green in plasma and flowing blood. Ann Biomed Eng. in press.

14.Rockey JH, Weiye L, Eccleston JE. Binding of Muorescein and carboxyfluorescein by human proteins: significance of kinetic and equilibrium parameters of association in ocular fluorometric studies. Exp Eye Res. 1983:37:455-466.

15.Eaton AM, Hatchell DL. Measurement of retinal blood vessell width using computenzed image analysis. Inwest Ophthalmol Vis Sci. 1988;29:1258-1264.

16. Wolf S. Jung $F$, Kiesewetter $H$, Kriber N, Reim M. Video fluorescein angiography: method and clinical application. Graefe's Arch Clin Exp Ophthalmol. 1989:227:145-151. 


\section{CHA P TER 6}

DYE EXTRAVASATION IN THE CHOROID DURING

FLUORESCEIN ANGIOGRAPHY OF THE OCULAR FUNDUS.

P.R. van den Biesen, W.Th. Hermens, F.H. Jongsma, D.W. Slaaf. 


\section{ABSTRACT}

Purpose. To obtain insight into the process of dye extravasation during fluorescein angiography of the ocular fundus.

Methods. A mathematical model was constructed that allowed estimation of the yield of fluorescence from the various tissue layers of retina and choroid. Data from a previous report about the time course of intravascular SF concentration during fluorescein angiography in human subjects and anatomical data from literature were used as input for the model.

Results. Background fluorescence comes mainly from the retinal capillaries, choriocapillaris. and the large choroidal vessels during the early phase of the sodium fluorescein angiogram. The fluorescence from the extravascular compartment of the choroid reaches its maximum value much later than the fluorescence from the intravascular compartments.

Conclusion. Dye extravasation into the interstitial fluid of the choroid during fluorescein angiography is a relatively slow and limited process.

\section{INTRODUCTION}

Fluorescein angiography is routinely used in ophthalmology for diagnosis of retinal and choroidal diseases. Interpretation of the appearance pattern of the normal angiogram is based on simple assumptions concerning the relationship between fluorescence intensities of the angiogram on the one hand, and localisation and concentration of fluorescein molecules in choroidal and retinal tissues on the other. A better understanding of the way in which the intensities of the fluorescein angiogram are reached may facilitate the interpretation of the pathological angiogram and allow a more accurate diagnosis. In particular, information about the fluorescence yield of the extravasated dye in the choroid may increase our insight into disease processes in the choroid.

In the fluorescein angiogram the images of retina and choroid are superimposed. The fluorescence from the retina originates exclusively from the intravascular compartment, since the blood-retina barrier precludes dye extravasation. Fluorescein molecules, however, can extravasate from the choroidal circulation and hence, the choroidal fluorescence may be a summation of the intensities from the intra and extravascular compartment. Choroidal fluo-. rescence is attenuated by pigment in the retinal pigment epithelium and choroidal stroma. Superpostion of the fluorescence of the various tissue layers and the differential effects of various pigment layers complicates interpretation of the normal angiogram.

We constructed a mathematical model to gain insight into the contribution of various layers of retina and choroid to the fluorescein angiogram. Anatomical data for the model were obtained from literature. The yield of fluorescence from intravascular compartments of the model was calculated on the basis of data from a previous report on the time course of SF concentrations in ocular vessels during fluorescein angiography." The yield of fluorescence from the extravascular space in the choroid was estimated by subtracting the calculated fluorescence yield of all intravascular compartments from the intensity of the background fluorescence as measured directly from angiograms. An important new aspect of the model is that the larger choroidal veins act as an almost continuous monolayer of vessels which are responsible for a significant part of the background fluorescence, while blocking fluorescence from deeper layers. 


\section{MATERIALS AND METHODS}

\section{The model}

The model includes five tissue layers: retina, retinal pigment epithelium, choriocapillaris, choroidal stroma, and large choroidal veins (figure 1). The area of the optic disk is not considered in the model. The extent to which the various layers contribute to the background fluorescence depends on SF concentration, layer thickness and distribution of pigments. This will be discussed for each of them separately. Background fluorescence is defined as the fluorescence intensity of the ocular fundus during $\mathrm{SF}$ angiography as measured at sites where no large retinal vessels are located (figure 1). The various layers are assumed to be illuminated in the same way as in fluorescein angiography: frontal illumination by the excitation light and measurement of the emission light in the opposite direction. On its. way through the various layers, the intensity of the excitation light decreases because the light is either absorbed by fluorescein molecules causing fluorescence, or it is absorbed by pigments (hemoglobin or melanin). The emission light is also partly absorbed by pigments on its way back. Thin layers of blood with a low local hematocrit (capillaries) contain little absolute amounts of hemoglobin and SF. Therefore, they are supposed not to attenuate the passing excitation and emission light. Vessels with an hematocril close to systemic, and a diameter of $25 \mu \mathrm{m}$ or more (all larger retinal and choroidal vessels) block all fluorescence from deeper layers. "In the model "superficial" is used to indicate a location near the vitreous; "deep" a location near the sclera. The symbol I stands for local intensity of a layer, as would be measured without interposing layers; the symbol $\mathrm{Y}$ stands for the yield from a layer, as would actually be recorded on the angiogram. The level of excitation intensity is indicated by $E$.

The most superficial layer is the retina, which contains arterial and venous vessels, and a capillary network. Because in the retina the fluorescein remains intravascularly, only capillaries contribute to the background fluorescence (figure 1). They constitute an almost continuous, lacy mesh work between the large retinal vessels. Since the retina itself is transparent, the yield of fluorescence from the retina is equal to the yield $\mathrm{Yrc}$ of the retinal capillary layer: $\mathrm{YrC}=\operatorname{Irc}(\mathrm{E})$. The excitation light to and the emission light from deeper layers are not reduced on their way through the retina and its capillaries, but are completely blocked by the large ves. sells.

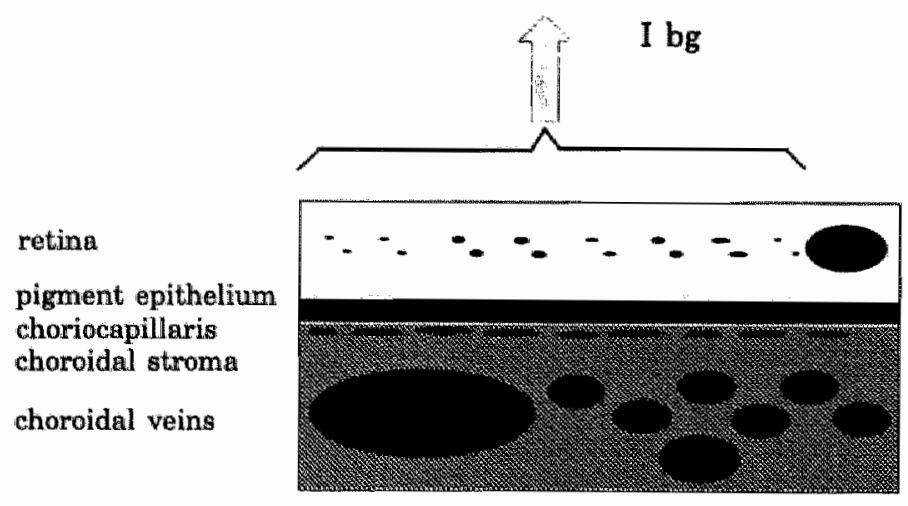

Figure 1. Schernatic cross section of the retina and choroid, indicating the five tissue layers represented in the model and the definition of the background fluorescence. 
The second layer in the model is the retinal pignent epithelium. It does not contain SF and, therefore, does not contribute to the background fluorescence. The melanin in this layer filters part of the excitation and emission light on its way forth and back, respectively. The transmission $\mathrm{Tr}$ is supposed to be equal for both spectra in both directions. Transmission may have a value between 1 (complete transmission) and 0 (complete blockade).

The third tissue layer is the choriocapillaris. Before reaching the choriocapillaris, the excitation light $E$ is attenuated by the absorption in the retinal pigment epithelium by a factor of Tr. The attenuated excitation light Tr.E will generate an emission light in the choriocapillaris Icc that is linearly related to excitation light: Icc(Tr.E). The fluorescence from the choriocapillaris is also altenuated by a factor of $T r$ when the emission light passes the retinal pigment epithelium. The contribution to the background fluorescence (Ycc) is therefore Tr.Icc(TrE). Since the fluorescence yield varies linearly with excitation light level, Tr.Icc(Tr.E) = $(\mathrm{Tr})^{2} . \operatorname{Icc}(\mathrm{E})$. As is the case with the retinall capillaries, the choriocapillaris itself does not attenuate passing light.

The fourth layer, the choroidal stroma, is accessible to fluorescein molecules and the fluorescence from the extravasated dye molecules (Ie) adds to the background fluorescence. Again, the excitation light is attenuated by a factor $\mathrm{Tr}$, as is the emission light. Therefore, le contributes to the background fluorescence by $(\mathrm{Tr})^{2}$.Ie(E). The extravascular SF concentration in the stroma in combination with its layer thickness is assumed to be insufficient to absorb significant amounts of excitation and emission light passing to and from deeper layers. The stroma, however, contains a considerable amount of melanin that does attenuate the intensities from deeper layers. Ts is defined as the transmission of the stroma. In the yield of the choroidal stroma, the inner filter effect of melanin within the stroma is included.

The density of the mesh work of the large choroidal vessels, the fifth layer in the model, is such that it constitutes an almost continuous layer with a certain thickness. This can best be appreciated from vascular cast studies. ${ }^{\text {*-11 }}$ The fluorescence from this layer (Iv) is attenuated by both the melanin in the retinal pigment epithelium and the choroidal stroma. Therefore, it contributes to the background fluorescence Yv by: (Tr) ${ }^{2}$.(Ts) ${ }^{2}$.Iv. Since this layer of blood vessels is thicker than $25 \mu \mathrm{m}$, it blocks all fluorescence from deeper layers. Therefore, the large choroidal arteries, which are located below the venous plexus, will not contribute to the fluorescence.

In summary the intensity of the background fluorescence as a function of $E$ can be written as the summation of yield from the four contributing tissue layers of the model Yrc. $\mathrm{Y}^{\mathrm{x}}, \mathrm{Ye}$, and $\mathrm{Y} \mathrm{w}$ :

$$
\operatorname{Ybg}(\mathrm{E})=\operatorname{Irc}(\mathrm{E})+(\mathrm{Tr})^{2} \cdot \operatorname{Icc}(\mathrm{E})+\operatorname{Ye}(\mathrm{E})+(\mathrm{Tr})^{2} \cdot(\mathrm{Ts})^{2} \cdot \operatorname{Iv}(\mathrm{E})
$$

The model was constructed to obtain the yield of fluorescence from the stroma of the choroid, Ye. Equation 1 can be rewritten as:

$$
\operatorname{Ye}(E)=\operatorname{Ybg}(E)-\operatorname{Irc}(E)-(\operatorname{Tr})^{2}\left[\operatorname{Icc}(E)+(\operatorname{Ts})^{2} \cdot \operatorname{Iv}(E)\right]
$$

To find the time course of $Y e(t)$ during an angiogram, walues have to be substituted for the various factors of equation 2 . Ybg(t) is a directly measured value. Irc(t), Icc(t), and Iv(t) are fluorescence intensities of intravascular origin that cannot be measured, but have to be estimated from the concentration distributions $\mathrm{C}(\mathrm{t})$ as have been derived from angiograms using 
indicator dilution techniques (see below).6 The values for $T r$ and $T$ s are obtained from literature. "The derivation of the values for all factors will be discussed in detail below.

\section{Measurements:}

Values for $\mathrm{Ibg}(\mathrm{t})$ and $\mathrm{C}(\mathrm{t})$ were obtained from the same fluorescein angiograms as used in a prewious paper. The angiograms were acquired from five healthy subjects with a scanning laser ophthalmoscope (SLO, Rodenstock, München, Germany). For each subject, two angiograms were made on different days with dye dosages of 100 and $400 \mathrm{mg}$ SF, respectively. Each angiogram was recorded on videotape together with the signal of a video time code generator using an U-matic videorecorder.

Images from the angiograms were evaluated at 0.5 second intervals from still frames using a frame grabber (PC Vision plus, Imaging Technology Inc., Woburn, MA, USA) and video analysis software (Java, version 1.40, Jandel Scientific, Corte Madera, CA, USA), installed on a $486 \mathrm{DX}$ personal computer. The time course of the intensities of an area of $19 \times 19$ pixels of background fluorescence (an area of about $300 \times 400 \mu \mathrm{m}$ on the retina) at a distance of approximately two disk diameters below the optic disk was measured from each angiogram. Mean values of the assessed time-intensity curves of the five subjects Ibg(t) were calculated for each of the two dye dosages. In the model, all intensities were expressed in the arbitrary intensity units used for the in vitro experiments. To convert the intensities in hardware grey units of the angiograms into the arbitrary intensity units of the model, the intensities of the angiogram were multiplied with $\mathrm{k}$, the calibration factor, that converts hardware grey units into intensity units of the in vitro experiments as determined in our previous paper."

Mean $\mathrm{C}(\mathrm{t})$ of the five subjects for each of the dye dosages was determined as described previously:"

\section{Calculated values}

The yield of intravascular compartments depends on dye concentrations in plasma and plasma volumes.

\section{Intravascular dye concentrations}

Fluorescence time-intensity curves of retinal arteries can be converted into time-SF concentration curves. ${ }^{3}$ Since the shape of the indicator dilution curve in the arta is almost maintained when passing through the arterial tree, the shape of the time-concentration curve of retinal arteries may be used to describe the time-concentration curve in the choroidal arteries. In the microcirculation, the local hematocrit is reduced by the Fâhraeus-Lindquist effect and, as a consequence, the concentration of SF in blood that passes into the microcirculation will increase. The SF concentration of SF in plasma, however, will remain constant. Thus, the blood concentration in retinal arteries $\mathrm{C}(\mathrm{t})$ corrected for the red blood cell volume can be used as plasma concentration $\mathrm{Cp}(\mathrm{t})$ in retinal and choroidal capillaries.

The mean $\mathrm{C}(\mathrm{t})$ curves in blood after the two dosages are converted into time-concentration curves in plasma, $\mathrm{Cp}(\mathrm{t})$, by applying a factor of 1.8 to correct for volume of the red blood cells (hematocrit $=45 \%) ; \mathrm{Cp}(\mathrm{t})=1.8 \mathrm{C}(\mathrm{t})$. To calculate the yield of fluorescence from capillaries, we used $\mathrm{Cp}(\mathrm{t})$ in combination with the in vitro determined relationship between concentration and intensity for a 5 and $10 \mu \mathrm{m}$ thick layer of plasma (see below).

The relationship between yield of fuorescence and SF concentration in thin plasma 
layers, was assessed by measuring the yield of fluorescence from various SF concentrations in plasma in a setup slightly modified from the one reported in our previous paper on the rela. tionship between intensity and SF concentration in plasma and flowing blood. "A spherical lens with a radius of $30.7 \mathrm{~mm}$ was covered with a glass plate (figure 2). Plasma with various concentrations of SF was applied to the measuring chamber. Measurements were performed at layer thicknesses of 0,5 , and $10 \mu \mathrm{m}$ by starting at the center of the lens and subsequently shifting the lens over 0.55 and $0.78 \mathrm{~mm}$, respectively. Plasma was acquited by centrifugation of a sample of venous blood from a human subject. The blood was anticoagulated with $1.5 \mathrm{mig} / \mathrm{ml}$ EDTA. Various amounts of SF were added to the plasma to obtain a range of SF concentrations starting with $0.005 \mathrm{mg} / \mathrm{ml}$ and increasing it by factors of 2 up to a concentration of 0.5 $\mathrm{mg} / \mathrm{ml}$.

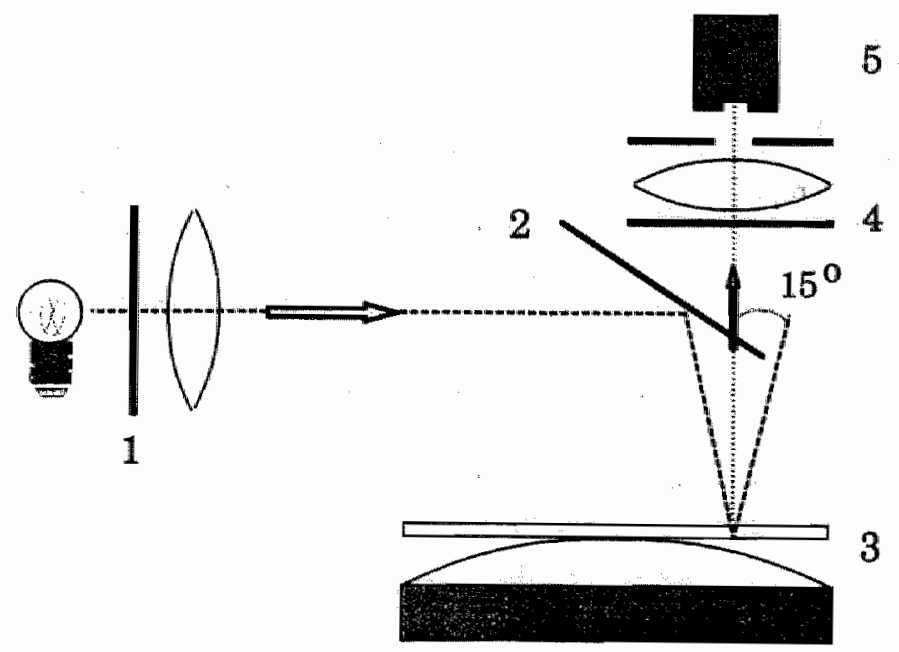

Figure 2. Experimental setup for determination of the relationship between vield of flucrescence and SF concentration in thin plasma lavers: Excitation light from a tungsten-halogen lamp passed through an excitation fitter (1) and was reflected by a dichroic blue reflective filter (2) on the plasma in the maasuring chamber (3). Emitted fluorescence passed through the dichroic filter (2) and a barrier filter (4) and was focused on a radiometer (5).

Since transition times along yarious pathways through the microcirculation differ, the bolus profile in the capillaries is further diluted and elongated in veins. Because arterialvenous transit times in the choriod are short (about 0.125 second) relative to passage time of the complete bolus (about 15 seconds) $)^{1 / 14}$ the bolus is only minimally elongated and diluted when arriving in the choroidal veins which mainly constitute the layer of larger choroidal vessels (fifth layer in the model). Therefore, the shape of the dye dilution curve in the choroidal veins is assumed to be identical to the curve in the retinal and choroidal arteries and capillaries. This means that the mean time-intensity curves in retinal arteries as measured from retinal vessels were directly applied to the intensities of the vessels in the fifth layer of our model.

\section{Plasma volumes in retinal capillaries and choriocapillaris}

The density of the retinal capillary network projected on a plane is estimated from published photographs of histological preparations of the retina to be about $0.4 .^{15-i x}$ The surface density of the network of the choriocapillaris has been reported to be 0.6 for the age category 
of our subjects." Surface density Ds is defined as the density of the projection of all capillaries. If capillaries were rectangular, the depth of the layer of capillaries would be $d$, where $d$ is the height of the capillaries. The effective cross-sectional area would be Ds.d. The actual crosssectional area of circular capillaries, however is D. $\mathrm{d}^{2} / 4$, rather than $\mathrm{d}^{2}$. Therefore, surface density has to multiplied by $\mathrm{D} / 4$ to obtain the relative intravascular volume.

The red blood cells act as an exclusion volume for SF. To obtain intravascular plasma volume, the intravascular volumes were multiplied with a factor of $(1-\mathrm{Ht})$. Local hematocrit (Ht) in the microcirculation is lower than the systemic hematocrit. Based on the data of Lipowsky and co-workers ${ }^{20}$ hematocrit values of $14 \%$ and $18 \%$ were used for the retinal and choroidal capillaries, respectively. Therefore, $(1-\mathrm{H} / / 100)$ was 0.86 and 0.82 for the retinal and choroidal network, respectively.

\section{Values obtained from literature}

The mean transmission of the retinal pigment epithelium ( $\mathrm{Tr}$ ) in the posterior pole outside the fovea has been reported to be $68 \%$ with a standard deviation of $8 \%$ for a spectral range of 500-600 nm.'2 The transmission of the superficial layers of the choroid, Ts, was set at $62 \%$, being the mean value of the reported transmissions of the superficial half of the choroid in the macular and equatorial area. ${ }^{12}$ The transmission of melanin was assumed to be equal for emission and excitation light.

All values as described above were substituted into formula 2 and the results were represented in time-intensity curves. The initial rise of each time-intensity curve was set at 10 seconds on the time axis. Intensities were expressed in the same arbitrary units as used in the in vitro experiments.

\section{RESULTS}

In figure 3 the in vitro measured values for the relationship between SF concentration and intensity are depicted for plasma layers of 5 and $10 \mu \mathrm{m}$. The relationship was approximated by the function $\mathrm{I}(\mathrm{t})=2.84 . \mathrm{C}(\mathrm{t}) /[0.81+\mathrm{C}(\mathrm{t})]$ for retinal capillaries and $I(t)=4.24 . C(t) /[0.63+C(t)]$ for the choriocapillaris, respectively. The fitted curves are also shown.

In figure 4 , the calculated time-intensity curves from the retinal capillaries Yrc, the choriocapillaris $Y c c$, and the layer of large choroidal vessels $Y v$ are presented for the 100 and $400 \mathrm{mg}$ angiograms. The contribution from the three vascular beds to the summed value of the three intravascular compartments Yi was about equal for both dye dosages.

In figure 5 the time-intensity curve of the background fluorescence (Ybg), as measured directly from the angiograms, and the total yield from the intravascular compartments (Yi) are shown for both dye dosages. The yield from the extravascular compartment (Ye) is calculated by subtracting the yield from the intravascular compartment from the yield from the background. The yield from the intravascular compartments constituted the major part of the background fluorescence during the first bolus passage. The yield from the extravascular compartment was very small in the initial phases of the angiogram, having even negative values in the first seconds after dye arrival. The yield from the extravascular compartment increased slowly reaching a steady level of about $25 \%$ and $30 \%$ of Ibg at 25 seconds after dye injection for the 100 and $400 \mathrm{mg}$ angiogram, respectively. 


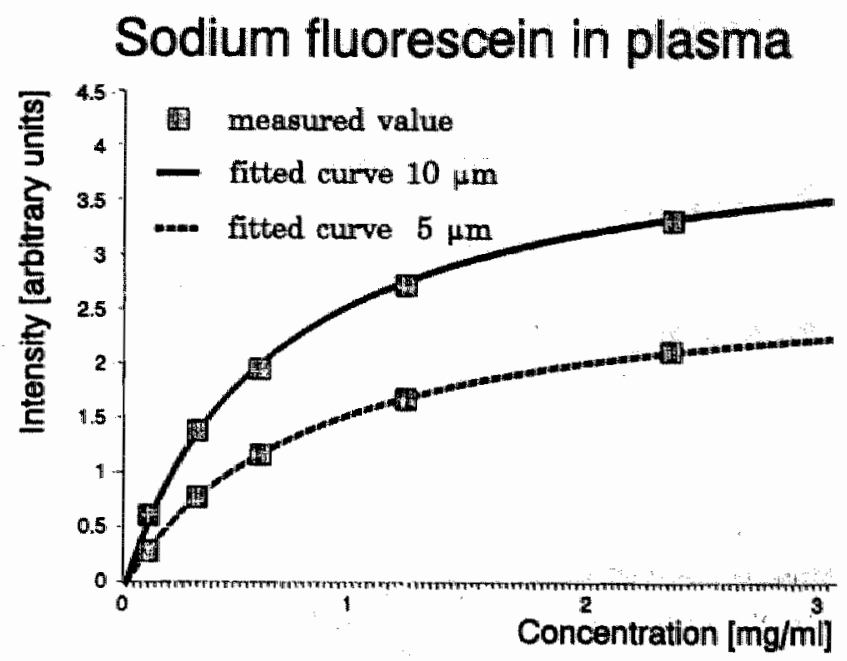

Figure 3. Relationship between the vield of fluorescence (imtensity) and sadium fluorescein concentration in plasma for a layer thicknesses of 5 and $10 \mu \mathrm{m}$, as assessed in vitro. Both the measured values and the fitted curves used in the model are represented.

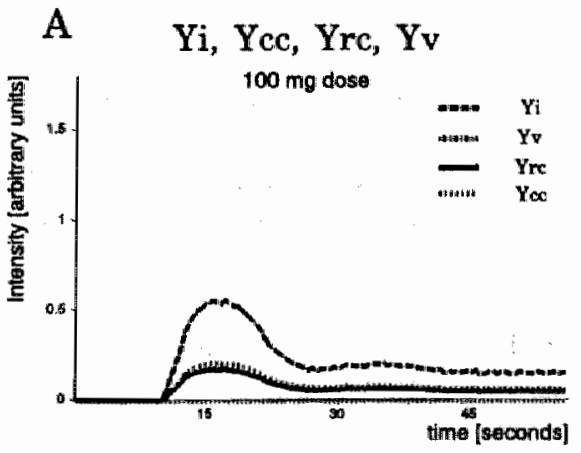

B

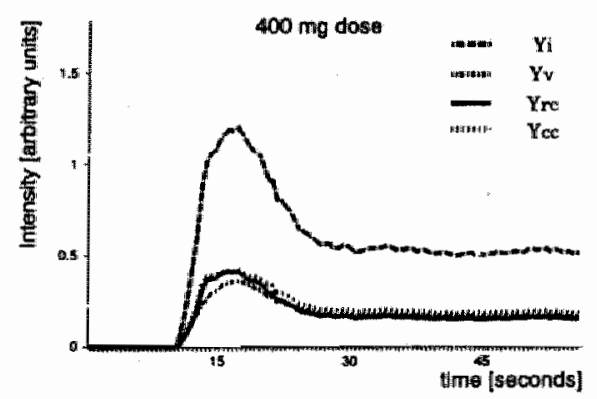

Figure 4. Calculated time-intensity curves of the vield of fluo. rescence from a retinal capillarias $(Y r c)$, choriocapillaris (Yccl, and large choroidal vessels (Yv) for an SF dosage of $100 \mathrm{mg}$ (A) and $400 \mathrm{mg}(B)$. The curve $V_{1}$ stands for the total yield from the intravascular compartments. The curves represent mean values of five subjects. Note that in panel A the curves for Yre and V'v almost coincide.

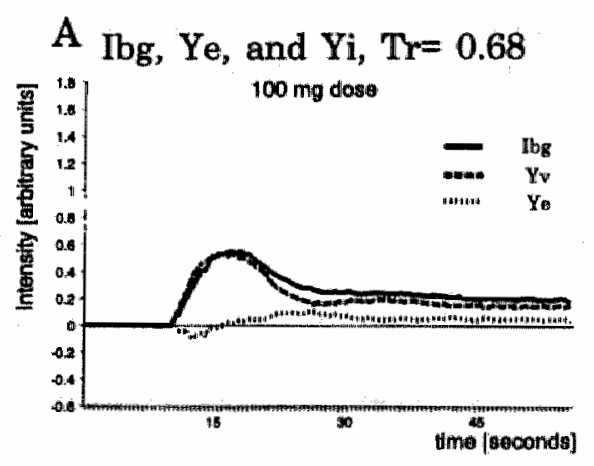

B

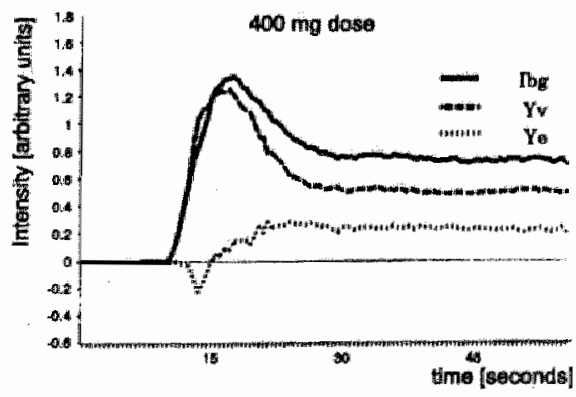

Figure 5. Vield of fluorescence from the extravascular compartment of the choroid (Ye) as estimated from the difference between the measured time intensity curve of the backg. round fluorescence (lbg) and the calculated time-intensity curve of the intravascular compartments (Mil for an SF dosa. ge of $100 \mathrm{mg}(\mathrm{Al})$ and $400 \mathrm{mg}(\mathrm{B})$. The curves represent mean values of five subjects. 


\section{DISCUSSION}

Background fuorescence ( $\mathrm{Ybg}$ ) comes mainly from intravascular compartments during the early phase of the sodium fluorescein (SF) angiogram. The fluorescence from the extravascular compartment of the choroid (Ye) reaches its maximum value much later than the fluorescence from the intravascular compartments (Yi). This indicates that dye extravasation into the choroidal interstitium is a relatively slow and limited process.

An important assumption in our model is, that the network of the larger choroidal vessels constitutes an almost continuous layer in the choroidal stroma when projected on a plane. This assumption is supported by vascular cast studies of the choroid. ${ }^{8-11}$ An other indication for a continuous vascular layer in the choroid is the uniform red reflection that is obtained from the choroid with fundusscopy. It is unlikely that the network of the retinal capillaries and the choriocapillaris account completely for this red reflex, because they have a relatively low hematocrit (see Materials and Methods) and only a small diameter.

The concept of a continuous layer of choroidal vessels explains the invisibility of indiwidual choroidal vessels in the early phases of the 400 as well as of the $100 \mathrm{mg}$ angiogram (unpublished observation). In theory, blockade of fluorescence from deeper layers by a massiwe extravasation of dye molecules into the choroidal interstitium might be an alternative explanation for this invisibility. However, this is rather unlikely. The layer in which the dye has to extravasate would have to be too thick. The maximall extravascular concentration can never exceed the intravascular peak concentration. After a $100 \mathrm{mg}$ bolus, the mean intravascular peak concentration for five subjects was estimated to be $0.13 \mathrm{mg} / \mathrm{ml}$ in blood (or about 0.25 $\mathrm{m} g / \mathrm{ml}$ in plasma). ${ }^{.6}$ The thickness of the choroid is reported to be about $150 \mu \mathrm{m} .{ }^{.4}$ The layer of extravascular fluid that is accessible to SF moleculles probably will not exceed half the thickmess of the choroid because of volume exclusion by blood vessels, stromal cells, and water binding in the extravascular tissues by large molecules like collagen. An indication of the transmission of a $75 \mu \mathrm{m}$ layer containing $0.25 \mathrm{mg} / \mathrm{ml} \mathrm{SF}$ can be obtained from the data on the yield of SF in plasma for various concentrations and layer thicknesses as reported previously. Even for these values of layer thickness and concentration that can be reached only in theory. the layer will absorb only $50 \%$ of the fluorescence from deeper layers. Thus, it is unlikely that absorption by extravasated dye molecules is the cause of the invisibility of large choroidal vessels during the early phases of the angiogram.

That in the early phase of the angiogram the contribution of extravasated dye molecules to the background ffuorescence must be small, may also directly be concluded from the similarity in shape of the time-intensity curve of retinal arteries and that of the background fluorescence. In figure 6 , this similarity in shape is demonstrated by normalization to peak values of curwes, that are obtained after a bolus injection of $100 \mathrm{mg}$ SF. Linear normalization may be done because after injection of this dosage the concentrations in the retinal vessels remain well within the linear part of the intensity-concentration curve for SF in blood and plasma. The initial phases of rising intensities bave nearly the same shape and the difference in the down slope is also small. When a substantial extravasation should have occurred, the down slope would have been much flatter, since long diffusion distances from the deep layers of the choroid to the choriocapillaris would result in a long washout period of SF from the extravascular space of the choroid."

We have assumed a similar shape of the dye dilution curves in the choroidal veins as compared to the retinal arteries and have justified this with the very high blood flow in the choroid. The similarity of the normalized curves of the yield from retinal vessels and the background supports this concept. However, some dye mixing will occur in the choroidal veins 


\section{Ibg and Ia $100 \mathrm{mg}$ dose}

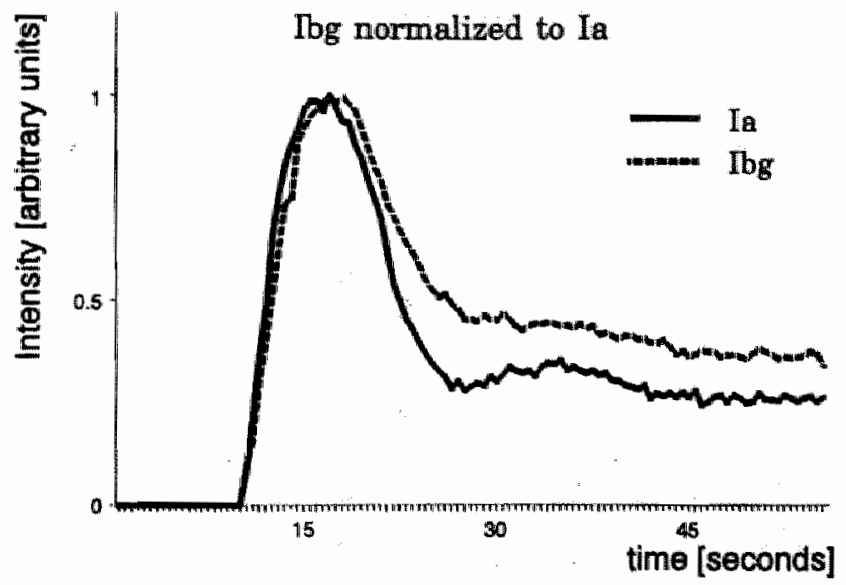

Figure 6. Measured time-intensity curve of the background fluorescence $(\mathrm{bg})$ normalized to the measured time-intensity curve of a retinal artery (la) for an SF dosage of $100 \mathrm{mg}$. The curves represent mean values of five subjects.

because of differences in transition times through the choriocapillaris. Dye mixing causes delay in the peak value and a prolongation of the dye dilution curve in the choroidal vessels. The fact that we did not take account of this dye mixing, may explain the slightly negative yield from the extravascular compartment of the choroid in the first seconds after dye arrival (figure 5) and the somewhat flatter down slope of the curve of the background fluorescence (figure 6).

An error in the value of the various parameters in the model may have consequences for our results. As can be deducted from equation 2 (see Material and Methods), errors in the transmission of the pigment epithelium ( $\mathrm{Tr}$ ) will have the most significant influence on the yield of the extravascular compartment: Whereas the three intravascular compartments contribute in about equal parts to the background fluorescence (figure 4), Tr determines the yield from two of them. An error in other parameters, like the transmission of the superficial strom mal layers and capillary network densities, affects the yield from only one compartment. We investigated the effect of an error in Tr. The error in Tr is not likely to be larger than the standard deviation of Tr because, in our model, data obtained from angiograms are mean values of five subjects. A Tr value of the mean Tr plus one standard deviation resulted in higher calculated peak values of the yield from the intravascular compartments than of the yield of the background as measured directly from the angiograms. Thus, values of Tr that are significantly higher than the mean value do not result in a realistic yield from the extravascular compartment. The results for a Tr of the mean value minus one standard deviation are represented in figure 7 . The relative yield from the extravascular compartment is still small. Even when twice the standard deviation of Tr is applied to the model (figure 8), our major conclusion that the fluorescence yield from the intravascular compartments constitutes the major part of the background fluorescence in the early phase of the angiogram, is not fundamentally affected.

The relative contribution of the various tissue layers depends on fundus pigmentation and, in addition, on dye concentrations when concentrations exceed the linear part of the concentration-intensity curve. The contribution of the extravascular compartment to the back- 
ground fluorescence, as estimated with our model, is based on mean values of the various parameters. Since fundus pigmentation cannot be assessed in vivo and varies widely, the relationship between the yicld from extravasated dye molecules in the choroid and the background fluorescence cannot be determined for individual subjects.

Figure 7. Estimated yield of fluorescence from the extravascular compartment of the choroid (Ye) after an SF dosage of $100 \mathrm{mg} \mathrm{(A)}$ and $400 \mathrm{mg}(B)$ when the transmission of the pigment epithelium (Tr) was set at 60\%. The intensity curve of the background fluorescence (Obg) and the calculated timeintensity curve of the intravascular compartments (Vi) are also shown. The curves represent mean values of five subjects.

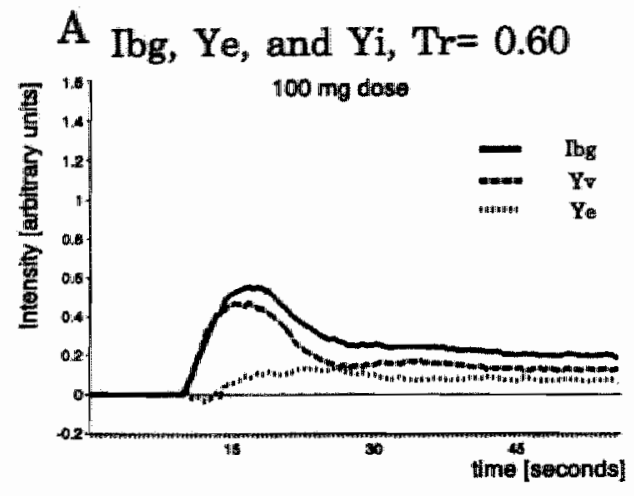

B

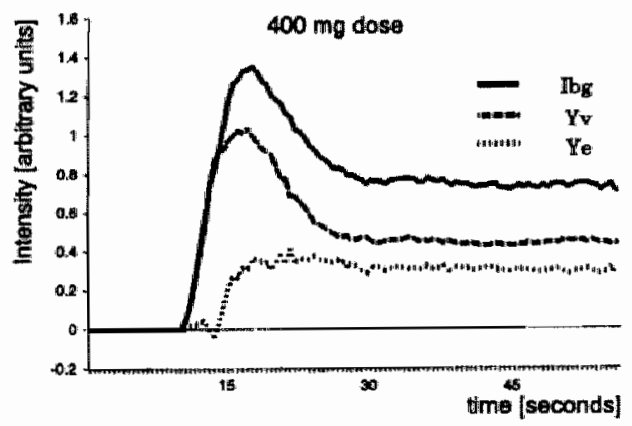

Riva and co-workers estimated the extravascular component from the fluorescence in the fovea for individuals with various degrees of ocular pigmentation by simultaneously injecting $500 \mathrm{mg} \mathrm{SF}$ and $50 \mathrm{mg}$ indocyanine green (ICG). ${ }^{23}$ ICG is a dye that in contrast to SF, remains predominantly intravascular. The intravascular component of the SF time-intensity curve was assumed to have the same shape as the ICG time-intensity curve. On the basis of the difference between the ICG and the SF curve, information was obtained on the extravascular compartment of the SF time-intensity curve. The shape of the time-intensity curve of lightly pigmented subjects was remarkably similar to the results of our model when the transmission of the pigment epithelium was set at $52 \%$ (figure 8). The contribution of the extravascular compartment was much higher for subjects with a medium and high degree of pigmentation. In the fovea centralis, however, the extravascular component is relatively large because there are no retinal capillaries in this area. In addition, Riva and co-workers did not account for the fact that intraocular concentrations exceed the linear part of the relationship between dye concentration and intensity after a dosage of $500 \mathrm{mg}$ SF or $50 \mathrm{mg} \mathrm{ICG}$. The maximum intravascular concentrations after such dosages will be approximately 1 and $0.1 \mathrm{mg} / \mathrm{ml}$ for SF and ICG, respectively." The value for ICG reaches much farther into the nonlinear part of the concentration-intensity curve. ${ }^{0.23}$ Because of this, the intravascular compartment is probably underestimated in the study of Riva an co-workers. Their major conclusion, however, agrees with our statement that the exact relationship between the fluorescence originating from 
the intravascular and extravacular compartment can not be determined as long as the degree of fundus pigmentation remains unknown.

Our results indicate that the major part of the background fluorescence during the first pass of the bolus originates from intravascular compartments.

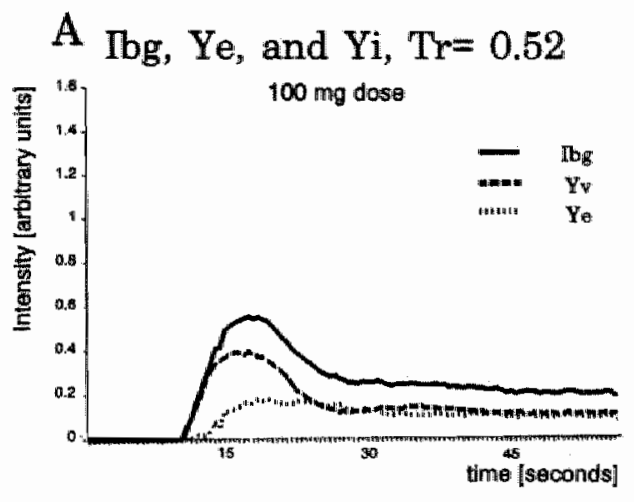

B

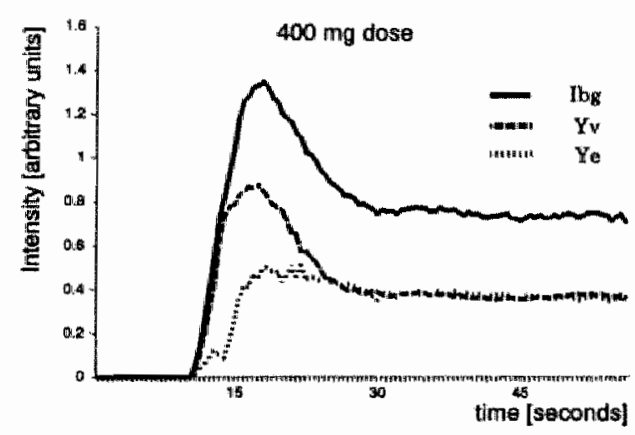

Figure 8. Estimated vield of fluorescence from the extravascular compartment of the choroid (Ye) after an SF dosage of $100 \mathrm{mg}(\mathrm{A})$ and $400 \mathrm{mg}(B)$ when the trans mission of the pigment epithelium (Tr) was set at $52 \%$. The intensity curve of the background fluorescence (Ibg) and the calculated timeintensity curve of the intravascular compartments (Yi) are also shown. The curves represent mean values of five subjects.

This has consequences for the interpretation of the changes in appearance of the background in the time course of the normal huorescein angiogram. When the larger choroidal vessels constitute an almost continuous layer and the interstitial fluid contains hardly any fluorescein, it is evident why no individual choroidal vessels can be seen in the early phase. In the customary interpretation of the appearance pattern of the early phase, however, most authors attribute the intensity of the background completely to the yield of fluorescence from the choriocapillaris and the extravascular compartment of the choroid. They explain the inwisibility of choroidal veins with a complete absorption by the more superficially located layers.

In the recirculation phase of the angiogram, the SF concentration in the interstitial fluid increases and the background fluorescence shows more variation in intensity because the layer of dye containing stroma in front of the vessels varies in thickness. In the very late phase of the angiogram, several minutes after dye injection, the SF concentration in the interstitial space is relatively high because of the slow washout of $\mathrm{SF}$ from the extravascular fluid. The depth localisation of the choroidal vessels determines the layer thickness of dye containing stroma in front of them and, thus, the intensity of the background fluorescence in that particular area. Especially superficially located vessels stand out as hypofluorescent structures. Because of this, the network density of choroidal vessels in the late phase of the angiogram appears to be less than can be appreciated from cast studies and than is being assumed in our model. Several 
explanations have been proposed in literature for the late hypofluorescence of the large choroidal vessels. One possible explanation is that the red blood cells in the vessels block scleral fluorescence and the fluorescent sclera can be seen through the network of choroidal vessels. Alternatively, there is a delay in the return of extravascular dye into the choriocapillaris and, thus, the interstitial fluid may contain more fluorescein than the vessel. A third possibility is that the dye in the extravascular spaces contributes to a larger extent than the dye in the vessel, because only the fluorescein molecules in the thin layer of plasma surrounding the central column of erythrocytes contribute to the fluorescence of the vessel, fluorescence from deeper layers being blocked by the red blood cells." ${ }^{1 . s}$ None of these interpretations is supported by detailed models based on experimental evidence.

In summary, dye extravasation during SF angiography is a relatively slow process. The relative contribution to background fluorescence from the extravascular compartment of the choroid is very limited during the first passage of the dye bolus, but increases in the later phases of the angiogram. This contribution cannol be assessed for individual subjects because it depends on fundus pigmentation and the degree of pigmentation cannot be determined in vivo. Our data alter the interpretation of the appearance pattern of the normal SF angiogram fundamentally. Further research based on our model should now be directed towards the interpretation of the angiographic appearance of chorioretinal diseases. This may lead to a better understanding of their pathophysiology.

\section{REFERENCES}

1. Oosterhuis JA, Boen-Tan TN. Choroidal fluorescence in the normal human eye. Ophthalmologica. $1971 ; 162: 246-260$.

2. Hyvarinen $L$, Maumenee, AE, George $T$, Weinstein GW. Fluorescein angiography of the choriocapillaris. Am J Ophth. 1969;67:653-666.

3. Archer D, Krill AE, Newell FW. Fluorescein studies of normall choroidal circulation. Am J Ophth. 1970;69: 543-554.

4. Gass JDM. Stereoscopic Atlas of Macular Diseases. 3rd ed. St.Louis: C.V.Mosby Company: 1987:12-18.

5. Schatz H. Fluorescein angiography: basic principles and interpretation. In: Ryan SJ ed. Retina. Volume II. St.Louis: C. V.Mosby Company. 1989:343

6. van den Biesen PR, Hermens WTh, Jongsma FH, Slaaf DW. Estimates of absolute dye concentrations in retinal vessels in fluorescein angiography. 1995

7. van den Biesen $P_{R}$, Jongsma FH, Tangelder GJ, Slataf DW. Shear rate and hematocrit dependence of fuorescence from retinal vessels in fluorescein angiography. Ann Biomed Eng. 1994;22:456-463.

8. Olver JM. Functional anatomy of the choroidal circulation: methyl methacrylate casting of human choroid. Eye. 1990;4:262-272.

9. Risco JM, Grimson BS, Johnson PT. Angioarchitecture of the ciliary artery circulation of the posterior pole. Arch Ophthalmol. 1981;99:864-868.

10.Ducournau D. La systematisation vasculaire de la choroide. J Fr Ophthalmol, 1980;3:5-16.

11. Yoneya S, Tso MO. Angioarehitecture of the human choroid. Arch Ophthalmol, 1987;105:681-687.

12. Weiter JJ, Delori FC, Wing GL. Fitch KA. Retinal pigment epithelial lipofuscin and melanin and choroidal melanin in human eyes. Invest Ophthalmol Vis Sci. 1986

13.Flower RW. Choroidal fluorescent dyo filling patterns. Int Ophthal. 1980;2:143-149.

14. Kiryu J, Shahidi M, Mori MT, Ogura Y, Asrani S, Zeimer R. Noninvasive visualization of the chorioca pillaris and its dynamic filling. Invest Ophthalmol Vis Sci. 1994:35:3724-3731.

15.Lutty GA, McLeod DS. A new technique for visualization of the human retinal vasculature. Arch Ophthalmol. 1992;110:267-276.

16. Krauss R. New technique to demonstrate the network of blood capillaries of the human retina in their three-dimensional arrangement. Graefe's Arch Clin Exp Ophthalmol. 1990;228:187-190. 
17.Schröer S, Schmid-Schönbein GW, Schmied-Schìnbein H. Brab M, Reim M. Methode zur Erfassung der Netzwerkropologie der menschlichen Retinagefässe. Klin Mbl Augentheitk. 1990;197:33-39.

18. Toussaint $D$, Danis $P$. Vascular densiry coefficients in normal human retina and relationship to distance from disc. Arch Ophthal. 1970:83:281-285.

19. Ramrattan RS, van der Schaft TL, Mooy CM, de Bruijn WC. Mulder PGH, de Jong PTVM. Morphometric analysis of Bruch's membrane, the choriocapillaris, and the choroid in aging. Invest Ophthalmoll Wis Sci. 1994;35:2857-2864.

20.Lipowsky HH, Usami S, Chien S. In vivo measurement of apparent viscosity and microvessel hemato crit in the mesentery of the cat. Microvascular Research. 1980;19:297.319.

21 . Bassingthwaighte JB, Goresky CA. Modeling in the anallysis of solute and water exchange in the nicro vasculature. In: Renkin EM. Michel CC. eds. Handbook of Physiology, The Cardiovascular System, Volume IV. Bethesda. MD: American Plrysiological Society; 1984:549-626.

22.Riva CE, Ben-Sira 1, Feke GT. Flow and diffusion of indocyanine green and fluorescein dyes in the fovea centralis. Exp Eye Res. 1977:24:15-23.

23.van den Biesen PR. Jongsma FH. Tangelder GJ, Slaaf DW. Yield of fuorescence from indocyanine green in plasma and flowing blood. Ann Biomed Eng. 23:475-482,1995 


\section{CHAPTER 7}

SUMMARY AND GENERAL DISCUSSION 
The aim of this thesis was to estimate the contribution of various tissue layers of the retina and choroid to the fluorescence yield of the human fluorescence angiogram. In vitro experiments indicated a nonlinear relationship between concentration and yield of fluorescence for SF and ICG in flowing blood (Chapters 3 and 4). This nonlinear relationship and the fact that blood vessels with diameters larger than $25-50 \mu \mathrm{m}$ block all fluorescence from deeper layers in SF angiography, allowed us to estimate the time course of dye concentrations in retinal arteries during SF angiography in human subjects. The time course of fluorescence intensity of retinal vessels could be converted into a intravascular time-concentration curve of SF (Chapter 5). With the use of data from literature on anatomical dimensions and pigment content of retina and choroid and by application of fundamental principles of blood flow, it was possible to calculate the time course of the contribution of intravascular compartments to the intensities of the SF angiogram in Caucasian subjects (Chapter 5). By subtracting the calculated intravascular contribution from background intensity as measured directly from angiograms, the time course of the fluorescence yield from the extravascular compartment of the choroid could be estimated (Chapter 6).

The intensity of the background fluorescence outside the macular area of the SF angiogram during the first bolus passage proved to originate mainly from intravascular compartments, i.e., from the retinal capillaries, the choriocapillaris, and the large choroidal vessels. The contribution from each of the three intravascular compartments was estimated to be about equal. In this phase, the contribution from the extravascular compartment of the choroid increased slowly, but remained relatively small. In the recirculation phase of the SF angiogram, about 30 seconds after dye injection, the fluorescence yield from the extravascular compartment of the choroid became more significant and constituted about one third of the background fluorescence because the yield from the intravascular compartments decreased.

The conclusion that fluorescence intensities during the first minute of the SF angiogram originate mainly from intravascular compartments and that dye extravasation into the choroidal interstitial fluid is a relatively slow process (Chapter 6), is in contradiction with the current interpretation of the appearance pattern of the normal SF angiogram. Most authors assume that uniform background fluorescence in the early phase predominantly comes from extravasated dye molecules in the choroid and that large choroidal veins are invisible by overshining by fluorescence from this extravasated dye. This demands short transit times and ralher rapid extravasation of the dye. In this thesis, the uniform background fluorescence is explained by the fact that the large choroidal vessels constitute an almost continuous layer of more than $50 \mu \mathrm{m}$ thickness, thereby creating a homogeneous background. This makes visualization of individual vessels impossible (Chapter 3 ).

Most investigators assume that the relative hypofluorescence of choroidal vessels in the late phase merely depends on dye retention in the surrounding interstitial fluid of the choroid and not on depth location of the large choroidal vessel at that specific fundus site. This study, however, indicates that the intensity at a specific fundus location in the late phase of the angiogram depends on how deep a major choroidal vessel is located: due to the ongoing distribution of dye over body fluids, the intravascular SF concentration decreases, while extravasated dye molecules are retained in the extravascular fluid of the choroid. At a site in the fundus where a major choroidal vessel is located superficially, fluorescence intensity is mainly determined by this vessel and will be relatively low. At a location where the choroidal vessel is situated deeper, dye molecules in the interstitium in front of the vessel will also contribute to fluorescence and local intensity will be relatively high.

It is important to notice that the discussion so far only concerns fluorescence intensi- 
ties outside the macular area and is restricted to the case of a mean value of fundus pigmentation as applies for Caucasians. In the macular area, where the pigment content of the retinal pigment epithelium is higher than in other sites of the fundus, and in human subjects with a fundus pigmentation that deviates from the mean mentioned above, the relationship between the yield of fluorescence from various tissue layers will be different. In addition, the results reported in this thesis give an estimate of the yield of fluorescence intensity from extravasated SF molecules in the choroid. They allow no statements about absolute extravasular dye concentrations.

Although quantitative analysis of the contribution of various tissue layers is not possible in ICG angiography, some remarks can be made about the interpretation of the appearance pattern of the early and late phase of the ICG angiogram. In contrast to conditions in SF angiography, the yield of fluorescence from large blood vessels in ICG angiography depends on vessel diameter. Combined with the lower optical resolution in ICG angiography, this will result in relatively poor visualization of smaller arteries and veins and may explain the apparent low density of the network of choroidal vessels in the ICG angiogram as compared to vascular cast studies of the choroid. The faint flush of diffuse fluorescence that veils the image of the large choroidal vessels in the early phase of the angiogram thus probably does not only originate from the retinal and choroidal capillaries, as most authors assume, but also from the smaller choroidal arteries and veins. In the very late phase of the ICG angiogram, 20-40 minutes after dye injection, choroidal vessels are hypofluorescent in contrast to surrounding structures. The only reasonable explanation for this hypofluorescence is, that, like in the late phase of the SF angiogram, extravasated dye is retained in the interstitial fluid of the choroid. Most. authors, however, assume that ICG extravasation does not occur to a significant extent. During ICG angiography, less dye molecules will extravasate than in SF angiography, because a larger fraction of $\mathbb{C G}$ molecules is bound to plasma proteins. This may explain the relatively late occurrence of hypoftuorescence of choroidal vessels in IGC angiography when compared to SF angiography. It takes longer before the intravascular yield of fluorescence has faded away to such an extent that the low extravascular fluorescence becomes visible. In the case of ICG angiography, it is not the depth localisation of large choroidal vessels that determines the yield of fluorescence at a specific fundus location, but the relationship between the intra and extravascular volume at that site. The choroidal vessels thus act as an exclusion volume for ICG. For the same reasons as in the early phase, only the largest vessels will be visible.

With the techniques presented in this thesis, dye extravasation can be estimated. The approach, however, is relatively elaborate and allows only statements about mean values for Caucasians. A more convenient way to obtain information on dye extravasation is to compare the time course of the intensity at the site to be evaluated with the time course of the intensity of the intravascular compartments, as can be obtained directly from any larger retinal vessel. With the assumption that no significant dye extravasation has occurred at the measuring site before the peak value in the retinal artery has been reached, the two time-intensity curves can be normalized and subtracted (compare figure 5 and 6 of chapter 6 ). The resulting curve is a relative measure for the time course of dye extravasation provided that dye concentrations remain in the linear range of the intensity-concentration curve for SF (i.e., the SF dose should not exceed $100 \mathrm{mg}$ ) and angiographic equipment is used that generates a limited amount of scatter (i.e., a scanning laser ophthalmoscope). The shape of the curve will be independent of fundus pigmentation since light absorption by pigments is a linear process. With this technique, future research can be directed to quantitative analysis of dye extravasation in individual patients with various choroidal and retinal diseases like uveitis, macular edema in diabetes, and age related macular degeneration. 


\section{NEDERLANDSE SAMENVATTING}

Doel van het in dit proefschrift beschreven onderzoek was beter inzicht te verwerven in de beelden verkregen met fluorescentie angiografie van het oog.

Fluorescentie angiografie (letterlijk: het afbeelden van bloedvaten met fluorescerende stoffen) is een techniek die sinds begin zestiger jaren in de oogheelkunde gebruikt wordt voor het aantonen van afwijkingen van het netvlies, het pigmentblad en het vaatvlies van het oog. Deze drie structuren spelen een essentiele rol bij het zien. In genoemde volgorde bekleden zij de binnenzijde van de oogbol (zie figuur).

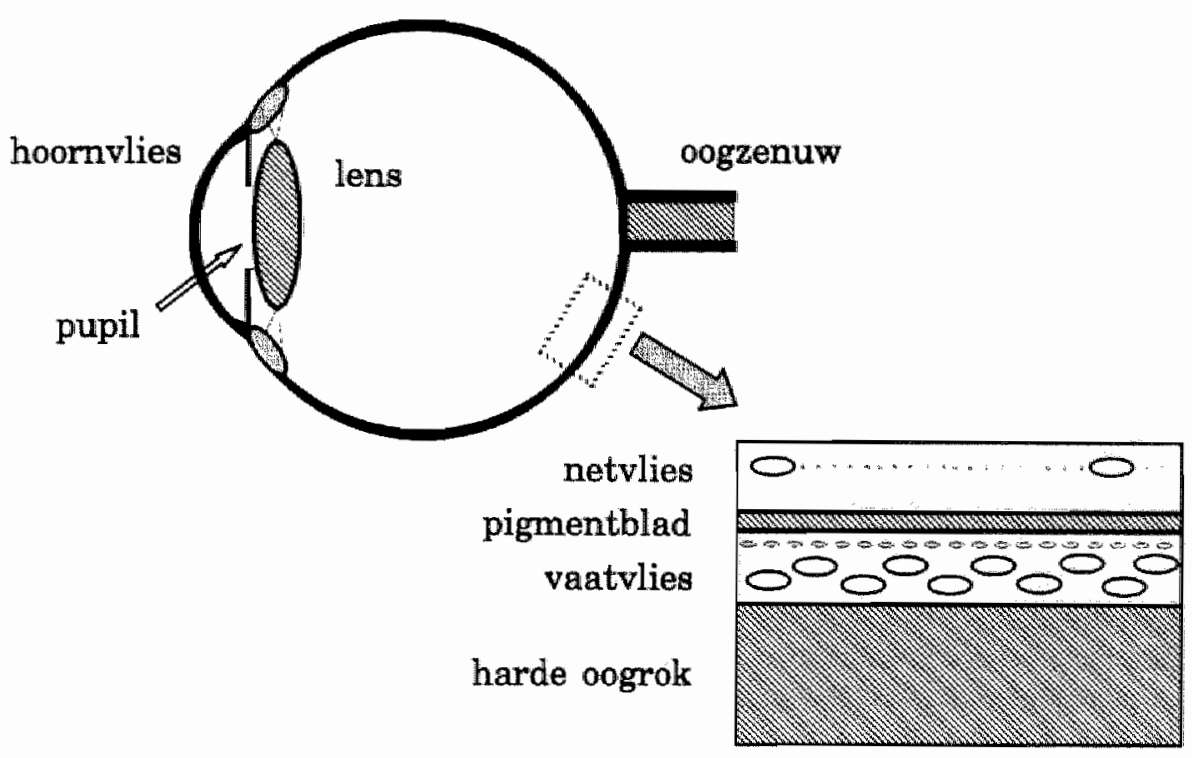

Bij fuorescentie angiografie wordt een kleine hoeweelheid kleurstof in een ader van de arm geinjecteerd. De kleurstof verspreidt zich via het vaatstelsel over het hele lichan en bereikt ook het oog. De passage van de kleurstof door de bloedvaten van netvlies en vaatvlies kan door de pupilopening worden gevolgd en met behulp van een camera worden vastgelegd op fotografische film of videoband.

Twee kleurstoffen worden voor fluorescentie angiografie gebruikt: natrium fluoresceine (sodium fluorescein, SF) en indocyanine groen (indocyanine green, ICG). Beide stoffen hebben de eigenschap gemeen dat zij, wanneer zij met een bepaalde kleur licht worden beschenen, een andere kleur licht uitstralen. Deze eigenschap heet fluorescentie. Bij fluorescentie angiografie wordt met behulp wan lichtfilters gezorgd dat alleen het uitgestraalde licht wordt vastgelegd. Het gevolg is dat uitsluitend die delen van het netvlies en vaatvlies waargenomen worden die daadwerkelijk de fluorescerende kleurstof bevatten. Het SF en ICG angiogram verschillen aanzienlijk van elkaar. Op het SF angiogram worden vooral de netvliesvaten goed afgebeeld. Op het ICG angiogram is juist het dichte vaatpatroon van het waatwlies goed zichtbaar.

Voor diagnostick wan afwijkingen aan vaatvlies en netvlies wordt in de praktijk uil.sluitend het beeld zoals vastgelegd op de foto's beoordeeld. De beoordeling berust op enkele algemene ideeen over kleurstofverdeling en de invloed daarvan op de hoeveelheid fluorescen- 
tielicht. Deze ideeen zijn nooit diepgaand getoetst op hun geldigheid bij fluorescentie angiografie van het oog. In dit proefschrift worden kleurstofverdeling en fluorescentieopbrengst in het netvlies en het vaatvlies nader onderzocht.

In experimenten met een speciaal daarvoor onfwikkeld apparaat werd buiten het lichaam (in vitro) de fluorescentieopbrengst van SF en ICG in stromend bloed woor versehillende kleurstofconcentraties en lagdiktes bepaald. Bepaald werd, onder andere, to welke kleurstofconcentratie het verband tussen lichtopbrengst en kleurstofconcentratie nog lineair was. Dat wil zeggen, tot welke kleurstofconcentratie een toename van die kleurstof nog leidt tot een evenredige toename van de uitgestraalde hoeveelheid licht. Boven deze kleurstoficoncentratie is het verband niet lineair, hetgeen betekent dat een verdubbeling van de hoeveelheid leidt tot minder dan de dubbele lichtopbrengst.

Voor ICG bleek dat het infra-rode fluorescentielicht dat ICG uitstraalt door dikke lagen heen kan dringen. Omdat bij angiografie met ICG niet bepald kan worden welk deel van het fluorescentielicht afkomstig is van een bloedvat en welk deel van diepere lagen, was ICG angiografie niet bruikbaar voor de verdere experimenten.

Bij fluorescentie angiografie van het menselijk oog (in vivo) kan de lichtopbrengst van een netwliesvat niet in absolute getallen bepalald worden omdat een onbekende hoeveelheid van het licht verloren gaat door verstrooiing en absorptie voor het de camera bereikt. Gebruik makend van het niet lineaire verband tussen de hoeveelheid SF en de lichtopbrengst was het toch mogelijk de kleurstofconcentratie te bepalen. Daartoe werden bij proefpersonen twee angiogrammen gemaakt met hoeveelheden kleurstof die een factor vier van elkaar verschilden. De grootste hoeveelheid werd zo gekozen dat de maximale kleurstofconcentratie die in de vaten van het oog zou worden bereikt niet meer binnen het lineaire deel van het verband tussen kleurstoficoncentratie en fluorescentieopbrengst zou vallen. Het gemeten verschil in lichtopbrengst tussen de twee angiogrammen was bij het bereiken van de maximale kleurstofconcentraties in de vaten dus minder dam een factor vier. Uit het gemeten verschil in lichtopbrengst kon worden afgeleid welke kleurstofconcentraties tijdens de twee angiogrammen in de vaten werd bereikt. Immers, bij ieder verschil in fluorescentieopbrengst kunnen slechts twee kleurstofconcentraties gevonden worden die een factor vier van elkaar verschillen. Uitgaande van dit principe was het door toepassing van een rekenprocedure mogelijk het concentratieverloop van SF tijdens het hele angiogram te bepalen.

Op het fluorescentie angiogram zijn de structuren van het netvlies en het vaatvlies over elkaar heen geprojecteerd. De informatie uit het vaatvlies wordt door het pigmentblad afgezwakt. Onder normale omstandigheden lekt SF niet uit netvliesvaten. De opbrengst uit het netvlies is dus alleen afkomstig van kleurstof die zich in de bloedvaten bevindt. De vaten van het vaatvlies zijn poreus. De fluorescentieopbrengst van het vaatvlies kan dus deels afkomstig zijn van kleurstof die zich in hel weetsel buiten de vaten bevindt.

Voor beoordeling van het fluorescentie angiogram is het van belang te weten uit welke lagen de fluorescentie die op het angiogram gezien wordt afkomstig is. Met behulp van gegevens verkregen uit bovenomschreven experimenten werd voor alle afzonderlijke lagen van bloedvaten in het netvlies en vaatvlies de mate van fluorescentie berekend. Door de totale fluorescentieopbrengst van de vaten af te trekken van de gemeten totale opbrengst tijdens het angiogram was het mogelijk een indruk te krijgen van de fluorescentie die afkomstig is uit het weefsel tussen de vaten van het vaatvlies. Tijdens de eerste tien seconden van het angiogram bleek de fluorescentie voornamelijk van SF binnen de vaten te komen en nauwelijks van daarbuiten. Later in het angiogram was de fluorescentie afkomstig van het naar buiten gelekte SF groter maar bleef toch nog beperkt tot, ongeveer, eenderde van de totale opbrengst.

Het onderzoek geeft een verklaring voor het beeld op het normale SF angiogram. Deze 
verklaring wijkt op twee belangrijke punten af van de gebruikelijke: 1. De lekkage van SF uit de vaten van het vaatvlies is een relatief beperkt en traag proces. 2 . Tijdens de vroege fase van het $\mathrm{SF}$ angiogram zijn geen afzonderlijke vaten in het vaatvlies waarneembaar omdat de vaten in het vaatvlies dicht tegen elkaar liggen. Tot nu toe wordt aangenomen dat door een massale lekkage van SF in het weefsel van het vaatvlies de vaten van het vaatvlies in de vroege fase worden gemaskeerd. Naast de verklaring van het normale SF angiogram is een aanzet gegeven voor kwantitatieve fluorescentie angiografie. Zo blijkt bijvoorbeeld dat de uittreding van kleurstof uit het vaatvlies op vrij eenvoudige wijze gemeten kan worden. Voortbouwend op de hier gepresenteerde gegevens kan verder onderzoek zich richten op de verklaring van angiogrammen en het meten van de uittreding van kleurstof bij ziekten van netvlies en vaatwlies. 


\section{NAWOORD}

Mijn belangstelling voor fluorescentie angiografie, met name van de chorioidea, werd gewekt tijdens mijn opleiding tot oogarts in Nijmegen. Opleider Prof. Dr A.F. Deutman zette mij aan tot onderzoek naar densitometrie van het fluorescentie angiogram. De heer A.L. Aan de Kerk, oogheelkundig fotograal, gaf in die periode vele adviezen.

Na mijn opleiding kwam ik in dienst van de Rijksuniversiteit Limburg. Dankzij de sti mulerende houding van Prol. Dr W.P.M.A. Lamers en de ruimte die de vakgroep oogheelkunde mij bood kon ik het onderzoek in Maastricht voortzetten. Samen met de heer F.H. Jongsma. research medewerker van de vakgroep oogheelkunde, en de beide oogheelkundig lotografen de heer $\mathrm{K}$. de Boer en mevrouw $\mathrm{M}$. Meulendijks taste ik de mogelijkheden van de kwantitatieve fluorescentie angiografie al. De eerste jaren van het onderzoek verliepen moeizaam. Veel wegen die wij insloegen bleken een doodlopend spoor. Intrigerend waren de videoangiogrammen bij varkens die ik in samenwerking met Prof. Dr P. Simoens wan de Faculteit Diergeneeskunde van de Universiteit Gent en met Drs A.J.E.M. van den Bogaard van de Centrale Proefdiervoorzieningen in Maastricht makte. We konden deze beelden echter niet goed verklaren. Hiervoor ontbrak basale kenmis over het fluorescentie angiogram.

Intussen was ik in contact gekomen met Dr D.W. Slaaf van de vakgroep biofysica en (toen nog) Dr G.J. Tangelder van de vakgroep fysiologie van de Rijksuniversiteit Limburg. Aanvankelijk liep dit contact in wetenschappelijke zin wat stroef omdat we elkaars taal niet spraken. Later bleek de samenwerking zeer vruchtbar en kwam het onderzoek in cen stroomversnelling. De heer $\mathbb{R}$. Alewijnse, mevrouw $S$, van Velzen, mevrouw $\mathbb{P}$. Muller, mevrouw $M$. Janssen, de heer B. Stultiens en een aantal studenten ondersteunden het werk. Velen waren bereid om bloed voor experimenten af te staan of fluorescentie angiografie te ondergaan. De promotie kwam in zicht. Prof. Dr R.S. Reneman van de vakgroep fysiologie en Prof. Dr W.P.M.A. Lamers vond ik bereid als promotor op te treden. Dr W.Th. Hermens van het Cardiovascular Research Institute raakte bij de experimenten betrokken. Voor het onderzoek noodzakelijke fluorescentie angiogrammen, opgenomen met een Scanning Laser Ophthalmoscoop, werden met hulp van Dr Dr S. Wolf, oogarts aan de RheinischWestfaelischen Technischen Hochschule in Aken gemakk. Ontbrekende basale gegevens over het normale fluorescentie angiogram zoals fluorescenticopbrengst wan fluoresceine in stromend bloed, het concentratieverloop wan fluoresceine in de oculaire vaten en de extravasatie van fluoresceine in de chorioidea werden onderzocht en de resultaten vormen de inhoud van het hier gepresenteerde proefschrift.

In mei van dit jaar kwam ik in dienst van de Universiteit Utrecht en dankzij Prof. Dr J.S. Stilma en Prof. Dr W.F. Treffers zall ik in samenwerking met Prof. Dr D. van Norren, Dr T.J.M. Berendschot en de heer J. van der Kraats het onderzoek in een meer klinische richting kunnen voortzetten. De oogheelkundig fotografen, de heer $\mathrm{G}$. de Graaf, mevrouw $\mathrm{H}$. Schenk en mevrouw J. Dieben hielpen met hel voorbereiden van de foto's.

In chronologische volgorde wil ik alle genoemde personen bedanken voor hun steun bij het tot stand komen van dit proefschrift.

Prof. Dr A.F. Deutman. Beste August, jij bent degene geweest die de eerste aanzet heeft gegeven tot dit onderzoek en ik vind het jammer dat de af stand Maastricht-Nijmegen uiteindelijk te groot bleek voor een blijvende betrokkenheid.

A.L. Aan de Kerk. Beste Albert , de kwaliteit van je foto's maakte mij enthousiast voor 
de fuorescentie angiografie en je bereidheid tot adviezen blijki uit de forse stapel memo"s en fotocopieen van artikelen die ik nog van je bezit.

Prof. Dr W.P.M.A. Lamers. Beste Wiel, ik ben je zeer dankbaar dat je mij, ook in de tijden dat het onderzoek moeizaam liep, steeds hebt gesteund. Je belangstelling voor de voortgang was steeds een stimulans. Ik heb op vele terreinen wan je geleerd en ben er trots op dat je mijn promotor bent.

De vakgroep oogheelkunde. Beste collega's, terdege ben ik mij ervan bewust dat de ruimte die ik voor mijn onderzoek heb gekregen jullie werklast jaren lang heeft verzwaard. Mijn dank hiervoor. Beste arts-assistenten en alle andere medewerkers en medewerksters, de sfeer was uitstekend!

FH. Jongsma. Beste Frans, al die jaren hebben we samen gezwoegd. Je bleef bereid om mij op mijn dwaalwegen te volgen en als maar nicuwe experimenten op te zetten. Ik heb je leren kennen als een integer mens en heb de samenwerking zeer op prijs gesteld

K. de Boer en M. Meulendijks. Beste Klaas en Marjon, steeds stonden jullie klaar tussen alle andere werkzaamheden door jullie kennis en kunde in te zetten voor mijn onderzoek.

Prof, Dr P Simoens en Drs A.J.E.M. van den Bogaard. Beste Paul, ik voel mij enigszins schuldig dat onze samenwerking in dierexperimenteel onderzoek (nog) niet tot gemeenschappelijke publicaties heeft kunnen leiden. Weet echter dat mijn contact met $U$ van grote waarde is geweest om de juiste richting voor verdere experimenten te kumnen kiezen. Beste Ton, ook voor jou geldt dat ik het jammer vindt dat we met onze dierexperimenten geen direct resultaat hebben kumnen bereiken. Graag had ik de samenwerking willen voortzetten.

Dr D.W. Slaaf. Beste Dick, jij komt bijna an het eind.

Prof. Dr G.I. Tangelder. Beste Geert Jan, jij stond aan het begin van de goede weg. Vele gesprekken over vaak dezelfde onderwerpen heb je getrotseerd, mar met resultaat? Helaas stond het promotieregelement slechts twee promotores toe.

R. Alewijnse, S. van Velzen en P. Muller, M. Janssen en B. Stultiens. Beste Rinus, Sabrina, Puck, Mieke en Berto, dank voor jullie adviezen, hulp en geduld bij werkzaamheden waar ik weinig kennis van had.

De studenten die betrokken waren bij dit onderzoek. Beste Liesbeth. Olaf, Frank, Roel. en Dennifs, ds studenten 'hében ju'llie vaăk zeer bewerkelijke delen van het onderzoek op jullie genomen. Jullie inzet was groot en jullie doorzettingsvermogen bewonderenswaardig.

Velen hebben zich laten prikken, sommigen hebben zich bovendien laten inspuiten en belichten. Nog sta ik versteld hoe makkelijk jullie instemden deze kwellingen te ondergaan. Mijn dank.

Prof. Dr R.S. Reneman. Beste Rob, in vrijwel ieder onder jou tot stand gekomen proefschrift dat ik opensla stan ongeveer dezelfde bewoordingen die ook ik tot jou wil richten. Hoewel je het verloop van het onderzoek enigszins op afstand volgde was het indrukwekkend te merken hoezeer je steeds op de hoogte was van de stand van zaken. Ik ben er zeker van dat ik dit werk nooil zonder jouw steun van achter de coulissen had kunnen afronden. Het is woor mij een eer dat je mijn promotor hebt willen zijn.

Dr W.Th. Hermens. Beste Wim, al vroeg in het onderzoek stond je klaar met belangeloze hulp en adviezen, maar vooral bij de laatste hoofdstukken is jouw inbreng van grote waarde geweest. Ik bewonder de nauwkeurigheid waarop je wetenschappelijke problemen benadert. Ik heb in een aangename sfeer veel van je geleerd.

Dr Dr S. Wolf. Lieber Sebastian, ich danke dir für den Bereitwilligkeit womit du mir mit die Experimenten geholfen hast und für die offene Weise auf die du mir Informationen gegeben hast.

Prof. Dr W.F. Treffers en Prof. Dr J.S. Stilma. Beste Frits, beste Jan, ik ben blij dat jul- 
lie mij de gelegenheid geven in Utrecht onderzoek te blijven doen.

Prof. Dr D. van Norren, Dr T.J.M. Berendschot en J. van de Kraats. Beste Dik $\mathrm{Jan}_{\mathrm{s}}$ onder de indruk van jullie prestaties hoop ik een waardevolle bijdrage te kunmen leveren aan jullie onderzoek. Onze onderzoekslijnen zijn opvallend nauw aan elkaar verwant. Uit onze samenwerking moet lets goeds kunnen komen.

De heer G. de Grataf, mevrouw H. Schenk en mevrouw J. Dieben. Beste Gerard, Hille, Julia, gelukkig vonden jullie tijdens jullie drukke werkzaamheden nog tijd voor het prepareren van de foto's. Mijn dank.

Beste Dick, je beweert voor een groot deel slechts een klankbord te zijn geweest. Ik ben dat met je eens in de zin zoals Plato zijn leerlingen in een dialoog hielp met de waar heidsvinding. Altijd to the point, recht door zee en met mededogen woor de leerling, ook al dwaalde deze. Je hebt mij onderzoek leren doen en een artikel leren schrijven. Ik dank je voor deze introductie in de wetenschap. Daarnaast ben je op het persoonlijk vlak tot grote steun geweest.

Lieve Anne Marie, iedereen die ons wat beter kent weet waarom de omslag de kleur heeft die hij heeft. 


\section{CURRICULUM VITAE}

\section{PETRUS ROVERIUS VAN DEN BIESEN}

Geboren 18 september 1955 te Breda.

Gehuwd met Anne Marie Josemans, vader van Paul en Emelie.

1967-73 Gymnasium B, Bisschoppelijk College Roermond.

1973-81 Geneeskunde. Rijksuniversiteit te Utrecht, Artsexamen.

1976-80 Rechtsgeleerdheid, Rijksuniversiteit te Utrecht, Kandidaatsexamen.

1981-82 Militaire Dienstplicht bij de Koninklijke Marine.

1982-86 Opleiding Oogheelkunde, Katholieke Universiteit Nijmegen. Opleider Prof.Dr A.F. Deutman.

1986-95 Universitair Docent Rijksuniversiteit Limburg en Staflid Vakgroep Oogheelkunde Academisch Ziekenhuis Maastricht.

1988 Fellowship Vitreoretinale Chirurgie Oogziekenhuis Rotterdam bij $R$. Živojnovic.

1989-95 Promotieonderzoek bij Prof.Dr R.S. Reneman, Cardiovascular Research Institute Maastricht, Prof.Dr W.P.M.A. Lamers, Hoogleraar Oogheelkunde Maastricht.

1995- Universitair Docent Universiteit Utrecht en Staflid Vakgroep Oogheelkunde Academisch Ziekenhuis Utrecht. 


\section{COLOFON}

lay out: Roland Klaverstijn, Utrecht druk: FEBO druk Enschede/Utrecht 